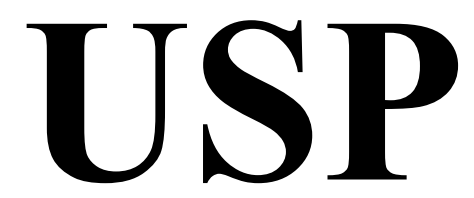

\title{
EMPREGO DO MÉTODO DE RESÍDUOS PONDERADOS PARA A ANÁLISE DE TUBOS
}

AUTOR: MICHELL MACEDO ALVES

ORIENTADOR: Prof. Dr. SERGIO PERSIVAL BARONCINI PROENÇA 
Michell Macedo Alves

\title{
EMPREGO DO MÉTODO DE RESÍDUOS PONDERADOS PARA A ANÁLISE DE TUBOS
}

\author{
Dissertação apresentada à Escola de \\ Engenharia de São Carlos da Universidade \\ de São Paulo, como parte dos requisitos \\ para a obtenção do Título de Mestre em \\ Engenharia de Estruturas.
}

Orientador Prof. Dr. Sergio Persival Baroncini Proença

São Carlos 
Ao meu tio Carlos (In memorian) Ao meu inesquecível professor Adnauer Tarquínio Daltro 


\section{Agradecimentos}

A Deus por tudo.

A Jesus e Maria por me ensinarem que o melhor conhecimento adquirido é aquele empregado para a construção de um mundo melhor e mais fraterno.

À Escola de Engenharia de São Carlos pela oportunidade concedida.

Ao Prof. Dr. Sergio Persival Baroncini Proença, pelo acompanhamento, pela extraordinária dedicação, por trazer com mais freqüência o estímulo e o elogio que incentiva, pela paciência para com as minhas imperfeições, e pelo exemplo como profissional e principalmente como pessoa.

Ao professor Roberto Luiz de Arruda Barbato pelo disposição em auxiliar.

Aos funcionários do Departamento de Estruturas, Rosi, Nadir, Toninho, Silvia e demais pela permanente disposição de ajudar.

Ao colega e irmão de estudos Gustavo Nirschl pela amizade e pelo auxílio em todos os momentos.

Ao $\mathrm{CNPq}$ pela bolsa de estudo concedida e principalmente por acreditar no desenvolvimento de nosso país.

Ao meu pai Jânio, minhas mães Neiva e Glacy, minha avó Dilma, por serem a razão do meu viver.

Aos meus colegas de República: Ciro, César Santaela, Robson Caldo, Sherfis Gibran, Rômulo Dinalli, Rodrigo Perenha, Maximiliano Azambuja, Antônio Mateus, Vilmar e Edmar por terem me acolhido como irmão na cidade de São Carlos.

Aos meus colegas de mestrado: Fernando Fontes, César Ataíde, Caio Gorla, Geílson Vasconcelos, Vladimir Haach, Kenneth Jaguaribe, Dimas Ribeiro, Daniane Vicentini, Edson de Assis e, em especial, à Sandra Almeida pela ajuda nos estudos recebida nos meus primeiros dias de Mestrado.

Aos amigos Wesley Góis, Wesley Wutzow, Rodrigo Paccola, Selma Nóbrega e Francisco Adriano pela mão amiga nos momentos que precisei.

Aos meus amigos de longa data: Francisco Thiesen, Mãe Zeferina, Auta de Souza por me ajudarem nos momentos mais difíceis que passei em São Carlos, dandome forças pra vencer todos os desafios e tarefas que a Vida me concedeu. 
Aos irmãos da Associação Espírita Francisco Thiesen pela mão amiga que ampara nos momentos de dificuldade e que esclarece nos momentos de dúvida e incerteza.

À todos que direta ou indiretamente contribuíram para realização desta pesquisa. 
"Deus é menor que um átomo e maior que o Himalaia. Encontra-se em uma única gota d'água e, todavia, nem os Sete Mares podem contê-lo. A razão é impotente para conhecê-lo, Ele está fora de seu alcance. Aqui a fé é essencial"

Mahatma Gandhi 


\section{Resumo}

Alves, M. M. (2005). Emprego do método de resíduos ponderados para a análise de tubos. Dissertação (Mestrado) - Escola de Engenharia de São Carlos, Universidade de São Paulo, São Carlos, 2005.

O presente trabalho trata da aplicação do Método de Resíduos Ponderados, mais especificamente do Método dos Mínimos Quadrados, na obtenção de soluções aproximadas de problemas de estruturas em casca, em especial os reservatórios cilíndricos submetidos a carregamento hidrostático em regime de comportamento linear. Os meios empregados para a obtenção das soluções aproximadas referem-se à adoção de bases aproximativas lineares, polinomiais, além da possibilidade de enriquecimento da aproximação mediante a adição de funções com características similares à própria solução exata. Uma outra alternativa utilizada refere-se à aplicação do Método dos Mínimos Quadrados com divisão do domínio de integração. Tais procedimentos podem ser úteis na análise de estruturas por evitar, de modo significativo, a elevação do esforço computacional, mediante a utilização de uma base aproximativa que corresponda às características requeridas pela solução analítica do problema.

Palavras-chave: casca cilíndrica; tubo; método de resíduos ponderados; método dos elementos finitos; enriquecimento. 


\begin{abstract}
Alves, M. M. (2005). Application of weighted residual method to the analysis of cylindrical shells. M.Sc. Dissertation - Escola de Engenharia de São Carlos, Universidade de São Paulo, São Carlos, 2005.

The present dissertation deals with the application of the Weighed Residual Method, more specifically the Least Squared Method, to the analysis of cilindrical shells, to obtain approximate solutions of shells structural problems, specially the cylindrical reservoirs subjected to hydrostatic shipment in the linear behavior regime. The ways of obtaining the approximate solutions refer to the adotion of linear, polynomial approximate bases, as well as the possibility of enriching the approximation by adding functions with similar characteristics to the accurate solution itself. Another used alternative refers to the application of the Least Squared Method with division of the integration domain. Such procedures can be useful in the analysis of structures to significantly prevent the rise of the computational effort, by means of an approximate base that corresponds to the characteristics required by the analytical solution of the problem.
\end{abstract}

Keywods: cildrical shells; container; weighted residual method; finite elements method; enrichment. 


\section{Lista de gráficos}

GRÁFICO 01 - Deslocamento de membrana - Galerkin 23

GRÁFICO 02 - Esforço normal de membrana - Galerkin 23

GRÁFICO 03 - Deslocamento obtido por aproximação polinomial - Base articulada - Galerkin 25

GRÁFICO 04 - Momento Fletor obtido por aproximação polinomial - Base articulada - Galerkin

GRÁFICO 05 - Esforço Cortante obtido por aproximação polinomial - Base articulada - Galerkin

GRÁFICO 06 - Deslocamento obtido por aproximação polinomial - Base engastada - Galerkin

GRÁFICO 07 - Momento Fletor obtido por aproximação polinomial - Base engastada - Galerkin

GRÁFICO 08 - Esforço Cortante obtido por aproximação polinomial - Base engastada - Galerkin 28

GRÁFICO 09 - Deslocamento de membrana - MMQ 30

GRÁFICO 10 - Esforço normal de membrana - MMQ

GRÁFICO 11 - Deslocamento obtido por aproximação polinomial - Base articulada - MMQ

GRÁFICO 12 - Momento Fletor obtido por aproximação polinomial - Base articulada-MMQ

GRÁFICO 13 - Esforço Cortante obtido por aproximação polinomial - Base articulada-MMQ

GRÁFICO 14 - Deslocamento obtido por aproximação polinomial - Base engastada - MMQ

GRÁFICO 15 - Momento Fletor obtido por aproximação polinomial - Base engastada - MMQ 34

GRÁFICO 16 - Esforço Cortante obtido por aproximação polinomial - Base engastada - MMQ

GRÁFICO 17 - Deslocamento obtido pelo enriquecimento da aproximação - Base articulada - Galerkin 40 
GRÁFICO 18 - Momento fletor obtido pelo enriquecimento da aproximação

- Base articulada - Galerkin

GRÁFICO 19 - Esforço cortante obtido pelo enriquecimento da aproximação

- Base articulada - Galerkin

GRÁFICO 20 - Deslocamento obtido pelo enriquecimento da aproximação

- Base engastada - Galerkin

GRÁFICO 21 - Momento fletor obtido pelo enriquecimento da aproximação

- Base engastada - Galerkin

GRÁFICO 22 - Esforço cortante obtido pelo enriquecimento da aproximação

- Base engastada - Galerkin

GRÁFICO 23 - Deslocamento obtido por aproximação exponencialtrigonométrica - Base articulada - MMQ

GRÁFICO 24 - Momento Fletor obtido por aproximação exponencialtrigonométrica - Base articulada - MMQ

GRÁFICO 25 - Esforço Cortante obtido por aproximação exponencialtrigonométrica - Base articulada - MMQ 45

GRÁFICO 26 - Deslocamento obtido por aproximação exponencialtrigonométrica - Base engastada - MMQ 46

GRÁFICO 27 - Momento Fletor obtido por aproximação exponencialtrigonométrica - Base engastada - MMQ 46

GRÁFICO 28 - Esforço Cortante obtido por aproximação exponencialtrigonométrica - Base engastada-MMQ

GRÁFICO 29 - Funções de forma referentes ao deslocamento - Elemento finito com seis parâmetros 59

GRÁFICO 30 - Funções de forma referentes a rotação - Elemento finito com seis parâmetros 59

GRÁFICO 31 - Funções de forma referentes a curvatura - Elemento finito com seis parâmetros 60

GRÁFICO 32 - Aproximação obtida utilizando 1 elemento finito com seis parâmetros - MMQ - Viga Engastada-livre - Deslocamento

GRÁFICO 33 - Aproximação obtida utilizando 1 elemento finito com seis parâmetros- MMQ - Viga Engastada-livre - Momento fletor 62 
GRÁFICO 34 - Aproximação obtida utilizando 1 elemento finito com seis parâmetros- MMQ - Viga Engastada-livre - Esforço cortante _63

GRÁFICO 35 - Aproximação obtida utilizando 1 elemento finito com seis parâmetros - MMQ - Tubo com base engastada - Deslocamento

GRÁFICO 36 - Aproximação obtida utilizando 1 elemento finito com seis parâmetros- MMQ - Tubo com base engastada - Momento fletor

GRÁFICO 37 - Aproximação obtida utilizando 1 elemento finito com seis parâmetros-MMQ - Tubo com base engastada - Esforço cortante

GRÁFICO 38 - Aproximação obtida utilizando 3 elementos finitos com seis parâmetros - MMQ - Tubo com base engastada - Deslocamento

GRÁFICO 39 - Aproximação obtida utilizando 3 elementos finitos com seis parâmetros-MMQ - Tubo com base engastada - Momento fletor 66

GRÁFICO 40 - Aproximação obtida utilizando 3 elementos finitos com seis parâmetros- MMQ - Tubo com base engastada - Esforço cortante

GRÁFICO 41 - Funções de forma referentes ao deslocamento - Elemento finito com oito parâmetros

GRÁFICO 42 - Funções de forma referentes a rotação - Elemento finito com oito parâmetros

GRÁFICO 43 - Funções de forma referentes a curvatura - Elemento finito com oito parâmetros 72

GRÁFICO 44 - Funções de forma referentes a derivada de ordem 4 - Elemento finito com oito parâmetros

GRÁFICO 45 - Aproximação obtida utilizando 1 elemento finito com oito parâmetros - MMQ - Viga Engastada-livre - Deslocamento

GRÁFICO 46 - Aproximação obtida utilizando 1 elemento finito com oito parâmetros- MMQ - Viga Engastada-livre - Momento fletor 
GRÁFICO 47 - Aproximação obtida utilizando 1 elemento finito com oito parâmetros- MMQ - Viga Engastada-livre - Esforço cortante _ 74

GRÁFICO 48 - Aproximação obtida utilizando 1 elemento finito com oito parâmetros - MMQ - Tubo com base engastada

- Deslocamento 75

GRÁFICO 49 - Aproximação obtida utilizando 1 elemento finito com oito parâmetros- MMQ - Tubo com base engastada - Momento fletor 76

GRÁFICO 50 - Aproximação obtida utilizando 1 elemento finito com oito parâmetros- MMQ - Tubo com base engastada

- Esforço cortante 76

GRÁFICO 51 - Aproximação obtida utilizando 3 elementos finitos com oito parâmetros - MMQ - Tubo com base engastada - Deslocamento 77

GRÁFICO 52 - Aproximação obtida utilizando 3 elementos finitos com oito parâmetros- MMQ - Tubo com base engastada Momento fletor 77

GRÁFICO 53 - Aproximação obtida utilizando 3 elementos finitos com oito parâmetros- MMQ - Tubo com base engastada

- Esforço cortante 78

GRÁFICO 54 - Aproximação obtida utilizando 3 elementos finitos com oito parâmetros - MMQ - Tubo com base articulada - Deslocamento 78

GRÁFICO 55 - Aproximação obtida utilizando 3 elementos finitos com oito parâmetros- MMQ - Tubo com base articulada Momento fletor 79

GRÁFICO 56 - Aproximação obtida utilizando 3 elementos finitos com oito parâmetros - MMQ - Tubo com base articulada - Esforço cortante 79 


\section{Lista de tabelas}

TABELA 5.1 - Comprimento dos elementos finitos __ 65 


\section{Lista de figuras}

FIGURA 2.1 - Casca de revolução ___ 4

FIGURA 2.2 - Parâmetros geométricos da casca de revolução ___ 5

FIGURA 2.3 - Pressão hidrostática no reservatório cilíndrico ___ 6

FIGURA 2.4 - Esforços solicitantes no reservatório cilíndrico ___ 7

FIGURA 5.1 - Aproximação para o campo de deslocamentos ___ 49

FIGURA 5.2 - Interpolação dada pelo MEF ___ 49

FIGURA 5.3 - Viga em balanço ___ 61 


\section{Lista de siglas}

$\begin{array}{ll}\text { CNPq } & \text { Conselho Nacional de Desenvolvimento Científico e Tecnológico } \\ \text { EESC } & \text { Escola de Engenharia de São Carlos } \\ \text { MEF } & \text { Método dos Elementos Finitos } \\ \text { MEFG } & \text { Método dos Elementos Finitos Generalizados } \\ \text { MMQ } & \text { Método dos Mínimos Quadrados } \\ \text { PU } & \text { Partição da unidade } \\ \text { PVC } & \text { Problema de Valor de Contorno } \\ \text { SET } & \text { Departamento de Engenharia de Estruturas } \\ \text { USP } & \text { Universidade de São Paulo }\end{array}$




\section{Lista de símbolos}

a) letras romanas maiúsculas

$\boldsymbol{A}(\boldsymbol{u})$ Operador diferencial sobre a função $\boldsymbol{u}$

$\boldsymbol{C}_{\boldsymbol{n}} \quad$ Constante $n$ de integração da equação diferencial em $\boldsymbol{w}$

D Rigidez à flexão da parede da casca

E Módulo de elasticidade

$\boldsymbol{H} \quad$ Altura do reservatório cilíndrico

$\boldsymbol{K}_{i j} \quad$ Matriz de rigidez global

$\boldsymbol{K}_{i j}{ }^{e} \quad$ Matriz de rigidez do elemento $\boldsymbol{e}$

$\boldsymbol{M}_{\boldsymbol{y}}$ Momento fletor segundo a direção $\boldsymbol{y}$

$\boldsymbol{M}_{\boldsymbol{\theta}}$ Momento fletor segundo a direção $\boldsymbol{\theta}$

$\boldsymbol{N}_{\boldsymbol{\theta}}$ Esforço normal segundo a direção $\boldsymbol{\theta}$

$\boldsymbol{N}_{\boldsymbol{y}} \quad$ Esforço normal segundo a direção $\boldsymbol{y}$

$\boldsymbol{P}_{\boldsymbol{x}}$ Pressão hidrostática segundo o eixo $\boldsymbol{x}$

$\boldsymbol{P}_{\boldsymbol{y}}$ Pressão hidrostática segundo o eixo $\boldsymbol{y}$

$\boldsymbol{P}_{\boldsymbol{z}}$ Pressão hidrostática segundo o eixo $\boldsymbol{z}$

$\boldsymbol{Q}_{\boldsymbol{y}} \quad$ Esforço cortante segundo a direção $\boldsymbol{y}$

$\boldsymbol{R}(\tilde{\boldsymbol{u}})$ Resíduo sobre a função $\tilde{\boldsymbol{u}}$

$\boldsymbol{U}_{n}{ }^{\boldsymbol{e}} \quad$ Parâmetro nodal do elemento $\boldsymbol{e}$

b) letras romanas minúsculas

$f \quad$ Função independente

$f_{i} \quad$ Vetor de forças nodais equivalentes global

$\boldsymbol{f}_{\boldsymbol{i}}^{\boldsymbol{e}} \quad$ Vetor de for;as nodais equivalentes do elemento $\boldsymbol{e}$

$\mathbf{f}_{\mathbf{n}} \quad$ Função enriquecedora $\mathbf{n}$

f(y) Solução particular de reservatório cilíndrico submetido a pressão hidrostática

$\boldsymbol{h}$ Espessura da casca cilíndrica

l Comprimento da viga

$q$ Carregamento na viga

$r \quad$ Raio da casca cilíndrica 


$\begin{array}{ll}\boldsymbol{u} & \text { Função qualquer } \\ \boldsymbol{u}_{\boldsymbol{o}} & \text { Função que satisfaz restrições essenciais e naturais de contorno } \\ \tilde{\boldsymbol{u}} & \text { Função aproximada da função } \boldsymbol{u} \\ \tilde{\boldsymbol{u}}_{\boldsymbol{e}} & \text { Função aproximada da função } \boldsymbol{u} \text { enriquecida } \\ \boldsymbol{w} & \text { Função deslocamento segundo o eixo } \boldsymbol{x} \text { da casca cilíndrica } \\ \boldsymbol{w}_{\boldsymbol{h}} & \text { Solução homogênea da equação diferencial } \\ \boldsymbol{w}_{\boldsymbol{p}} & \text { Solução particular da equação diferencial } \\ \widetilde{w} & \text { Função aproximativa de deslocamento da casca cilíndrica } \\ \widetilde{w}_{e} & \text { Função aproximativa de deslocamento enriquecida da casca cilíndrica } \\ & \\ & \end{array}$

$\Sigma \quad$ Somatório

$\boldsymbol{\Psi}_{\boldsymbol{j}} \quad$ Funções que constituem uma base linearmente independente

$\boldsymbol{\Omega} \quad$ Domínio de integração

$\boldsymbol{\Omega}^{e} \quad$ Domínio de um elemento finito

d) Letras gregas minúsculas

$\alpha \quad$ Parâmetro incógnito

$\boldsymbol{\beta}$ Constante indicativa da maior ou menor realização de efeitos de flexão induzidos por vínculos de contorno ou forças aplicadas na casca cilíndrica

$\boldsymbol{\beta}_{j}$ Coeficientes de uma combinação linear de funções base

$\gamma \quad$ Peso específico do líquido contido no reservatório cilíndrico

$\eta \quad$ Função deslocamento segundo o eixo $\boldsymbol{z}$ da casca cilíndrica

$\boldsymbol{\theta}$ Curvatura da casca cilíndrica

$v$ Coeficiente de Poisson

$v \quad$ Função ponderadora ou peso

$\phi \quad$ Função aproximativa 


\section{Sumário}

Resumo

Abstract viii

Lista de gráficos ix

Lista de tabelas

xiii

Lista de figuras

xiv

Lista de siglas XV

Lista de símbolos xvi

\section{Introdução}

1.1 Considerações iniciais 1

1.2 Justificativa 1

1.3 Objetivos 2

1.4 Estrutura do trabalho 3

2 Tubos em regime de flexão : conceituação do problema de valor de contorno e solução analítica _ـ $\mathbf{4}$

2.1 Tubos com carregamento axissimétrico de revolução 4

3 Método de Resíduos Ponderados

3.1 Conceituação 12

3.2 Método de Galerkin 15

3.3 Método dos Mínimos Quadrados 16

3.4 O problema dos tubos formulado por Resíduos Ponderados 17

3.4.1 O problema dos tubos formulado pelo Método de Galerkin 20

3.4.1.1 Aplicações desenvolvidas 20 
3.4.1.2 Estudo da solução aproximada do problema de membrana 22

3.4.1.3 Estudo da solução aproximada do problema de flexão

3.4.2 O problema dos tubos formulado pelo Método dos Mínimos Quadrados _ 28

3.4.2.1 Estudo da solução aproximada do problema de membrana 29

3.4.2.2 Estudo da solução aproximada do problema de flexão 31

\section{Método de Resíduos Ponderados e o enriquecimento da} aproximação 35

4.1 Enriquecimento da aproximação 35

4.2 Método de Resíduos Ponderados com enriquecimento para o problema dos tubos 35

4.2.1 Enriquecimento da base polinomial linear com base exponencialtrigonométrica 36

4.3 Método de Galerkin 40

4.4 Método dos Mínimos Quadrados 44

\section{Método dos Mínimos Quadrados com divisão do domínio de integração} 48

5.1 Método dos Elementos Finitos 48

5.2 Método dos Elementos Finitos sobre uma formulação em Mínimos

Quadrados 50

5.3 Elemento Finito com seis parâmetros 56

5.3.1 Método dos Mínimos Quadrados com divisão do domínio de integração: aplicação do elemento de seis parâmetros ao problema de viga 60

5.3.2 Método dos Mínimos Quadrados com divisão do domínio de integração aplicado ao problema dos tubos 63

5.4 Elemento Finito com oito parâmetros 68

5.4.1 Método dos Mínimos Quadrados com divisão do domínio de integração: aplicação do elemento finito de oito parâmetros ao problema de viga 73

5.4.2 Método dos Mínimos Quadrados com divisão do domínio de integração: aplicação do elemento de oito parâmetros ao problema dos tubos 75 
6 Considerações finais e conclusões

Referências Bibliográficas __ 83 


\section{Introdução}

\subsection{Considerações iniciais}

Neste trabalho apresentam-se resultados e conclusões de uma pesquisa realizada sobre a aplicação de Métodos de Resíduos Ponderados, mais destacadamente o Método dos Mínimos Quadrados, à análise de estruturas em casca, em especial os reservatórios cilíndricos submetidos a carregamento hidrostático em regime de comportamento linear. As aproximações são geradas a partir de bases polinomiais enriquecidas mediante a adição de funções com características similares à própria solução exata. A alternativa numérica é ainda complementada com a possibilidade de divisão do domínio de integração.

\subsection{Justificativa}

O Método de Resíduos Ponderados e processos dele derivados constituem-se em formulações que propiciam a obtenção de soluções aproximadas suficientemente precisas de um problema de valor de contorno (PVC) e expressam-se, em uma forma geral, mediante a integração ponderada da própria equação diferencial representativa do problema.

No que concerne às estruturas em casca, devido às características específicas de suas equações diferenciais, os processos convencionais de resolução numérica que empregam aproximações polinomiais podem apresentar um grau de dificuldade bastante significativo. Sendo assim, Métodos de Resíduos Ponderados combinados com técnicas não-convencionais de enriquecimento da função aproximativa, podem se constituir em alternativa eficiente para reduzir o grau de dificuldade na resolução do problema. Porém, as funções polinomiais nem sempre são as mais eficientes para fins de enriquecimento da aproximação inicial, notadamente nos problemas das estruturas em casca. Geralmente as soluções analíticas apresentam características tais que só podem ser reproduzidas mediante a adoção de um polinômio de grau muito elevado para o 
enriquecimento, o que implica em alto custo computacional. Com isso, o recurso ao emprego de funções especiais não polinomiais para o enriquecimento pode evitar, de modo significativo, a elevação do esforço computacional em análise estrutural.

Neste trabalho, busca-se primeiramente aplicar, sobre uma formulação em resíduos ponderados, a técnica de enriquecimento das funções aproximativas sugerida no Método dos Elementos Finitos Generalizados (MEFG), proposto por Duarte, Babuŝkka e Oden (2000). Posteriormente trata-se da alternativa formulada pela combinação do Método dos Mínimos Quadrados com divisão do domínio de integração. Ambas as alternativas podem propiciar respostas aproximadas de grande qualidade e precisão.

\subsection{Objetivos}

O presente trabalho tem por objetivo avaliar o desempenho de soluções aproximadas obtidas pela aplicação de Métodos de Resíduos Ponderados, especificamente o Método de Galerkin e o Método dos Mínimos Quadrados, à análise de estruturas de tubos submetidas a carregamento hidrostático.

Em relação aos métodos adotados para o desenvolvimento da pesquisa analisamse, as formas forte e em resíduos ponderados com que se expressa o PVC. Desenvolvese, em seguida, um estudo comparativo de soluções aproximadas obtidas pelo emprego de bases de funções lineares e polinomiais de grau superior para a geração da função de aproximação, assim como de funções especiais que possuem as mesmas características da solução analítica.

O emprego da técnica de enriquecimento da função aproximativa sugerida no trabalho de Duarte, Babuŝka e Oden (2000) sobre a forma em resíduos ponderados é também explorado. Finalmente aplica-se o Método dos Elementos Finitos para a geração de aproximação para o PVC formulado pelo Método dos Mínimos Quadrados. Nesse sentido o trabalho apresenta contribuições originais, como a combinação de técnicas de enriquecimento da aproximação sobre Métodos de Resíduos Ponderados, e a aplicação do Método de Mínimos Quadrados com divisão do domínio de integração, para a resolução do problema dos tubos em regime de comportamento linear. 


\subsection{Estrutura do trabalho}

No capítulo 2 inicialmente apresenta-se a equação diferencial representativa do problema dos tubos cilíndricos submetidos à pressão hidrostática, bem como as hipóteses adotadas para a formulação do problema e as condições de contorno que poderão ser aplicadas à estrutura.

O capítulo 3 faz uma abordagem de dois Métodos de Resíduos Ponderados: o Método de Galerkin e o Método dos Mínimos Quadrados, bem como a sua aplicação para a resolução do problema dos tubos cilíndricos. As formulações apresentadas por estes métodos se restringem somente à forma integral ponderada. Neste capítulo apresentam-se, ainda, os primeiros exemplos numéricos da aplicação do método, com a utilização de bases aproximativas lineares e polinomiais.

A técnica de enriquecimento da aproximação é abordada no capítulo 4, bem como a sua aplicação ao problema dos tubos cilíndricos. Desenvolvem-se exemplos numéricos com o emprego do enriquecimento da aproximação por funções que possuem características similares às funções contidas nas soluções exatas e compara-se a qualidade dos resultados obtidos com aqueles do capítulo anterior.

O capítulo 5 trata da aplicação do Método dos Mínimos Quadrados (MMQ) com divisão do domínio de integração, essencialmente uma combinação MEF-MMQ. Apresentam-se exemplos numéricos nos quais empregam-se dois tipos de elementos finitos. Os resultados obtidos com a aplicação do MMQ puro e de sua combinação com o MEF são, então, confrontados. As análises conduzidas permitem avaliar as vantagens apresentadas por cada alternativa, bem como as condições mínimas exigidas para a aplicação dos mesmos.

No capítulo 6 apresentam-se as considerações finais e conclusões, embasadas nos resultados e observações comparativas realizadas entre as diversas formulações.

Ao final da dissertação constam os trabalhos que foram referencias para a realização desta pesquisa. 


\section{Tubos em regime de flexão : Conceituação do problema de valor de contorno e solução analítica}

\subsection{Tubos com carregamento axissimétrico}

As cascas são elementos estruturais laminares e que possuem superfície média não plana. Esta definição abrange várias formas estruturais, sendo a casca dita de revolução quando sua forma geométrica pode ser gerada através da rotação de uma reta em torno de um eixo denominado eixo de revolução. Neste trabalho consideram-se, entre as cascas de revolução, os tubos, cujos elementos geométricos principais, tendo como referência sua superfície média, estão ilustrados na figura 2.1.

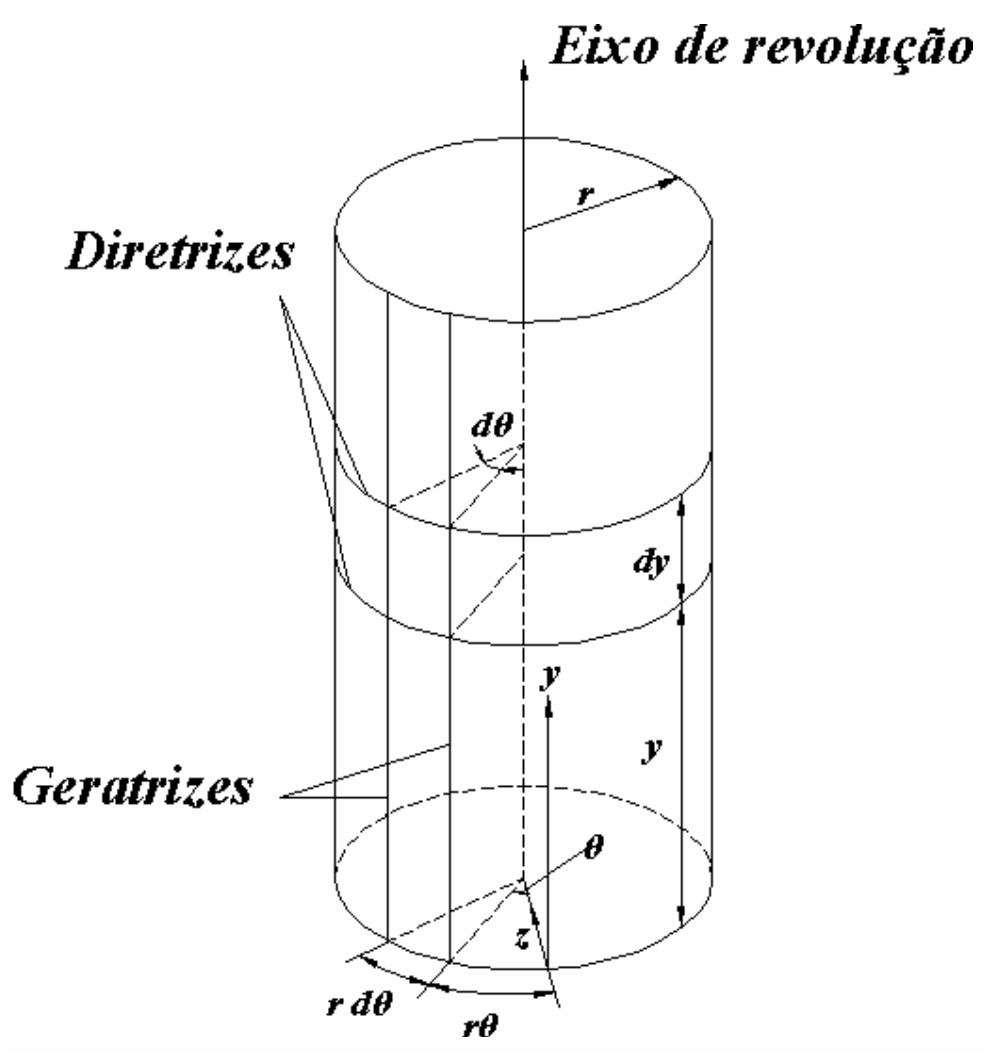

Figura 2.1 - Tubo cilíndrico. 
Entre os seus elementos geométricos, destacam-se ainda a altura $\boldsymbol{H}$, a espessura $\boldsymbol{h}$ e o raio de curvatura $\boldsymbol{r}$ de sua superfície média, indicados na figura 2.2

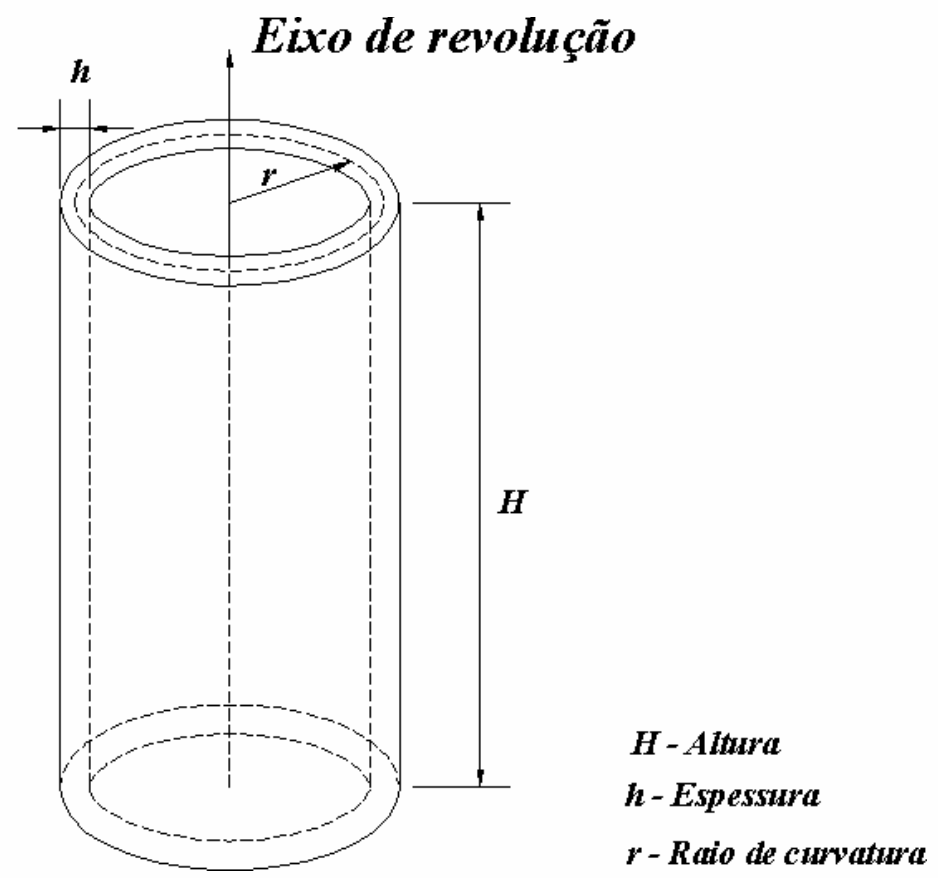

Figura 2.2 - Parâmetros geométricos da casca de revolução.

Os tubos delgados são assim definidos por apresentarem a relação entre o raio de curvatura médio $\boldsymbol{r}$ e a espessura $\boldsymbol{h}$ verificando a seguinte condição:

$$
\frac{h}{r} \leq \frac{1}{20}
$$

Para a análise dos tubos delgados estabeleceram-se previamente três hipóteses:
$\checkmark$ simetria radial geométrica,
$\checkmark$ simetria radial de carregamento e
$\checkmark$ pequenos deslocamentos. 
Com relação às forças externas, considera-se apenas a atuação de uma pressão interna, representando a ação de um líquido contido pelo tubo, sendo o tubo completamente cheio (figura 2.3), dada pela seguinte equação:

$$
P_{z}=-\gamma \cdot(H-y)
$$

Nessas condições o tubo se caracteriza como um reservatório cilíndrico.

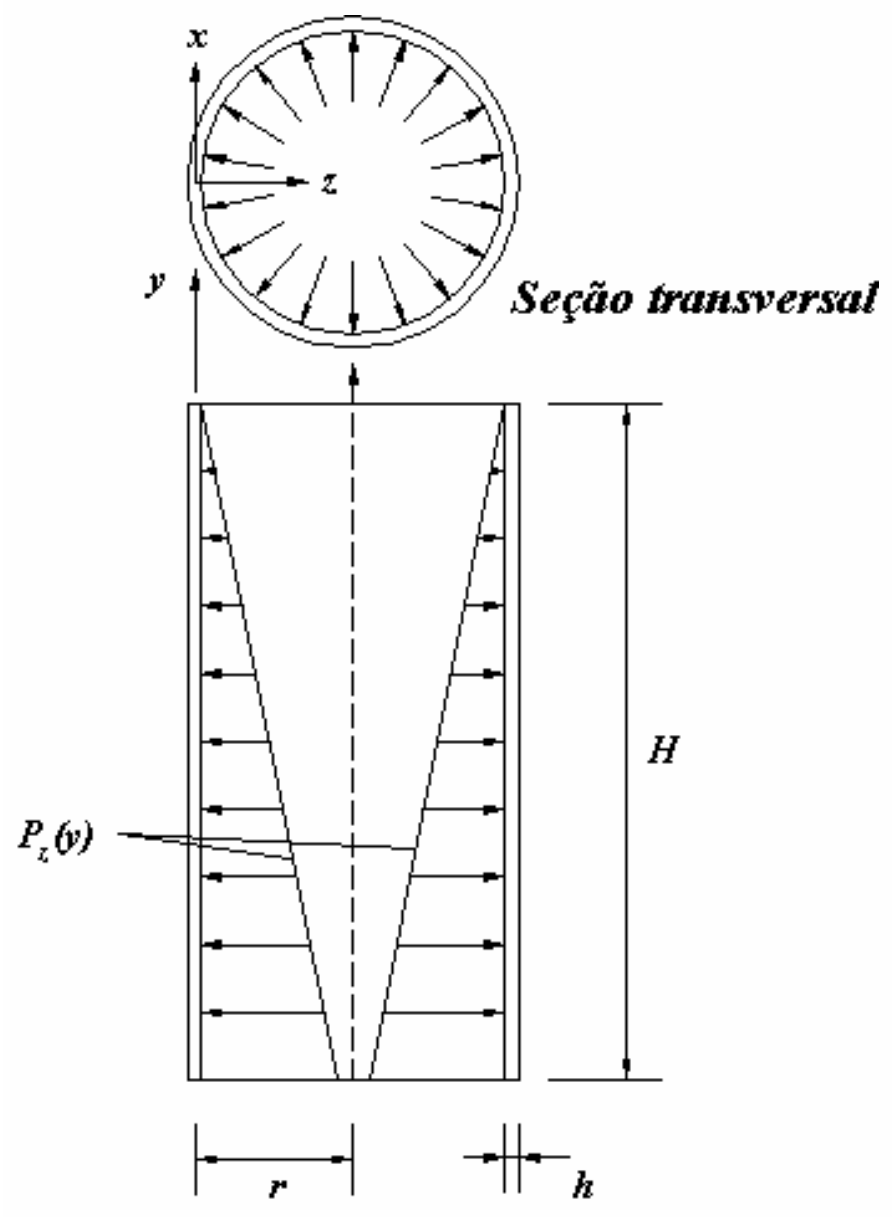

Seção longitudinal

Figura 2.3 - Pressão hidrostática no reservatório cilíndrico.

Tomando-se um elemento genérico da superfície média, delimitado por duas geratrizes e duas diretrizes, conforme a figura 2.1, indicam-se os esforços solicitantes oriundos da atuação da pressão do líquido contido no reservatório na figura 2.4, cujas 
variações são coerentes com as restrições de simetria axial geométrica e de carregamento.

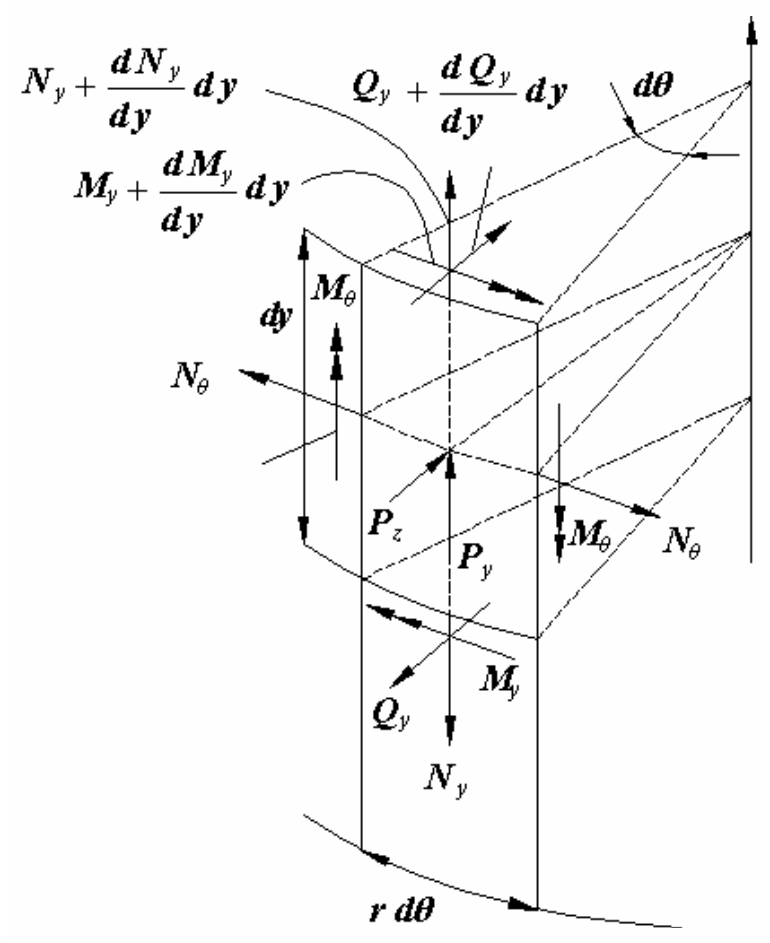

Figura 2.4 - Esforços solicitantes no reservatório cilíndrico.

Impondo-se o equilíbrio estático de forças e momentos no elemento de casca genérico, segundo as direções definidas pelos eixos $\boldsymbol{x}, \boldsymbol{y}$ e $\boldsymbol{z}$, resultam, as seguintes relações de equilíbrio:

$$
\begin{aligned}
& -\frac{d M_{y}}{d y}+Q_{y}=0 \\
& \frac{d N_{y}}{d y}+P_{y}=0 \\
& r \cdot \frac{d Q_{y}}{d y}+N_{\theta}+P_{z} \cdot r=0
\end{aligned}
$$


Combinando-se as eq.(2.3 a) e eq.(2.3 c), obtém-se:

$$
r \cdot \frac{d^{2} M_{y}}{d y^{2}}+N_{\theta}+P_{z} \cdot r=0
$$

Nota-se que a eq.(2.3 b) se refere ao equilíbrio em relação ao peso próprio da parede, sendo esta equação independente das demais eq.(2.3 a) e eq.(2.3 c). No caso em que o momento fletor ao longo de toda a sua altura for nulo, através da eq.(2.4) obtêmse:

$$
N_{\theta}=-P_{z} \cdot r
$$

Neste caso, nota-se que o deslocamento da parede do reservatório pode ser determinado pela variação do comprimento do raio do reservatório, eq.(2.8). Tendo em vista a eq.(2.5), a eq.(2.6), e a eq.(2.7) mencionadas abaixo:

$$
\begin{gathered}
\varepsilon_{\theta}=\frac{\sigma_{\theta}}{E} \\
\sigma_{\theta}=\frac{N_{\theta}}{h}
\end{gathered}
$$

têm-se que :

$$
w(y)=\Delta \mathrm{r}=-\varepsilon_{\theta} \cdot r=\frac{-\gamma \cdot(H-y) \cdot r^{2}}{E \cdot h}
$$

Sendo assim, a rotação da parede do reservatório pode ser expressa pela derivada primeira da função deslocamento :

$$
\frac{d w(y)}{d y}=\frac{\gamma \cdot r^{2}}{E \cdot h}
$$


Tendo em vista a eq.(2.3 a) e a eq.(2.3 c) que definem o problema de flexão em cascas de paredes cilíndricas, são duas equações e três incógnitas: $N_{\boldsymbol{\theta}}, \boldsymbol{M}_{\boldsymbol{y}}$ e $\boldsymbol{Q}_{\boldsymbol{y}}$. Neste caso, é necessário introduzir uma relação entre esforços e deslocamentos, em virtude do problema ser internamente hiperestático. Esta relação pode ser obtida da eq.(2.8):

$$
w(y)=\Delta \mathrm{r}=-\varepsilon_{\theta} \cdot r=-\left(\frac{\sigma_{\theta}}{\mathrm{E}}\right) \cdot r=-\frac{r}{E} \cdot\left(\frac{N_{\theta}}{h}\right)=-N_{\theta} \cdot \frac{r}{E \cdot h}
$$

de modo que:

$$
w(y)=-N_{\theta} \cdot \frac{r}{E \cdot h} \Rightarrow \frac{w(y)}{r}=\frac{-N_{\theta}}{E \cdot h} \Rightarrow N_{\theta}=-\frac{E \cdot h}{r} \cdot w(y)
$$

Com isto, a eq. $(2.3 \mathrm{c})$ pode ser descrita da seguinte forma:

$$
r \cdot \frac{d Q_{y}}{d y}-\frac{E \cdot h}{r} \cdot w+P_{z} \cdot r=0
$$

Já a terceira equação do problema é dada por:

$$
M_{y}=-D \cdot \frac{d^{2} w}{d^{2} y}
$$

Sendo assim, tem-se agora um problema com três equações: eq.(2.3 a), eq.(2.11) e eq.(2.12). E três incógnitas $\left(\boldsymbol{N}_{\boldsymbol{\theta}}, \boldsymbol{M}_{\boldsymbol{y}}\right.$ e $\left.\boldsymbol{Q}_{\boldsymbol{y}}\right)$ que podem ser reduzidas à duas equações: eq.(2.12) e eq.(2.13). E duas incógnitas $\left(\boldsymbol{N}_{\boldsymbol{\theta}}\right.$ e $\left.\boldsymbol{M}_{\boldsymbol{y}}\right)$ : 


$$
\begin{aligned}
& Q_{y}=\frac{d M_{y}}{d y} \Leftrightarrow r \cdot \frac{d Q_{y}}{d y}-\frac{E \cdot h}{r} \cdot w+P_{z} \cdot r=0 \\
& \Rightarrow \frac{d^{2} M_{y}}{d y^{2}}-\frac{E \cdot h}{r^{2}} \cdot w+P_{z}=0
\end{aligned}
$$

Substituindo-se a eq.(2.12) na eq.(2.13), obtêm-se a equação que descreve o comportamento das paredes cilíndricas submetidas a pressão hidrostática, eq.(2.14):

$$
\begin{aligned}
& \frac{d^{2} M_{y}}{d y^{2}}-\frac{E \cdot h}{r^{2}} \cdot w+P_{z}=0 \Rightarrow \frac{d^{2}}{d y^{2}}\left(-D \cdot \frac{d^{2} w}{d y^{2}}\right)-\frac{E \cdot h}{r^{2}} \cdot w+P_{z}=0 \\
& \Rightarrow D \cdot \frac{d^{4} w}{d y^{4}}+\frac{E \cdot h}{r^{2}} \cdot w=P_{z}
\end{aligned}
$$

ou ainda:

$$
\frac{d^{4} w}{d y^{4}}+4 \cdot \beta^{4} \cdot w-\frac{P}{D}=0
$$

Sendo:

$$
\begin{aligned}
& \beta=\sqrt[4]{\frac{3 \cdot\left(1-v^{2}\right)}{h^{2} \cdot r^{2}}} \\
& D=\frac{E \cdot h^{3}}{12 \cdot\left(1-v^{2}\right)}
\end{aligned}
$$

Uma vez obtido o deslocamento $\boldsymbol{w}$ por meio da resolução da equação diferencial (2.15), podem ser determinados todos os parâmetros que caracterizam o regime estático da casca. De fato, o esforço $N_{\boldsymbol{\theta}}$ resulta de:

$$
N_{\theta}=\frac{-E \cdot h}{r} \cdot w
$$


O esforço $\boldsymbol{M}_{\boldsymbol{y}}$ pode ser calculado a partir de:

$$
M_{y}=-D \cdot\left(\frac{d^{2} w}{d y^{2}}\right)
$$

O esforço $\boldsymbol{Q}_{\boldsymbol{y}}$, por sua vez, é obtido mediante:

$$
Q_{y}=-D \cdot\left(\frac{d^{3} w}{d y^{3}}\right)
$$

Finalmente, o esforço $\boldsymbol{M}_{\boldsymbol{\theta}}$ :

$$
M_{\theta}=-D \cdot\left(\mathrm{v} \cdot \frac{d^{2} w}{d y^{2}}\right)=\mathrm{v} \cdot M_{y}
$$

A solução geral da eq.(2.15) é dada pela seguinte expressão:

$$
\begin{aligned}
w= & e^{\beta \cdot y}\left(C_{1} \cos (\beta y)+C_{2} \operatorname{sen}(\beta y)\right) \\
& +e^{-\beta \cdot y}\left(C_{3} \cos (\beta y)+C_{4} \operatorname{sen}(\beta y)\right)+f(y)
\end{aligned}
$$

onde $\boldsymbol{f}(\boldsymbol{y})$ representa uma solução particular do problema. No caso de pressão hidrostática, a solução particular da referida equação é dada por:

$$
f(y)=\left(\frac{r^{2}}{E \cdot h}\right) \cdot P_{z}=\left(\frac{\gamma \cdot r^{2}}{E \cdot h}\right) \cdot(H-y)
$$

As constantes que aparecem na eq.(2.22) devem ser obtidas a partir da imposição das condições de contorno. Neste trabalho, por simplificação, consideram-se apenas casos de reservatório com base articulada fixa e engastada, ambos com topo livre (momento fletor e esforço cortante nulos). 


\section{Método de Resíduos Ponderados}

\subsection{Conceituação}

O Método dos Resíduos Ponderados estabelece uma condição natural para a obtenção de soluções aproximadas de vários problemas de engenharia. Segundo ASSAN (2003), o Método dos Resíduos Ponderados difere dos métodos ditos variacionais por não necessitar da existência de um funcional, utilizando diretamente a equação diferencial (forma forte) do problema a ser resolvido.

A sua aplicação, no início, manteve-se restringida a problemas relativamente simples em virtude da dificuldade de se obter funções aproximadas em todo o domínio, principalmente nos casos de estruturas que apresentam sistemas de equações com um número apreciável de incógnitas. No entanto, essa dificuldade passou a ser superada com técnicas de geração da aproximação mediante divisão do domínio de integração

Para conceituar melhor o método, considere-se a equação diferencial de um problema genérico representada da seguinte maneira:

$$
A(u)=f
$$

onde $\boldsymbol{A}$ representa um operador diferencial sobre a função $\boldsymbol{u}$ (solução exata), responsável por gerar as parcelas contendo diferentes ordens de derivadas que podem aparecer em um problema específico.

Uma solução aproximativa deve verificar as condições de contorno essenciais e naturais do problema a ser analisado, e pode ser descrita da seguinte maneira:

$$
\tilde{u}(x)=\alpha_{i} \cdot \phi(x)_{i}+\tilde{u}_{o}(x) \quad c / i=1, \ldots n
$$


onde $\widetilde{u}_{o}(x)$ é uma função que satisfaz as restrições essenciais e naturais de contorno, $\phi_{i}(x)$ são funções homogêneas naquelas restrições, e $\alpha_{i}$ são os parâmetros incógnitos do problema.

Em se tratando da adoção da função aproximativa $\tilde{\boldsymbol{u}}$, resulta que :

$$
A(\tilde{u}) \neq f
$$

Uma vez que a aproximação descrita pela eq.(3.3) não corresponde à solução exata, pode-se definir o resíduo da aproximação com sendo:

$$
R(\tilde{u})=A(\tilde{u})-f \neq 0
$$

O Método dos Resíduos Ponderados estabelece que os coeficientes $\boldsymbol{\alpha}_{\boldsymbol{i}}$ que constam na função aproximativa sejam determinados mediante a condição de anulação do resíduo em forma ponderada no domínio da solução. Essa condição é expressa pela seguinte integral:

$$
\int_{\Omega} R(\tilde{u}) \cdot v d \Omega=0
$$

onde $\boldsymbol{V}$ é uma função homogênea nas condições de contorno essenciais em todo o domínio $\boldsymbol{\Omega}$ do problema.

A função ponderadora ou função peso pode ser expressa na forma de uma combinação linear de funções base:

$$
v(x)=\beta_{j} \cdot \Psi_{j}(x) \quad c / j=1, \ldots n
$$

sendo $\Psi_{\mathbf{j}}(\boldsymbol{x})$ uma base de funções linearmente independente.

Substituindo-se a eq.(3.6) na eq.(3.5) resulta em uma somatória de $\boldsymbol{n}$ parcelas com coeficientes $\boldsymbol{\beta}_{\boldsymbol{j}}$ quaisquer: 
$\beta_{j} \cdot \int_{\Omega} R(\tilde{u}) \cdot \Psi_{j} d \Omega=0 \quad c / j=1, \ldots n$

A condição anterior é atendida para qualquer combinação de $\boldsymbol{\beta}_{\boldsymbol{j}}$ (não todos nulos simultaneamente) se:

$$
\int_{\Omega} R(\tilde{u}) \cdot \Psi_{j} d \Omega=0 \quad c / j=1, \ldots n
$$

Admitindo-se a linearidade do operador $\boldsymbol{A}$ e considerando-se a eq.(3.2), pode-se então expressar a forma geral do Método dos Resíduos Ponderados da seguinte maneira:

$$
\begin{aligned}
& \int_{\Omega} R(\widetilde{u}) \cdot \Psi_{j} d \Omega=0 \Rightarrow \int_{\Omega}\left(\alpha_{i} \cdot A\left(\phi_{i}\right)+A\left(\widetilde{u}_{o}\right)-f\right) \cdot \Psi_{j} d \Omega=0 \Rightarrow \\
& \alpha_{i} \cdot \int_{\Omega} A\left(\phi_{i}\right) \cdot \Psi_{j} d \Omega=\int_{\Omega}\left[f-A\left(\widetilde{u}_{o}\right)\right] \cdot \Psi_{j} d \Omega
\end{aligned}
$$

Introduzindo-se a notação:

$$
\begin{aligned}
& A_{i j}=\int_{\Omega} A\left(\phi_{i}\right) \cdot \Psi_{j} d \Omega \\
& f_{j}=\int_{\Omega}\left[f-A\left(\tilde{u}_{o}\right)\right] \cdot \Psi_{j} d \Omega
\end{aligned}
$$

O sistema que permite determinar os coeficientes $\boldsymbol{\alpha}_{\boldsymbol{i}}$ pode ser representado da seguinte maneira:

$$
\alpha_{i} \cdot A_{i j}=f_{j}
$$


Reunindo-se os coeficientes $\boldsymbol{\alpha}_{\boldsymbol{i}}$ num vetor coluna $\underline{\alpha}$, os coeficientes $\boldsymbol{f}_{\boldsymbol{j}}$ em um outro vetor coluna $\underline{f}$ e os coeficientes $\boldsymbol{A}_{\boldsymbol{i} \boldsymbol{j}}$ nas posições de linha $\boldsymbol{i}$ e coluna $\boldsymbol{j}$ de uma matriz $\underline{\underline{A}}$, pode-se ainda representar o mesmo sistema em forma matricial:

$\underline{\underline{A^{T}}} \cdot \underline{\alpha}=\underline{f}$

Os Métodos de Resíduos Ponderados variam de acordo com a função $\boldsymbol{\Psi}_{\mathbf{j}}$ adotada. Dentre estes métodos, abordam-se a seguir o Método de Galerkin e o Método dos Mínimos Quadrados.

\subsection{Método de Galerkin}

O Método de Galerkin tornou-se o mais conhecido e o mais potente dos Métodos de Resíduos Ponderados em virtude do advento e rápido desenvolvimento dos computadores e de sua combinação com o Método dos Elementos Finitos, que introduziu uma forma engenhosa de construção de funções de aproximação.

Basicamente, o Método de Galerkin propõe que as funções base da função ponderadora sejam as mesmas da função aproximativa. Pode-se representar esta condição da seguinte maneira:

$\Psi_{j}=\phi_{j}$

Com isto, o Método de Galerkin pode ser descrito da seguinte forma:

$\alpha_{i} \cdot \int_{\Omega} A\left(\phi_{i}\right) \cdot \phi_{j} d \Omega=\int_{\Omega}\left[f-A\left(\tilde{u}_{o}\right)\right] \cdot \phi_{j} d \Omega$

Segue da relação anterior que para fins de utilização da forma matricial, definem-se: 


$$
\begin{aligned}
& A_{i j}=\int_{\Omega} A\left(\phi_{i}\right) \cdot \phi_{j} d \Omega \\
& f_{j}=\int_{\Omega}\left[f-A\left(\tilde{u}_{o}\right)\right] \cdot \phi_{j} d \Omega
\end{aligned}
$$

\subsection{Método dos Mínimos Quadrados}

No Método dos Mínimos Quadrados a aproximação é obtida por meio da minimização da norma ao quadrado do resíduo, ou seja:

$$
\frac{d\|R\|^{2}}{d \alpha_{j}}=0
$$

Onde $\|R\|^{2}$ pode ser definido como:

$$
\|R\|^{2}=\int_{\Omega}[R(\widetilde{u})]^{2} d \Omega=\int_{\Omega}\left[R\left(\alpha_{j} \cdot \phi_{j}+\widetilde{u}\right)_{o}\right]^{2} d \Omega
$$

De modo que:

$$
\frac{d\|R\|^{2}}{d \alpha_{j}}=2 \cdot \int_{\Omega} R(\tilde{u}) \cdot\left[\frac{d R\left(\alpha_{j} \cdot \phi_{j}+\tilde{u}_{0}\right)}{d \alpha_{j}}\right] d \Omega=0
$$

Esta última equação é equivalente à condição de anulação do resíduo e dela pode-se definir a função peso por: 
$\Psi_{j}=\frac{d R\left(\alpha_{j} \cdot \phi_{j}+\tilde{u}_{0}\right)}{d \alpha_{j}}=\frac{d\left\lfloor A\left(\alpha_{j} \cdot \phi_{j}+\tilde{u}_{0}\right)-f\right\rfloor}{d \alpha_{j}}=A\left(\phi_{j}\right)$

Com isto, o Método dos Mínimos Quadrados passa a ser descrito por:

$$
\alpha_{i} \cdot \int_{\Omega} A\left(\phi_{i}\right) \cdot A\left(\phi_{j}\right) d \Omega=\int_{\Omega}\left[f-A\left(\tilde{u}_{o}\right)\right] \cdot A\left(\phi_{j}\right) d \Omega
$$

Para fins de utilização da eq.(3.12), definem-se:

$$
\begin{aligned}
& A_{i j}=\int_{\Omega} A\left(\phi_{i}\right) \cdot A\left(\phi_{j}\right) d \Omega \\
& f_{j}=\int_{\Omega}\left[f-A\left(\tilde{u}_{o}\right)\right] \cdot A\left(\phi_{j}\right) d \Omega
\end{aligned}
$$

No caso deste método, deve-se observar que a matriz $\boldsymbol{A}_{i j}$ é simétrica.

\subsection{O problema dos tubos formulado por Resíduos Ponderados}

No caso dos tubos cilíndricos com espessura constante, a equação diferencial que representa o problema foi apresentada no item 2.1 como sendo:

$$
\frac{d^{4} w}{d y^{4}}+4 \cdot \beta^{4} \cdot w=\frac{p_{z}}{D}
$$

Para se obter uma solução aproximada por meio do Método dos Resíduos Ponderados, parte-se da eq.(2.12) representada da seguinte maneira: 


$$
A(w)=f
$$

Onde:

$$
\begin{aligned}
& A(w)=\frac{d^{4} w}{d y^{4}}+4 \cdot \beta^{4} \cdot w \\
& f=\frac{p_{z}}{D}
\end{aligned}
$$

A função aproximativa pode ser descrita da seguinte maneira:

$$
\widetilde{w}(y)=\alpha_{i} \cdot \phi_{i}+\widetilde{w}_{o}(y) \quad c / i=1, \ldots n
$$

Observa-se que a solução aproximativa deve verificar as condições de contorno essenciais e naturais do problema a ser analisado. Com a aproximação o operador diferencial resulta em:

$$
A(\widetilde{w})=A\left(\alpha_{i} \cdot \phi_{i}+\widetilde{w}_{o}(y)\right)
$$

Deste modo, pode-se dizer que a igualdade expressa na eq.(3.25) não mais existe, de modo que:

$$
A(\widetilde{w}) \neq f
$$

Como a aproximação descrita pela eq.(3.30) não corresponde à solução exata, pode-se definir o resíduo como sendo:

$$
R(\widetilde{w})=A(\widetilde{w})-f \neq 0
$$

Reescrevendo-se, por conveniência, a eq.(3.8): 


$$
\int_{\Omega} R(\tilde{u}) \cdot \Psi_{j} d \Omega \quad c / j=1, \ldots n
$$

Considerando-se a eq.(3.25) e a linearidade do operador $\boldsymbol{A}$, obtêm-se:

$$
\begin{aligned}
& \int_{\Omega}\left[A\left(\alpha_{i} \cdot \phi_{i}+\widetilde{w}_{o}(y)\right)-f\right] \cdot \Psi_{j} d \Omega=0 \Rightarrow \\
& \alpha_{i} \cdot \int_{\Omega} A\left(\phi_{i}\right) \cdot \Psi_{j} d \Omega=\int_{\Omega}\left[f-A\left(\widetilde{w}_{o}\right)\right] \cdot \Psi_{j} d \Omega
\end{aligned}
$$

Por analogia com a eq.(3.26) pode-se representar:

$$
A(\phi)=\frac{d^{4} \phi}{d y^{4}}+4 \cdot \beta^{4} \cdot \phi
$$

Assim sendo, a eq.(3.32) assume a forma:

$$
\alpha_{i} \cdot\left(\int_{\Omega} \frac{d^{4} \phi_{i}}{d y^{4}} \cdot \Psi_{j} d \Omega+4 \cdot \beta^{4} \cdot \int_{\Omega} \phi_{i} \cdot \Psi_{j} d \Omega\right)=\int_{\Omega}\left[f-A\left(\widetilde{w}_{o}\right)\right] \cdot \Psi_{j} d \Omega
$$

De modo que os coeficientes $\boldsymbol{\alpha}_{\boldsymbol{i}}$ podem ser determinados da seguinte maneira:

$$
\alpha_{i} \cdot A_{i j}=f_{j}
$$

Onde:

$$
A_{i j}=\int_{\Omega} \frac{d^{4} \phi_{i}}{d y^{4}} \cdot \Psi_{j} d \Omega+4 \cdot \beta^{4} \cdot \int_{\Omega} \phi_{i} \cdot \Psi_{j} d \Omega
$$


$f_{j}=\int_{\Omega}\left[f-A\left(\widetilde{w}_{o}\right)\right] \cdot \Psi_{j} d \Omega$

\subsubsection{O problema dos tubos formulado pelo Método de Galerkin}

Tendo-se por base a eq.(3.36), a eq.(3.37) e fazendo-se $\Psi_{j}=\phi_{j}$, o Método de Galerkin para o problema dos tubos cilíndricos passa a ser descrito da seguinte forma:

$$
\begin{aligned}
& A_{i j}=\int_{\Omega} \frac{d^{4} \phi_{i}}{d y^{4}} \cdot \phi_{j} d \Omega+4 \cdot \beta^{4} \cdot \int_{\Omega} \phi_{i} \cdot \phi_{j} d \Omega \\
& f_{j}=\int_{\Omega}\left[f-A\left(\widetilde{w}_{o}\right)\right] \cdot \phi_{j} d \Omega
\end{aligned}
$$

Um aspecto importante refere-se à exigência sobre o grau de continuidade que a função aproximativa deve apresentar, além de satisfazer as condições de contorno essenciais e naturais especificadas. No caso da eq.(3.38), a função aproximativa deve ser no mínimo quatro vezes diferenciável.

\subsubsection{Aplicações desenvolvidas}

Os exemplos propostos consistem em reservatórios cilíndricos submetidos a carregamento hidrostático, sendo abordados dois tipos de vinculações:

a) articulação na base e topo livre e;

b) engastamento na base e topo livre.

Logo abaixo estão relacionados os parâmetros utilizados e seus respectivos valores para a análise do problema: 
Altura do reservatório : $\mathrm{H}=10,00 \mathrm{~m}$

Espessura do reservatório $: \mathrm{h}=0,05 \mathrm{~m}$

Raio do reservatório : $\mathrm{r}=8,00 \mathrm{~m}$

Módulo de Young : $\mathrm{E}=2100000000,00 \mathrm{kgf} / \mathrm{m}^{2}$

Coeficiente de Poisson : $v=0,30$

Peso específico do líquido contido no reservatório : $\gamma=1000,00 \mathrm{kgf} / \mathrm{m}^{3}$

Com estes dados, por meio da eq.(2.2) e da eq.(2.3) obtêm-se os valores do módulo de rigidez à flexão da parede do reservatório e do parâmetro $\boldsymbol{\beta}$ que são:

Módulo de rigidez à flexão : $\mathrm{D}=24038,46 \mathrm{kgf} \cdot \mathrm{m}$

Parâmetro : $\beta=2,0324 \mathrm{~m}^{-1}$

Os resultados referentes ao deslocamento $\boldsymbol{w}$, assim como dos esforços

solicitantes $\boldsymbol{M}_{\boldsymbol{y}}$ e $\boldsymbol{Q}_{\boldsymbol{y}}$ foram obtidos com programa elaborado a partir do software MATHCAD $^{\circledR}$.

O primeiro estudo consiste na resolução de um reservatório em regime de membrana. Adota-se uma base linear para a função aproximativa, tendo como principal finalidade a verificação da capacidade do Método de Resíduos Ponderados em capturar soluções exatas, quando existirem.

O segundo estudo refere-se à resolução de um reservatório em regime de flexão. Será utilizada a base polinomial para a função aproximativa com objetivo de se verificar a convergência da solução aproximada com o aumento do grau da base polinomial utilizada. 


\subsubsection{Estudo da solução aproximada do problema de membrana}

A formulação do problema de membrana discretizado pelo método de Galerkin é dado à seguir pela seguinte expressão, onde despreza-se a derivada quarta contida no operador diferencial dado pela eq.(3.33):

$\alpha_{i} \cdot \int_{\Omega} 4 \cdot \beta^{4} \cdot \phi_{i} \cdot \phi_{j} d \Omega=\int_{\Omega} \frac{P_{z}}{D} \cdot \phi_{j} d \Omega \quad c / i, j=1, \ldots n$

Uma base aproximativa linear, possui as seguintes componentes:

$\phi_{1}=1 ; \phi_{2}=y$

as quais possibilitam uma solução para a eq.(3.40). Sendo que a eq.(2.19) reproduzida em seguida, fornece a solução exata deste problema:

$$
w=\left(\frac{r^{2}}{E \cdot h}\right) \cdot P_{z}=\left(\frac{\gamma \cdot r^{2}}{E \cdot h}\right) \cdot(H-y)
$$

Os resultados apresentados mostram a eficiência do método em capturar a solução analítica, quando existir. Neste caso, a solução aproximada coincide com a solução analítica, conforme indica o gráfico de deslocamento $\boldsymbol{w}$, assim como o do esforço $\boldsymbol{N}_{\boldsymbol{\theta}}$. 
Reservatório em regime de membrana

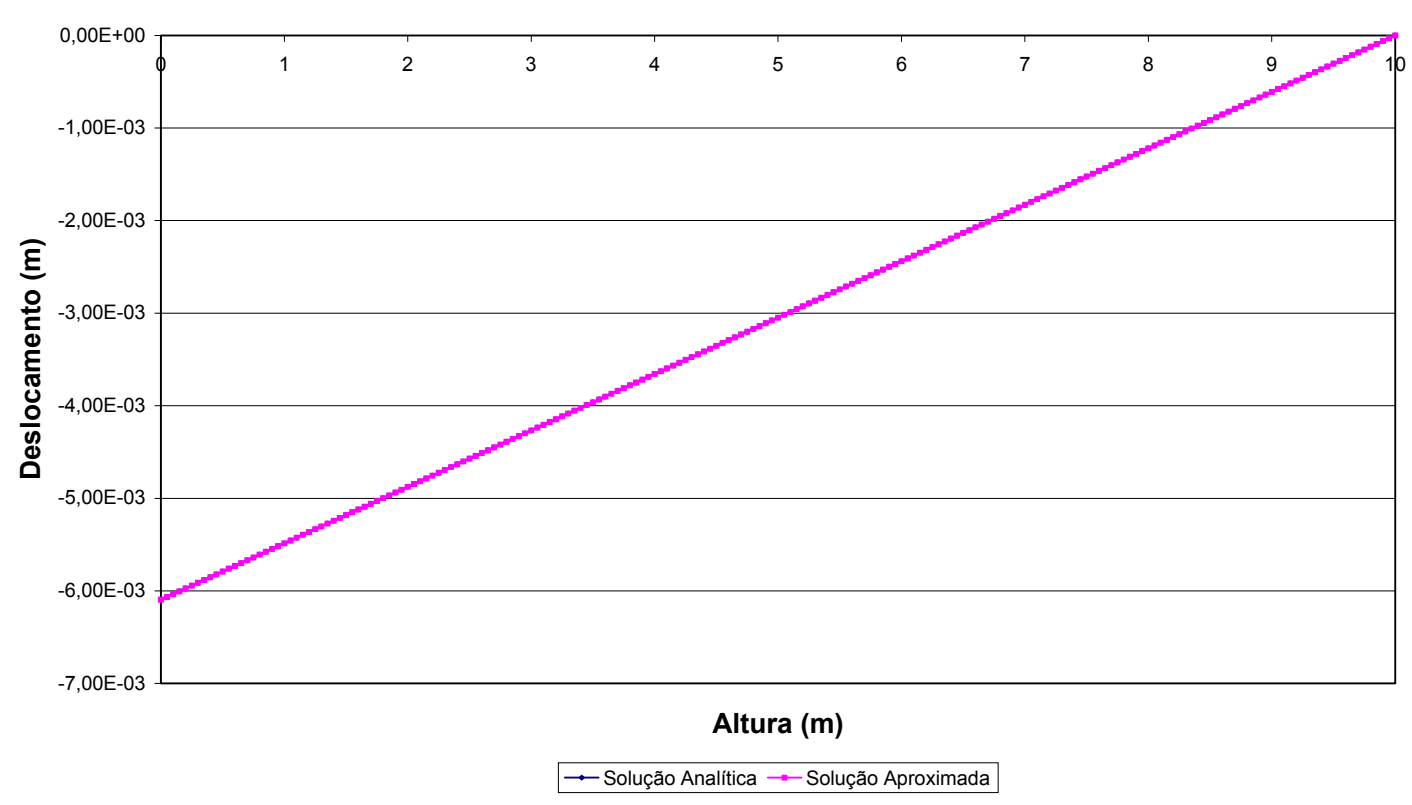

Gráfico 1 - Deslocamento de membrana - Galerkin

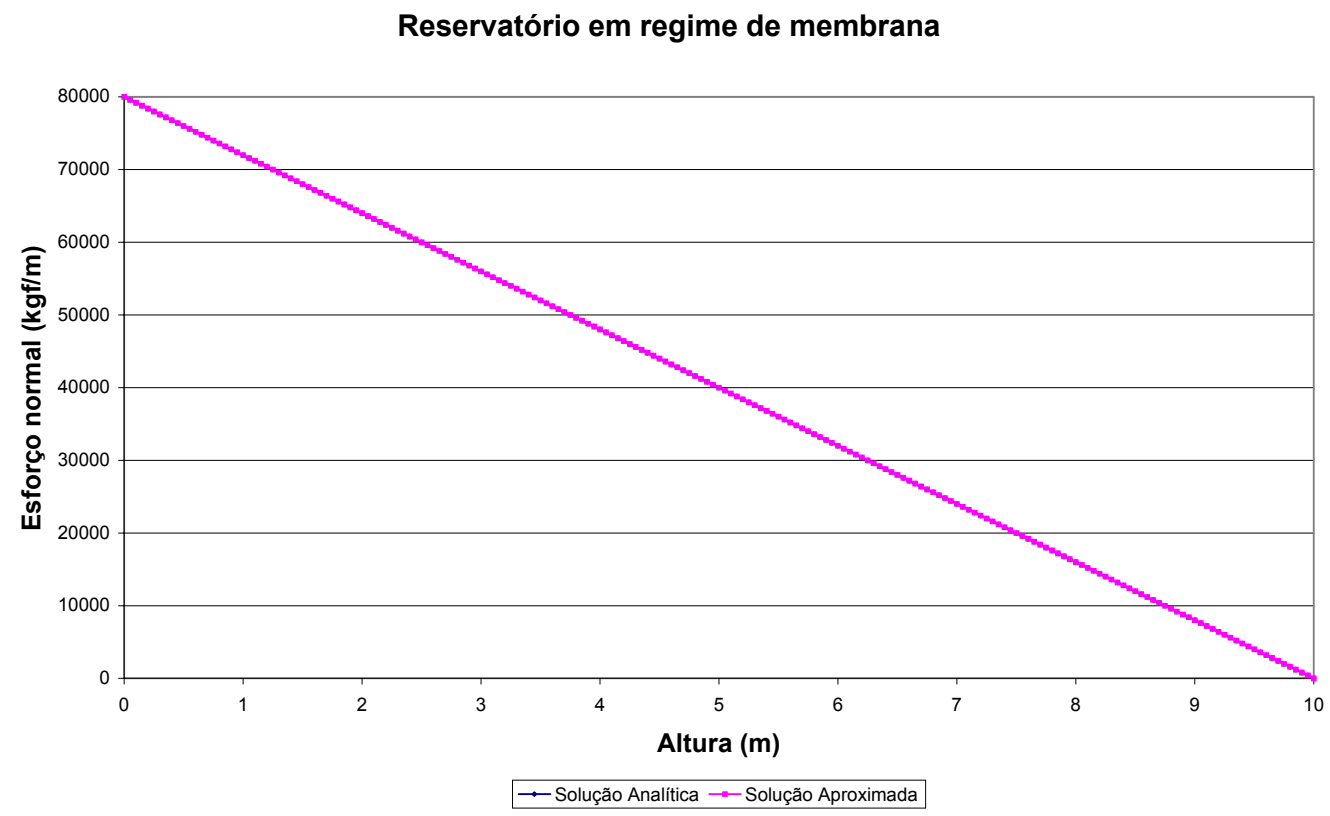

Gráfico 2 - Esforço normal de membrana - Galerkin 


\subsubsection{Estudo da solução aproximada do problema de flexão}

A formulação da integral ponderada para reservatórios cilíndricos em regime de flexão é dada pelo método de Galerkin através da seguinte expressão:

$$
\alpha_{i} \cdot\left(\int_{\Omega} \frac{d^{4} \phi_{i}}{d y^{4}} \cdot \phi_{j} d \Omega+4 \cdot \beta^{4} \cdot \int_{\Omega} \phi_{i} \cdot \phi_{j} d \Omega\right)=\int_{\Omega} \frac{p_{z}}{D} \cdot \phi_{j} d \Omega \quad c / i, j=1, \ldots n
$$

Uma função aproximativa polinomial de grau $\boldsymbol{n}$ pode ser representada na forma:

$$
\widetilde{w}(y)=\sum_{k=1}^{n+1} \alpha_{k} \cdot y^{k-1}
$$

Lembra-se que o polinômio de aproximação tem que possuir grau maior ou igual

a quatro $(n \geq 4)$, obedecendo desta forma a existência para a maior ordem de derivação que aparece na eq.(3.42).

Naturalmente, deve-se impor à aproximação a verificação das condições de contorno essenciais e naturais do problema.

Um outro aspecto relevante quanto à solução aproximada, é que na medida que se aumenta o grau do polinômio a resposta tende para a resposta exata, porém dependendo da precisão desejada e do tipo de solução exata pode ser necessário um polinômio de grau muito elevado para conseguir reduzir significativamente o erro de aproximação. Nas figuras que seguem apresentam-se resultados de exemplos de reservatórios articulados ou engastados na base e livres no topo. No caso de reservatório articulado, o deslocamento nulo na base é a condição de contorno essencial única existente. As condições de contorno naturais nesse caso são: momento fletor nulo na base e no topo, e esforço cortante nulo no topo. Já para o reservatório engastado as condições de contorno essenciais referem-se à nulidade do deslocamento e da rotação na base; as condições de contorno naturais são idênticas ao caso anterior.

A convergência lenta decorre essencialmente do fato que a aproximação polinomial não é a opção mais eficiente para reproduzir a solução exata, a qual é do tipo exponencial-trigonométrica. 
Os gráficos apresentados à seguir são referentes à: $\boldsymbol{w}, \boldsymbol{M}_{\boldsymbol{y}}$ e $\boldsymbol{Q}_{\boldsymbol{y}}$, aproximados com polinômios de diferentes graus. Chama-se a atenção particular para a lenta convergência e para a perda de precisão nas ordens de derivadas superiores necessárias para a obtenção dos esforços $\boldsymbol{M}_{\boldsymbol{y}}$ e $\boldsymbol{Q}_{\boldsymbol{y}}$.

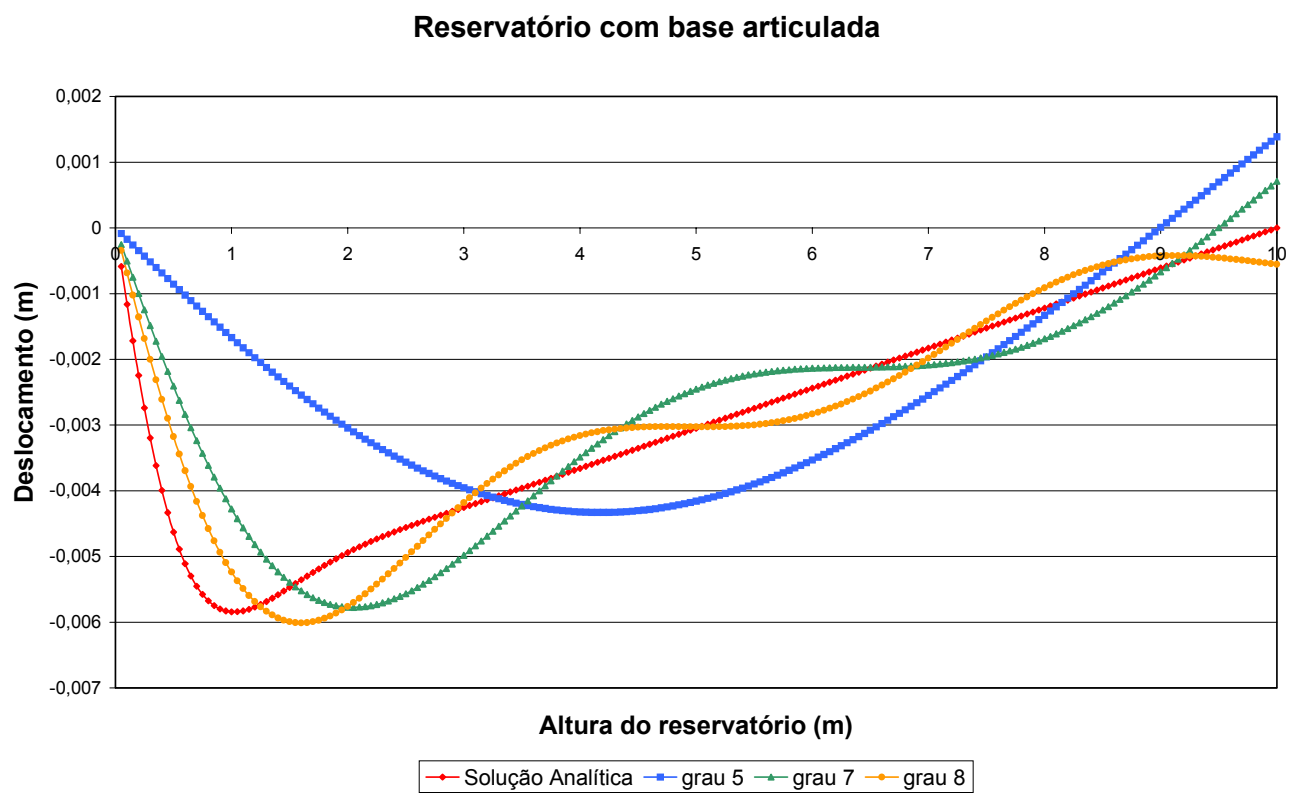

Gráfico 3 - Deslocamento obtido por aproximação polinomial base articulada - Galerkin 
Reservatório com base articulada

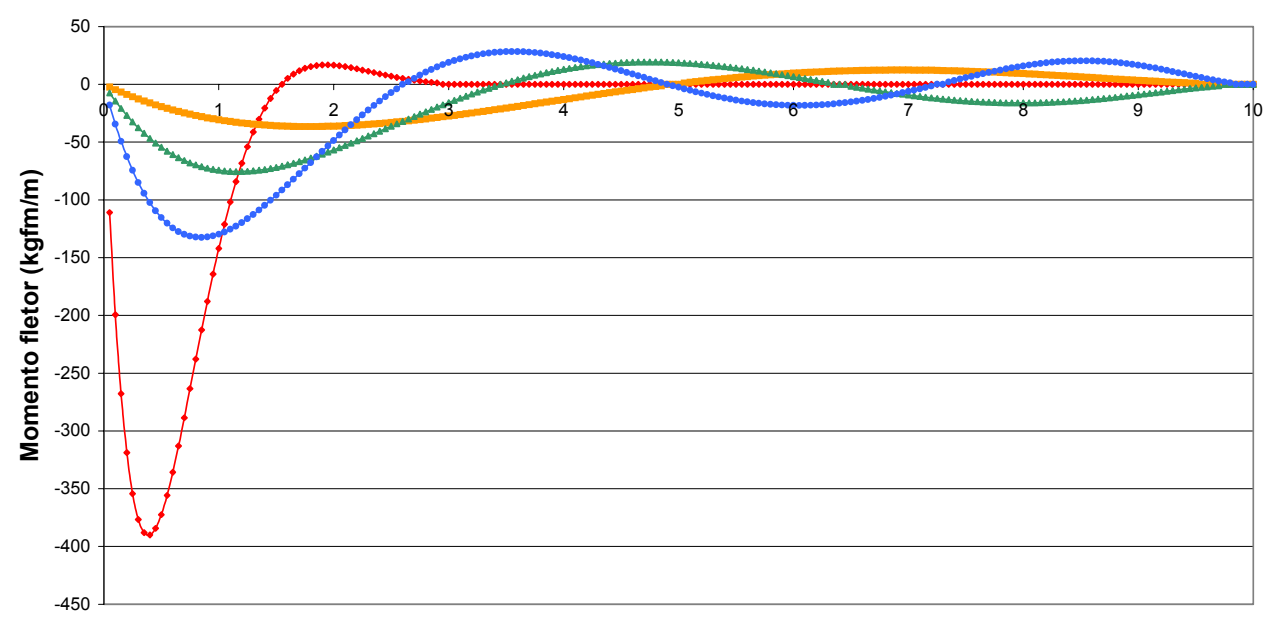

Altura do reservatório (m)

$\rightarrow-$ Solução Analítica - -grau $6 \rightarrow$ Grau $7 \rightarrow-$ Grau 8

\section{Gráfico 4 - Momento fletor obtido por aproximação polinomial base articulada - Galerkin}

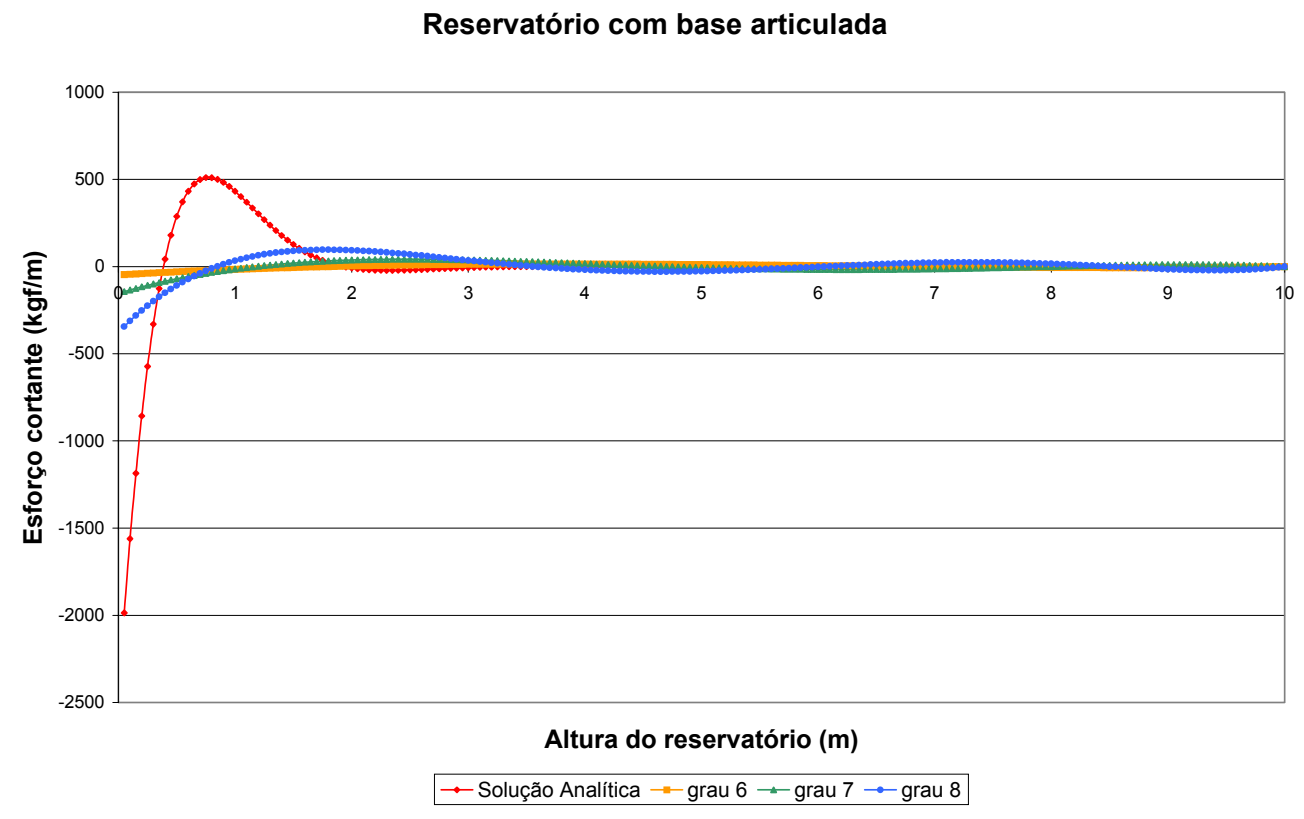

Gráfico 5 - Esforço cortante obtido por aproximação polinomial base articulada - Galerkin 


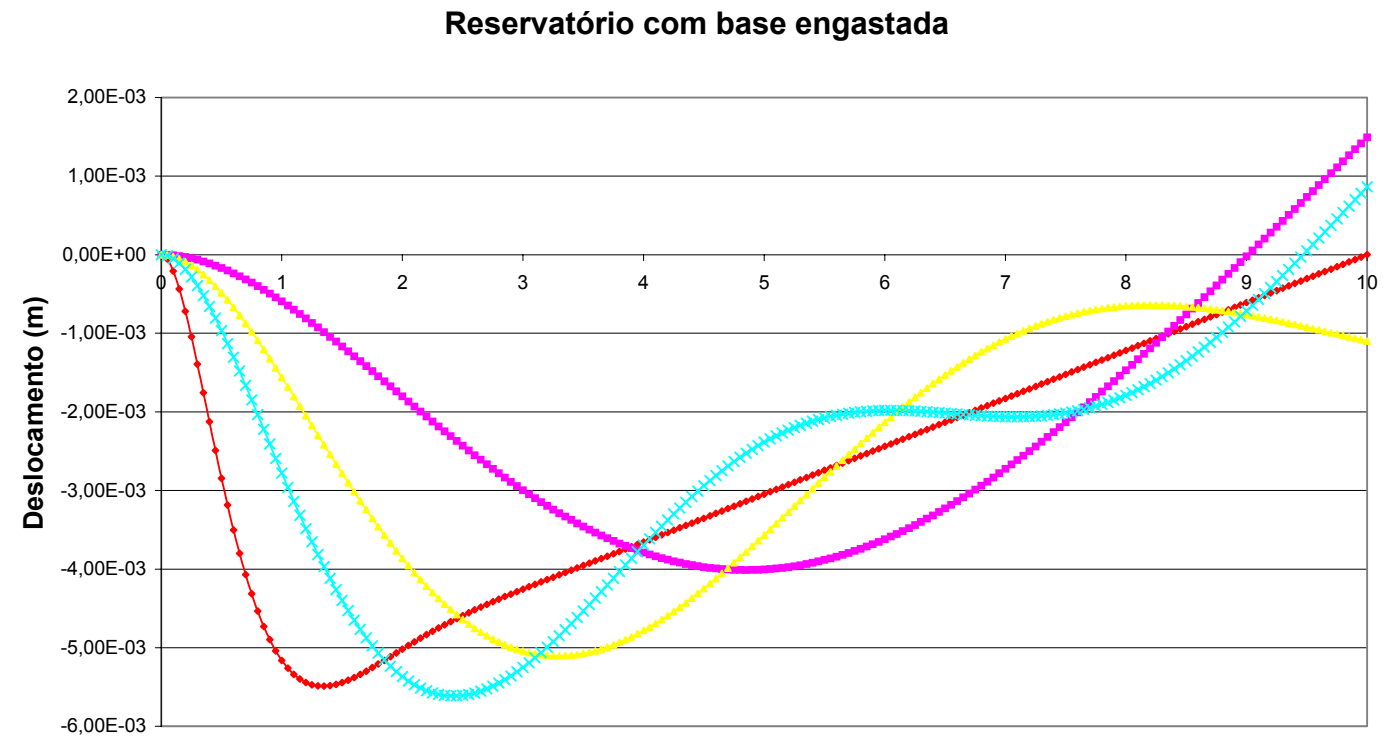

Altura do reservatório $(\mathrm{m})$

$\rightarrow$ Solução Analítica $\rightarrow$ grau $5 \rightarrow$ grau $6 *$ grau 7

Gráfico 6 - Deslocamento obtido por aproximação polinomial base engastada - Galerkin

Reservatório com base engastada

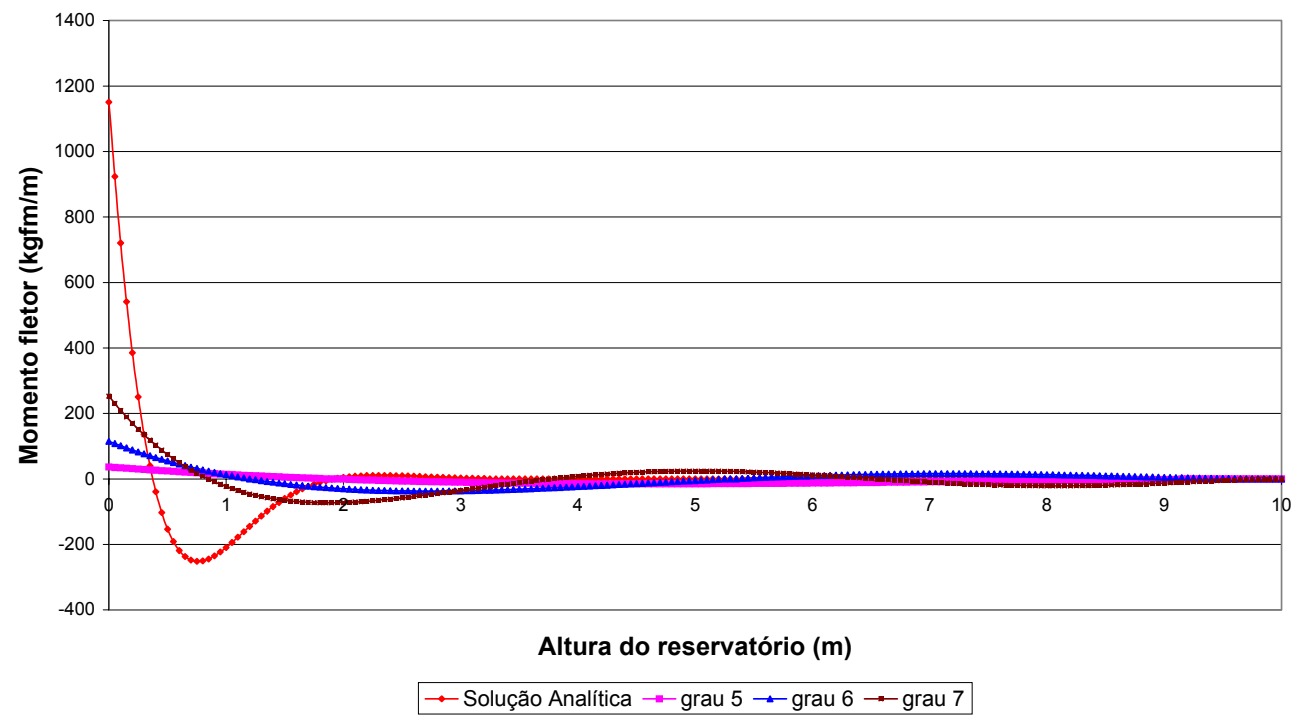

Gráfico 7 - Momento fletor obtido por aproximação polinomial base engastada - Galerkin 


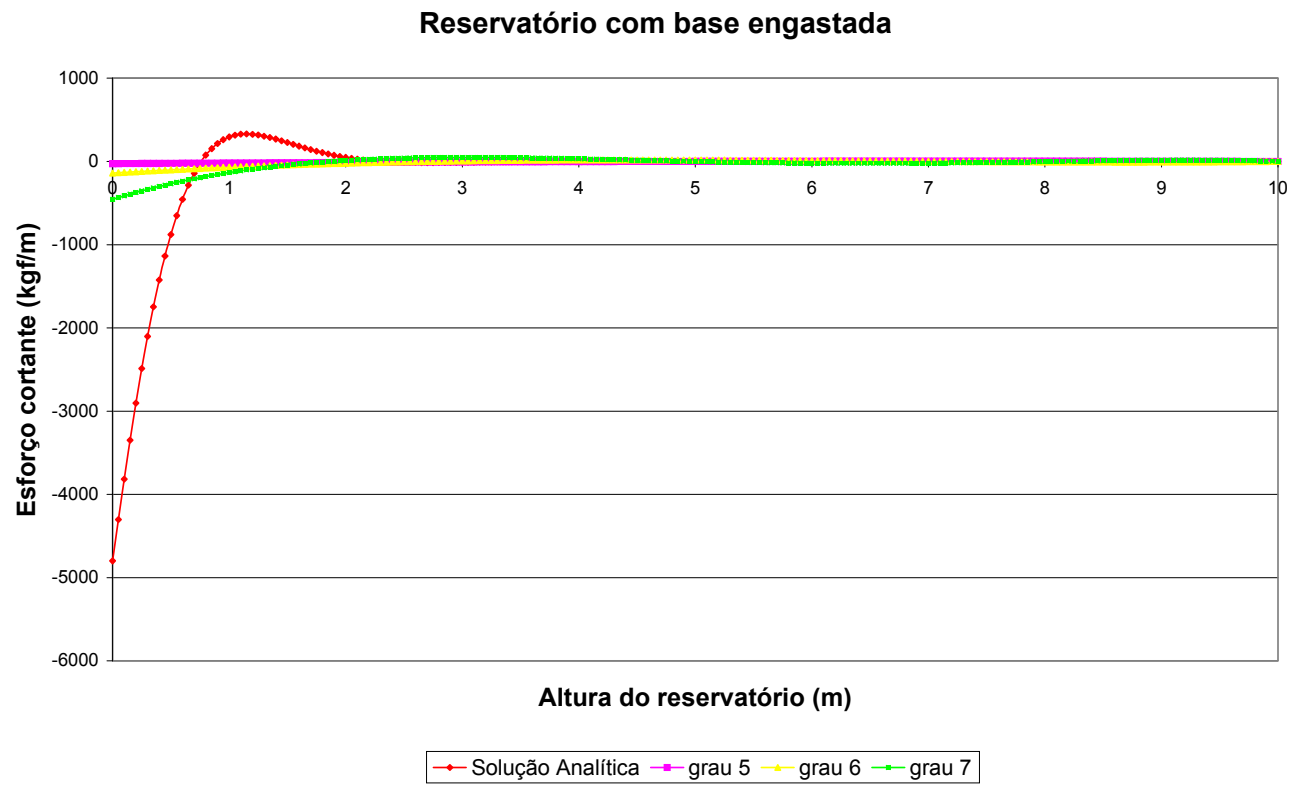

Gráfico 8 - Esforço cortante obtido por aproximação polinomial base engastada - Galerkin

\subsubsection{O problema dos tubos formulado pelo Método dos Mínimos Quadrados}

O Método dos Mínimos Quadrados baseia-se na adoção da função ponderadora como sendo aquela resultante da aplicação do operador diferencial sobre a própria aproximação, ou seja:

$$
\Psi_{j}=A\left(\phi_{j}\right)=\frac{d^{4} \phi_{j}}{d y^{4}}+4 \cdot \beta^{4} \cdot \phi_{j}
$$

Sendo assim, tendo-se por base a eq.(3.36) e a eq.(3.37), o problema dos tubos pode ser descrito da seguinte forma: 


$$
\begin{aligned}
& A_{i j}=\int_{\Omega} \frac{d^{4} \phi_{i}}{d y^{4}} \cdot\left(\frac{d^{4} \phi_{j}}{d y^{4}}+4 \cdot \beta^{4} \cdot \phi_{j}\right) d \Omega+4 \cdot \beta^{4} \cdot \int_{\Omega} \phi_{i} \cdot\left(\frac{d^{4} \phi_{j}}{d y^{4}}+4 \cdot \beta^{4} \cdot \phi_{j}\right) d \Omega \Rightarrow \\
& A_{i j}=\int_{\Omega} \frac{d^{4} \phi_{i}}{d y^{4}} \cdot \frac{d^{4} \phi_{j}}{d y^{4}} d \Omega+16 \cdot \beta^{8} \cdot \int_{\Omega} \phi_{i} \cdot \phi_{j} d \Omega+4 \cdot \beta^{4} \int_{\Omega}\left(\frac{d^{4} \phi_{i}}{d y^{4}} \cdot \phi_{j}+\phi_{i} \cdot \frac{d^{4} \phi_{j}}{d y^{4}}\right) d \Omega
\end{aligned}
$$

$$
f_{j}=\int_{\Omega}\left[f-A\left(\widetilde{w}_{o}\right)\right] \cdot\left(\frac{d^{4} \phi_{j}}{d y^{4}}+4 \cdot \beta^{4} \cdot \phi_{j}\right) d \Omega
$$

Da mesma forma ao caso anterior, a função ponderadora precisa ser homogênea nas condições de contorno essenciais especificadas do problema. Nota-se ainda que neste caso, a função aproximativa precisa ser no mínimo quatro vezes diferenciável.

\subsubsection{Estudo da solução aproximada do problema de membrana}

A resolução do problema de membrana pelo método dos Mínimos Quadrados reduz-se à seguinte expressão:

$$
\alpha_{i} \cdot \int_{\Omega} 16 \cdot \beta^{8} \cdot \phi_{i} \cdot \phi_{j} d \Omega=\int_{\Omega} 4 \cdot \beta^{4} \cdot\left(\frac{p_{z}}{D}\right) \cdot \phi_{j} d \Omega
$$

Novamente adota-se uma base aproximativa linear, devido à solução do problema ser expressa justamente por uma função linear, ou seja:

$$
\widetilde{w}(y)=\alpha_{1} \cdot y+\alpha_{2}
$$

Assim como no método de Galerkin, os resultados apresentados mostram, como era de se esperar, a eficiência do método em capturar a solução analítica quando esta 
for expressa por uma forma polinomial. O gráfico de deslocamento e esforço normal mostrado na figura seguinte ilustra a qualidade da aproximação.

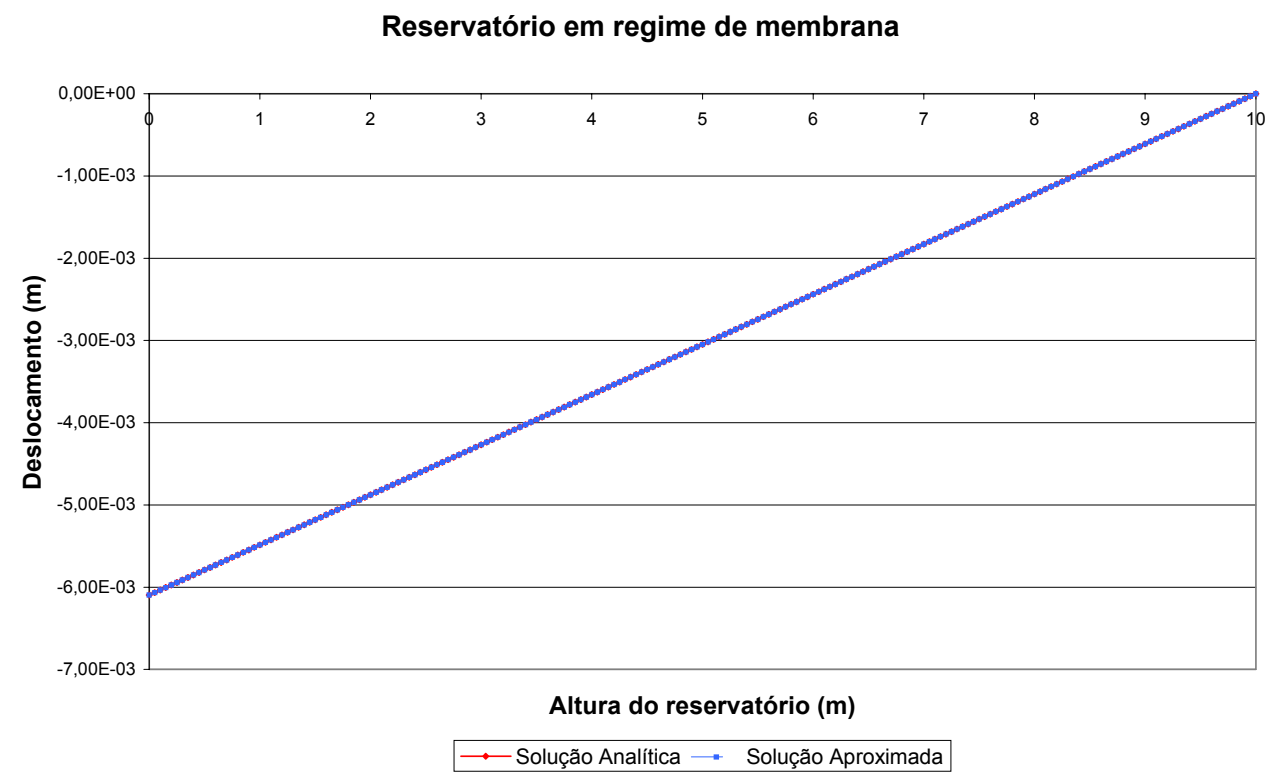

Gráfico 9 - Deslocamento de membrana - MMQ

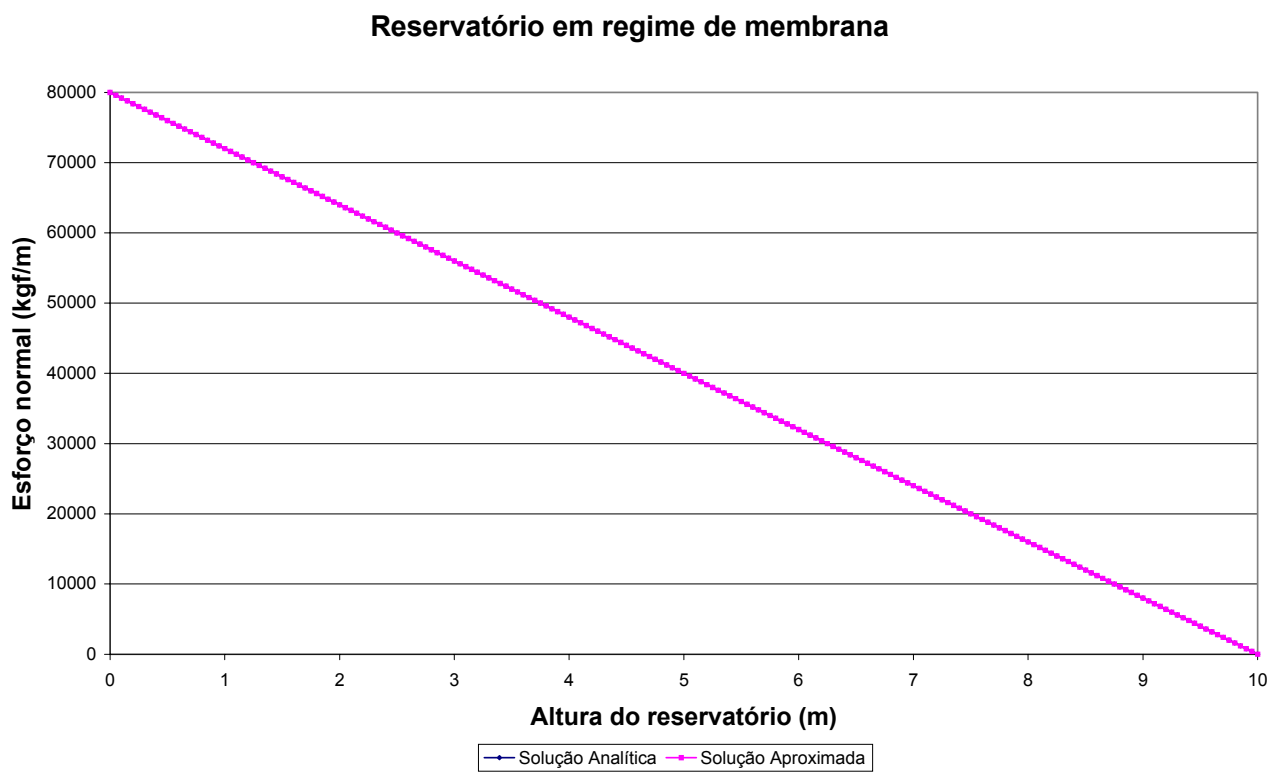

Gráfico 10 - Esforço normal de membrana - MMQ 


\subsubsection{Estudo da solução aproximada do problema de flexão}

A formulação em Resíduos Ponderados para o caso de reservatórios cilíndricos em regime de flexão pelo método dos Mínimos Quadrados é expressa pela seguinte equação:

$$
\begin{aligned}
& \int_{\Omega} \frac{d^{4} \phi_{i}}{d y^{4}} \cdot \frac{d^{4} \phi_{j}}{d y^{4}} d \Omega+16 \cdot \beta^{8} \cdot \int_{\Omega} \phi_{i} \cdot \phi_{j} d \Omega+4 \cdot \beta^{4} \int_{\Omega}\left(\frac{d^{4} \phi_{i}}{d y^{4}} \cdot \phi_{j}+\phi_{i} \cdot \frac{d^{4} \phi_{j}}{d y^{4}}\right) d \Omega= \\
& \int_{\Omega} f \cdot\left(\frac{d^{4} \phi_{j}}{d y^{4}}+4 \cdot \beta^{4} \cdot \phi_{j}\right) d \Omega
\end{aligned}
$$

Assim como no método de Galerkin, adota-se para a geração da função aproximativa um polinômio de grau $\boldsymbol{n}$. Assim sendo, para os deslocamentos radiais aproximados resulta:

$$
\widetilde{w}(y)=\sum_{k=1}^{n+1} \alpha_{k} \cdot y^{k-1}
$$

As mesmas restrições sobre a aproximação impostas nos exemplos pelo Método de Galerkin também se verificam aqui, como a imposição de uma ordem mínima no grau do polinômio adotado para a base da função aproximativa (neste caso, sendo: $n \geq 4$ ). Além disso, a função aproximativa também deve verificar as condições de contorno essenciais e naturais do problema.

Em seguida apresentam-se os resultados de exemplos de reservatórios articulados e engastados na base, e livres no topo. Os gráficos são referentes à: $\boldsymbol{w}, \boldsymbol{M}_{\boldsymbol{y}}$ e $\boldsymbol{Q}_{\boldsymbol{y}}$

Conforme esperado, na medida em que se aumenta o grau do polinômio, a resposta aproximada tende para a resposta exata, mas é de se notar que é preciso um polinômio de grau muito elevado para conseguir capturar, com boa precisão, a solução 
exata. Em termos comparativos, o método dos Mínimos Quadrados apresentou um maior esforço computacional e uma aproximação mais lenta que o Método de Galerkin.

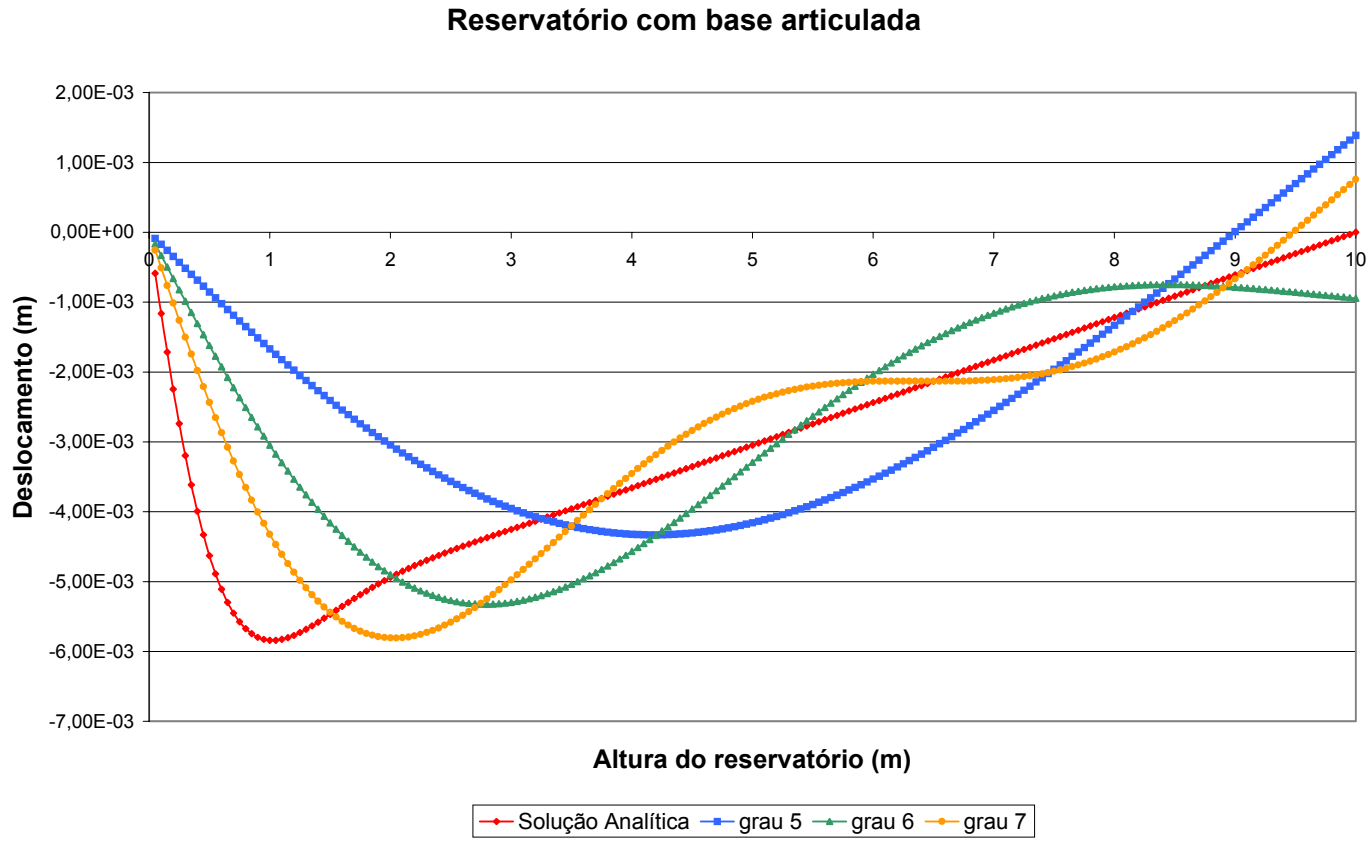

\section{Gráfico 11 - Deslocamento obtido por aproximação polinomial base articulada - MMQ}

Reservatório com base articulada

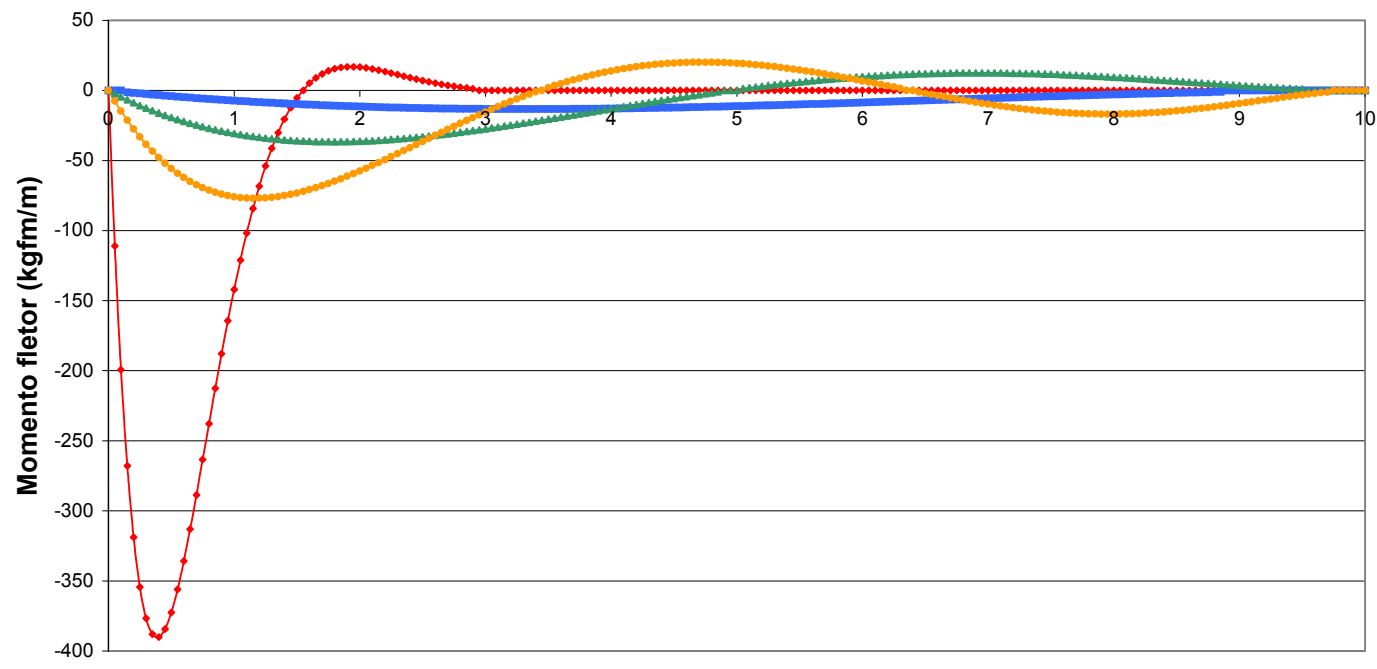

Altura do reservatório $(\mathrm{m})$

$\rightarrow$ Solução Analítica $\rightarrow$ grau $5 \multimap$ grau $6 \multimap$ grau 7

Gráfico 12 - Momento fletor obtido por aproximação polinomial base articulada - MMQ 


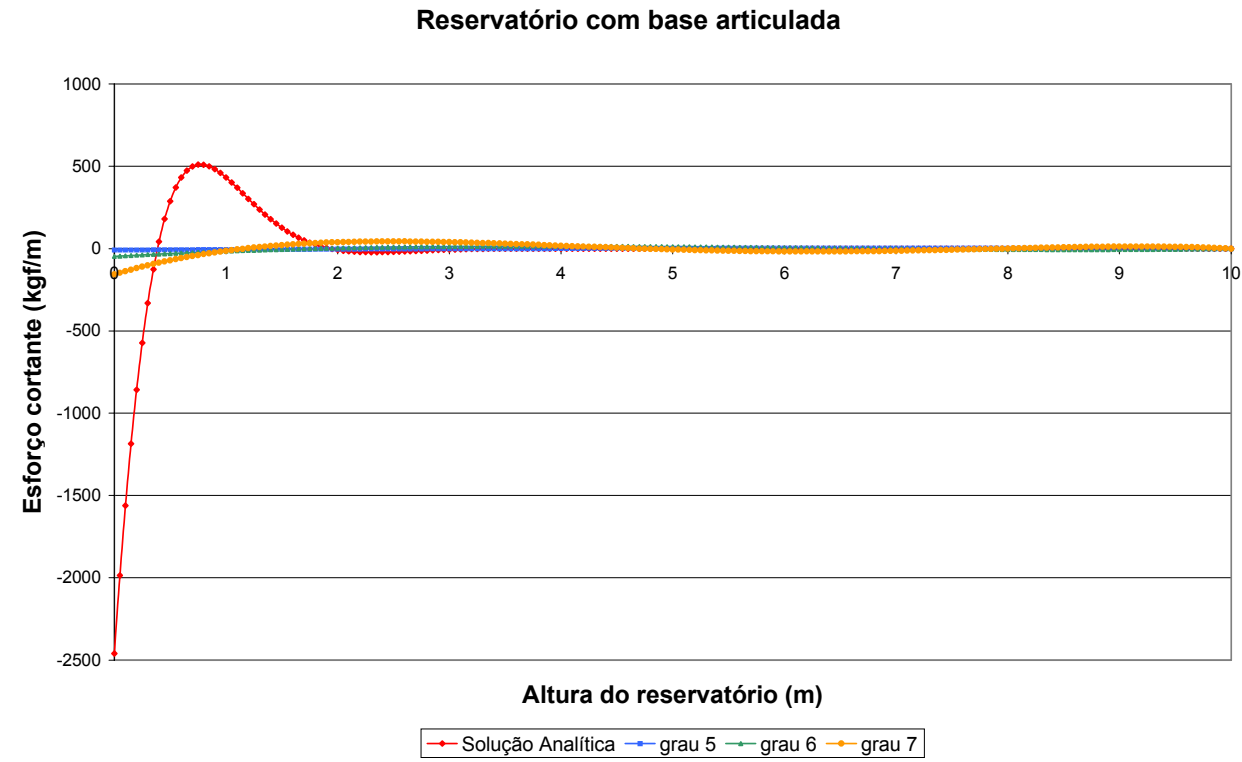

\section{Gráfico 13 - Esforço cortante obtido por aproximação polinomial base articulada - MMQ}

\section{Reservatório com base engastada}

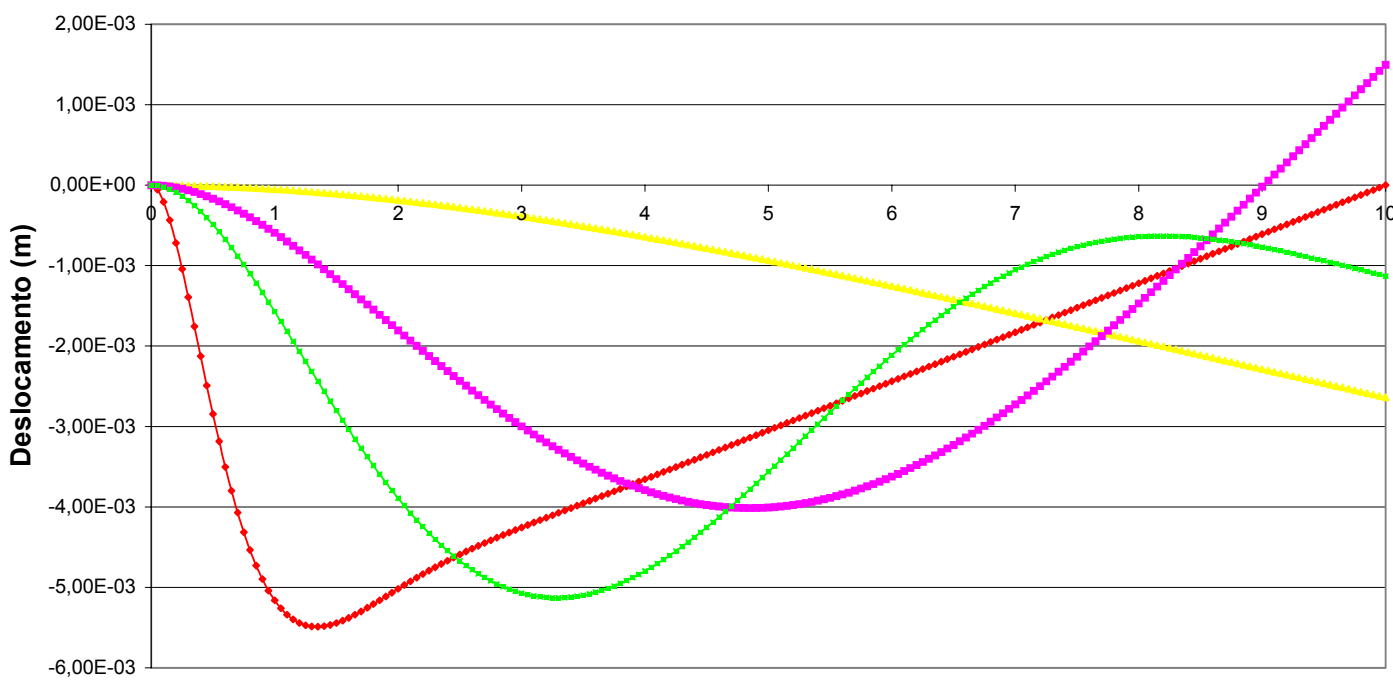

Altura do reservatório $(\mathrm{m})$

$\rightarrow$ Solução Analítica $\rightarrow$ grau $4 \rightarrow$ grau $5 \rightarrow$ grau 6

Gráfico 14 - Deslocamento obtido por aproximação polinomial base engastada - MMQ 
Reservatório com base engastada

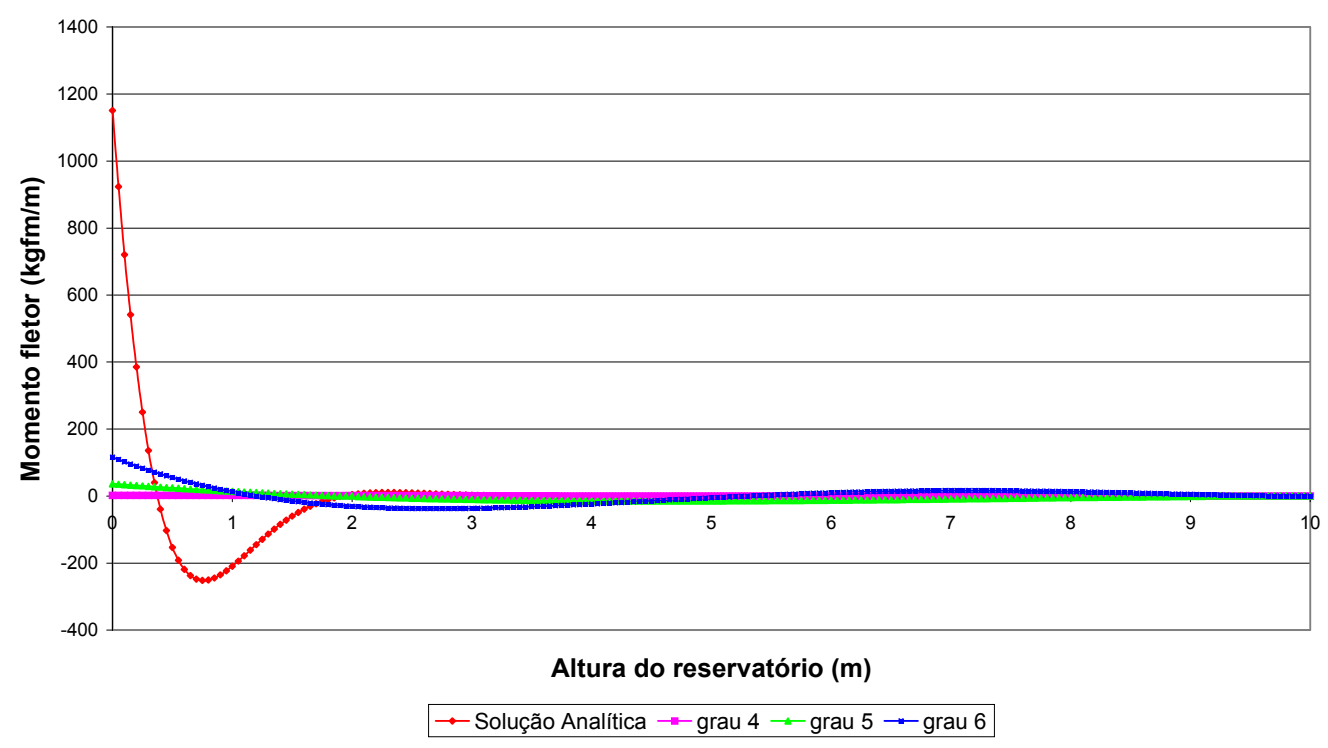

Gráfico 15 - Momento fletor obtido por aproximação polinomial base engastada - MMQ

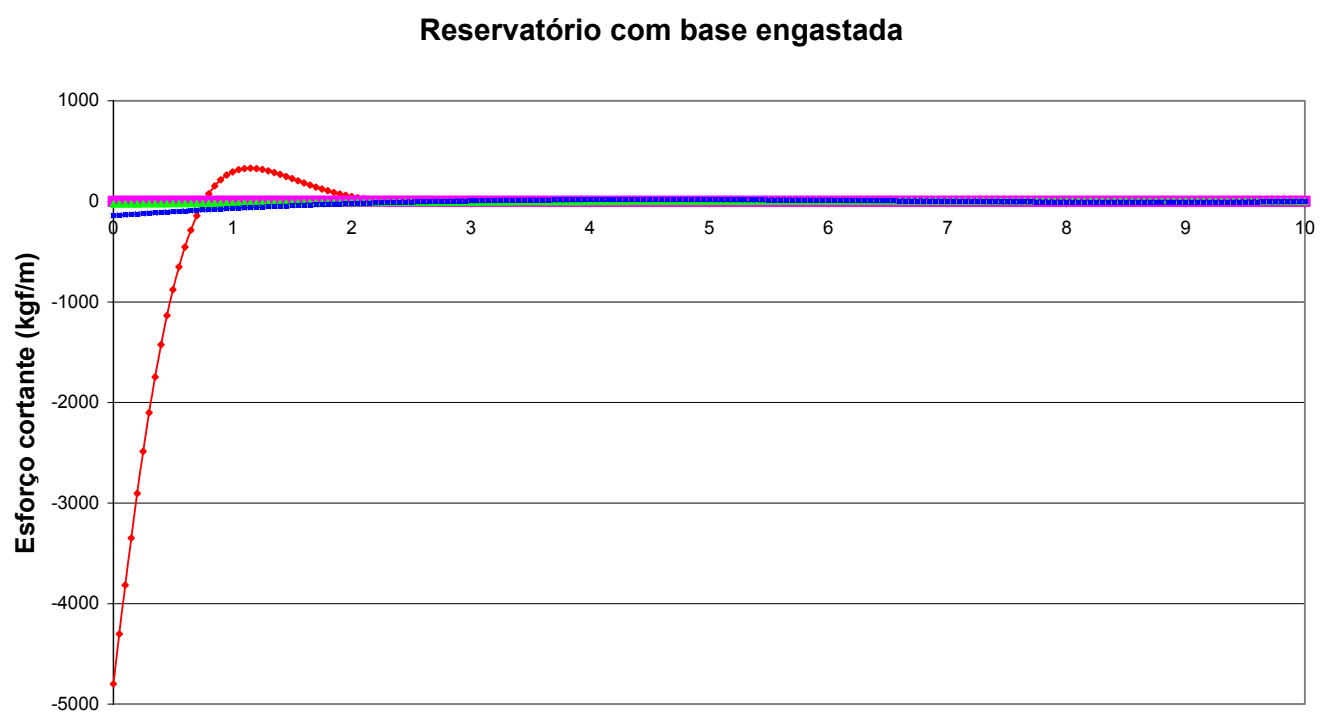

Altura do reservatório $(\mathrm{m})$

Solução Analítica $\rightarrow$-grau $4 \rightarrow$ grau $5 \rightarrow$ grau 6

Gráfico 16 - Esforço cortante obtido por aproximação polinomial base engastada - MMQ 


\section{Método de Resíduos Ponderados e o enriquecimento da aproximação}

\subsection{Enriquecimento da aproximação}

Com o objetivo de melhorar a qualidade da aproximação, pode-se optar pelo emprego de uma técnica de enriquecimento, que consiste em ampliar a base de funções aproximativas já existente. $\mathrm{O}$ enriquecimento pode-se realizar mediante adição direta de nova base de funções do conjunto já existente, ou por adição de termos resultantes da nova base multiplicada pela base anterior, quando esta constituir uma partição da unidade DUARTE \& ODEN (1995). Este trabalho apresenta a segunda opção de enriquecimento, no âmbito dos Métodos sem malha, Meshless. Apenas como observação complementar, tais métodos geram aproximações a partir de funções locais definidas em cada ponto nodal atrelando-se a ele um domínio local de influência denominado nuvem, DUARTE \& ODEN (1995).

\subsection{Método de Resíduos Ponderados com enriquecimento para o problema dos tubos}

Considerando-se a representação das funções aproximativas do Método de Resíduos Ponderados conforme a eq.(3.3):

$\tilde{u}(x)=\alpha_{i} \cdot \phi_{i}(x)+\tilde{u}_{o}(x) \quad c / i=1, \ldots n$

a técnica de enriquecimento consiste em introduzir uma base de funções $\varphi_{k}$, dita enriquecedora, de modo que a nova base para a aproximação $\widetilde{\boldsymbol{u}}_{e}$ resulte:

$\tilde{u}_{e}=\alpha_{i} \cdot \phi_{i}(x)+\lambda_{i k} \cdot \phi_{i}(x) \cdot \varphi_{k}+\tilde{u}_{o}(x) c / i=1, \ldots n \quad c / k=1, \ldots p$ 
onde $\boldsymbol{p}$ é o número de termos da nova base. Naturalmente, a solução aproximativa deve verificar as condições de contorno essenciais e naturais. Pela definição, tem-se que o resíduo da aproximação fica dado por meio da seguinte equação:

$$
R\left(\tilde{u}_{e}\right)=A\left(\tilde{u}_{e}\right)-f
$$

A anulação deste resíduo em forma ponderada consiste numa condição para a determinação dos coeficientes da solução aproximada, da seguinte maneira:

$$
\int_{\Omega} R\left(\widetilde{u}_{e}\right) \cdot \Psi_{j} d \Omega=0
$$

Como visto no item anterior, a eq.(4.3) gera o sistema linear dado pela eq.(3.12), o qual define as constantes da solução aproximada.

$$
\alpha_{i} \cdot A_{i j}=f_{j}
$$

Nota-se que, agora os $\alpha_{i}$ agora indicam todos os coeficientes da eq.(4.1).

Um dos inconvenientes apresentados pela técnica refere-se ao custo computacional que é requerido a cada vez que se introduz uma função enriquecedora no problema. Caso o sistema linear com base não-enriquecida seja de dimensão $n \times n$, após a introdução da função enriquecedora obtêm-se um sistema com dimensões $(p+1) \cdot n \times(p+1) \cdot n$, sendo $\boldsymbol{p}$ o número de funções enriquecedoras.

\subsubsection{Enriquecimento da base polinomial linear com base exponencial-trigonométrica}

Na solução analítica do tubo cilíndrico, aparecem termos polinomiais lineares, que representam bem o comportamento de membrana, e termos exponencial- 
trigonométricos que colhem os efeitos localizados de flexão. Estas características podem ser diretamente aproveitadas na geração de funções aproximativas.

Assim sendo, pode-se partir de uma função aproximativa de base polinomial e aplicar a técnica de enriquecimento com funções auxiliares $\mathbf{f}_{\mathbf{1}}$ e $\mathbf{f}_{\mathbf{2}}$, do tipo:

$$
\begin{aligned}
& \mathrm{f}_{1}=\mathrm{e}^{-\beta \mathrm{y}} \cdot \cos (\beta \mathrm{y}) \\
& \mathrm{f}_{2}=\mathrm{e}^{-\beta \mathrm{y}} \cdot \operatorname{sen}(\beta \mathrm{y})
\end{aligned}
$$

Mais especificamente, para um reservatório cilíndrico, articulado na base e livre no topo, considerando-se o enriquecimento por funções $\mathbf{f}_{\mathbf{1}}$ e $\mathbf{f}_{\mathbf{2}}$ de uma função linear $\widetilde{\boldsymbol{w}}$ definida pela eq.(4.6):

$$
\widetilde{w}(y)=\alpha_{1} \cdot y+\alpha_{2}
$$

resulta a seguinte função enriquecida $\widetilde{\boldsymbol{w}}_{e}$ :

$$
\begin{aligned}
\widetilde{w}_{e}(y)= & \alpha_{1} \cdot y+\alpha_{2} \cdot y \cdot e^{-\beta y} \cdot \cos (\beta y)+\alpha_{3} \cdot y \cdot e^{-\beta y} \cdot \operatorname{sen}(\beta y)+ \\
& \alpha_{4}+\alpha_{5} \cdot e^{-\beta y} \cdot \cos (\beta y)+\alpha_{6} \cdot e^{-\beta y} \cdot \operatorname{sen}(\beta y)
\end{aligned}
$$

As condições de contorno do problema são as seguintes:

a) Condição de contorno essencial: Deslocamento na base nulo

$$
\widetilde{w}_{e}(0)=0
$$

b) Condição de contorno natural: Momento fletor na base nulo 


$$
\frac{d^{2} \widetilde{w}_{e}(0)}{d y^{2}}=0
$$

De modo que ao aplicar-se estas condições sobre a função enriquecida resulta:

$$
\begin{aligned}
\widetilde{w}_{e}(y)= & \alpha_{1} \cdot y+\alpha_{2} \cdot y \cdot e^{-\beta y} \cdot[\operatorname{sen}(\beta y)+\cos (\beta y)]+ \\
& \alpha_{3} \cdot\left[1-e^{-\beta y} \cdot \cos (\beta y)\right]+\alpha_{4} \cdot e^{-\beta y} \cdot \operatorname{sen}(\beta y) \cdot(1+\beta y)
\end{aligned}
$$

Sendo assim, a base de funções enriquecidas fica definida da seguinte forma:

$$
\begin{aligned}
& \phi_{1}=y \\
& \phi_{2}=y \cdot e^{-\beta y} \cdot[\operatorname{sen}(\beta y)+\cos (\beta y)] \\
& \phi_{3}=1-e^{-\beta y} \cdot \cos (\beta y) \\
& \phi_{4}=e^{-\beta y} \cdot \operatorname{sen}(\beta y) \cdot(1+\beta y)
\end{aligned}
$$

Nessas condições a aproximação enriquecida, com as condições de contorno implícitas, pode ser representada como:

$$
\widetilde{w}_{e}(y)=\alpha_{1} \cdot \phi_{1}(y)+\alpha_{2} \cdot \phi_{2}(y)+\alpha_{3} \cdot \phi_{3}(y)+\alpha_{4} \cdot \phi_{4}(y)
$$

Aplicando-se a definição do Método de Resíduos Ponderados, pode-se determinar os coeficientes $\boldsymbol{\alpha}_{\boldsymbol{i}}$ por meio de:

$$
\alpha_{i} \cdot \int_{\Omega} A\left(\phi_{i}\right) \cdot \Psi_{j} d \Omega=\int_{\Omega} f \cdot \Psi_{j} d \Omega
$$


Recordando que no problema dos reservatórios cilíndricos o operador diferencial $A\left(\phi_{i}\right)$ e a função $\boldsymbol{f}$ são dados por:

$$
\begin{aligned}
& A\left(\phi_{i}\right)=\frac{d^{4} \phi_{i}}{d y^{4}}+4 \cdot \beta^{4} \cdot \phi_{i} \\
& f=\frac{P_{z}}{D}
\end{aligned}
$$

Sendo que a eq.( 4.16) pode ser reescrita da seguinte maneira:

$$
\alpha_{i} \cdot\left(\int_{\Omega} \frac{d^{4} \phi_{i}}{d y^{4}} \cdot \Psi_{j} d \Omega+4 \cdot \beta^{4} \cdot \int_{\Omega} \phi_{i} \cdot \Psi_{j} d \Omega\right)=\int_{\Omega} \frac{P_{z}}{D} \cdot \Psi_{j} d \Omega
$$

ou, implicitamente representada na forma:

$$
\alpha_{i} \cdot A_{i j}=f_{j}
$$

Na relação anterior tem-se:

$$
\begin{aligned}
& A_{i j}=\int_{\Omega} \frac{d^{4} \phi_{i}}{d y^{4}} \cdot \Psi_{j} d \Omega+4 \cdot \beta^{4} \cdot \int_{\Omega} \phi_{i} \cdot \Psi_{j} d \Omega \\
& f_{j}=\int_{\Omega} \frac{P_{z}}{D} \cdot \Psi_{j} d \Omega
\end{aligned}
$$

A variante específica do Método de Resíduos Ponderados que será empregada fica então dependente da função $\boldsymbol{\Psi}_{\mathbf{j}}$ a ser adotada. No que segue mostram-se as aplicações dos métodos de Galerkin e Mínimos Quadrados. 


\subsection{Método de Galerkin}

No primeiro exemplo deste caso, resolve-se um reservatório de base articulada, impondo-se previamente à aproximação as condições de contorno essencial na base em relação ao deslocamento e natural referente ao momento fletor. As condições de contorno naturais referentes ao topo do reservatório são verificadas diretamente pela aproximação. Nos gráficos de deslocamento, momento fletor e esforço cortante mostrados a seguir, evidencia-se a potencialidade do método de Galerkin em capturar soluções exatas ao se adotar uma base para a função aproximativa que contenha as mesmas características da solução.

Em seguida são apresentados os gráficos de deslocamento, momento fletor e esforço cortante:

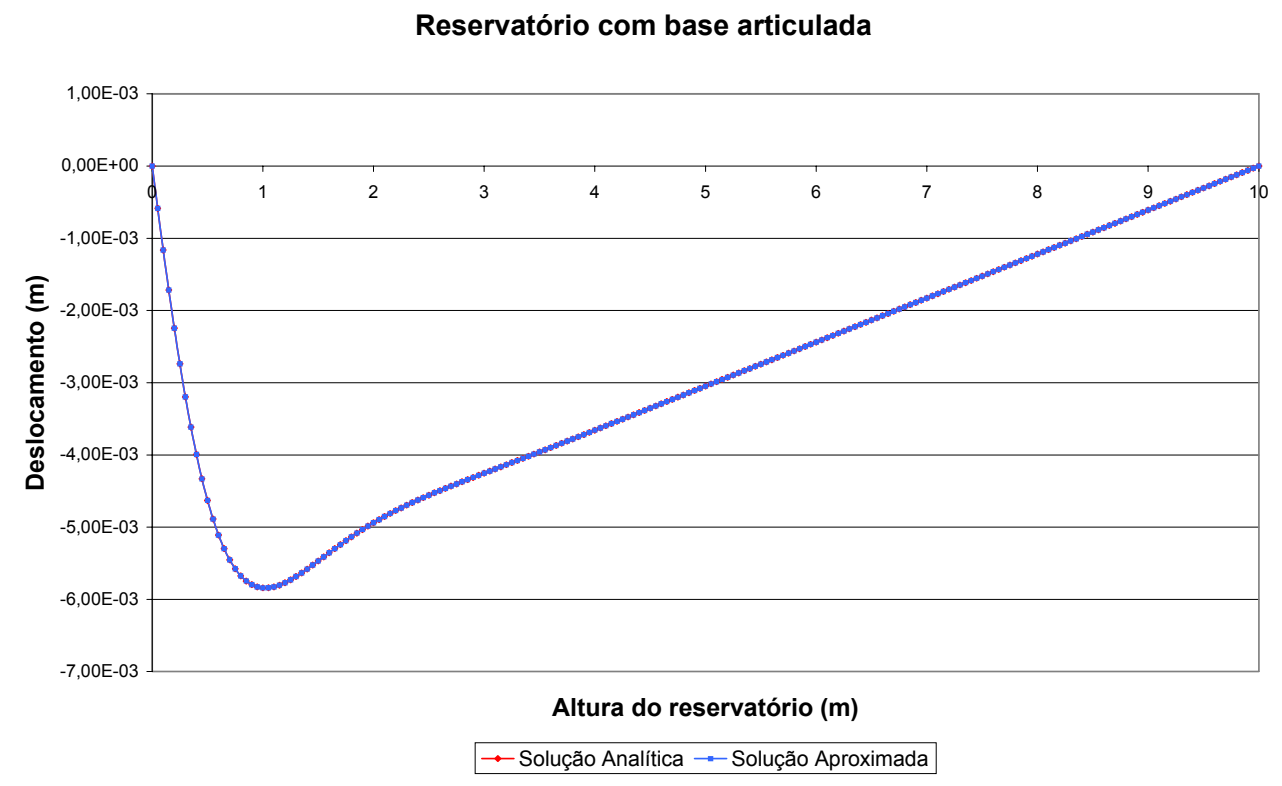

Gráfico 17 - Deslocamento obtido pelo enriquecimento da aproximação base articulada - Galerkin 


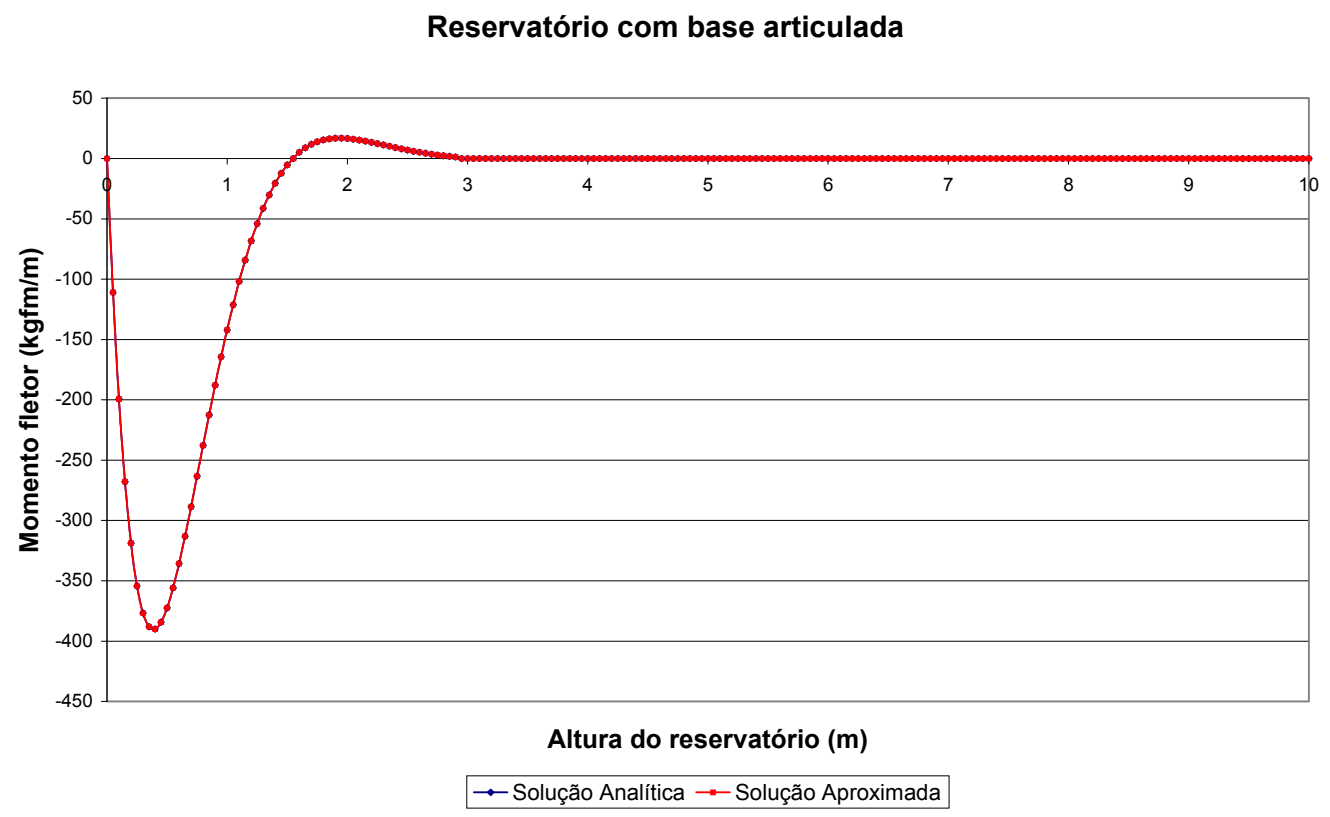

Gráfico 18 - Momento fletor obtido pelo enriquecimento da aproximação base articulada - Galerkin

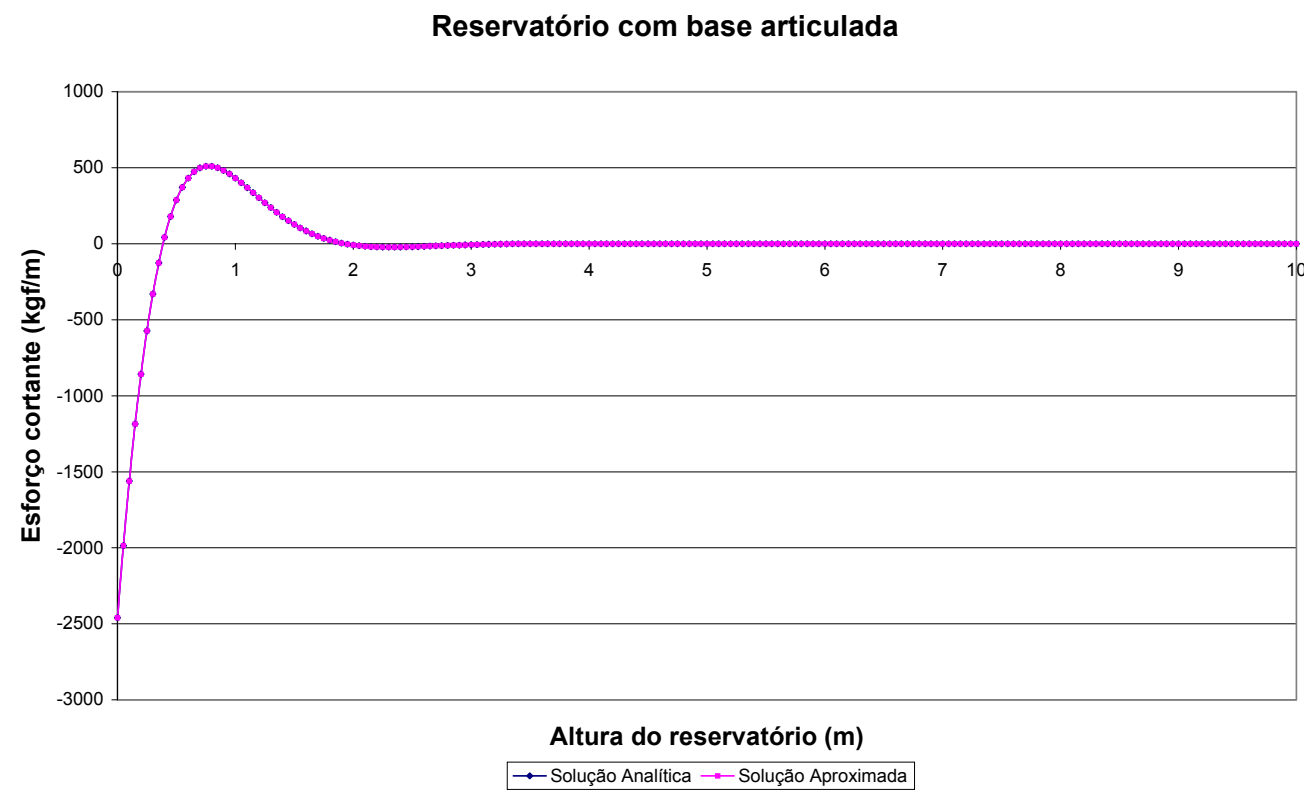

Gráfico 19 - Esforço cortante obtido pelo enriquecimento da aproximação base articulada - Galerkin 
No segundo exemplo deste caso, resolve-se um reservatório com base engastada, impondo-se previamente as condições de contorno essenciais na base em relação à nulidade do deslocamento e da rotação. Assim como no exemplo do reservatório articulado, evidencia-se a potencialidade do método de Galerkin em capturar soluções exatas ao se adotar uma base para a função aproximativa que contenha as mesmas características da solução exata.

Reservatório com base engastada

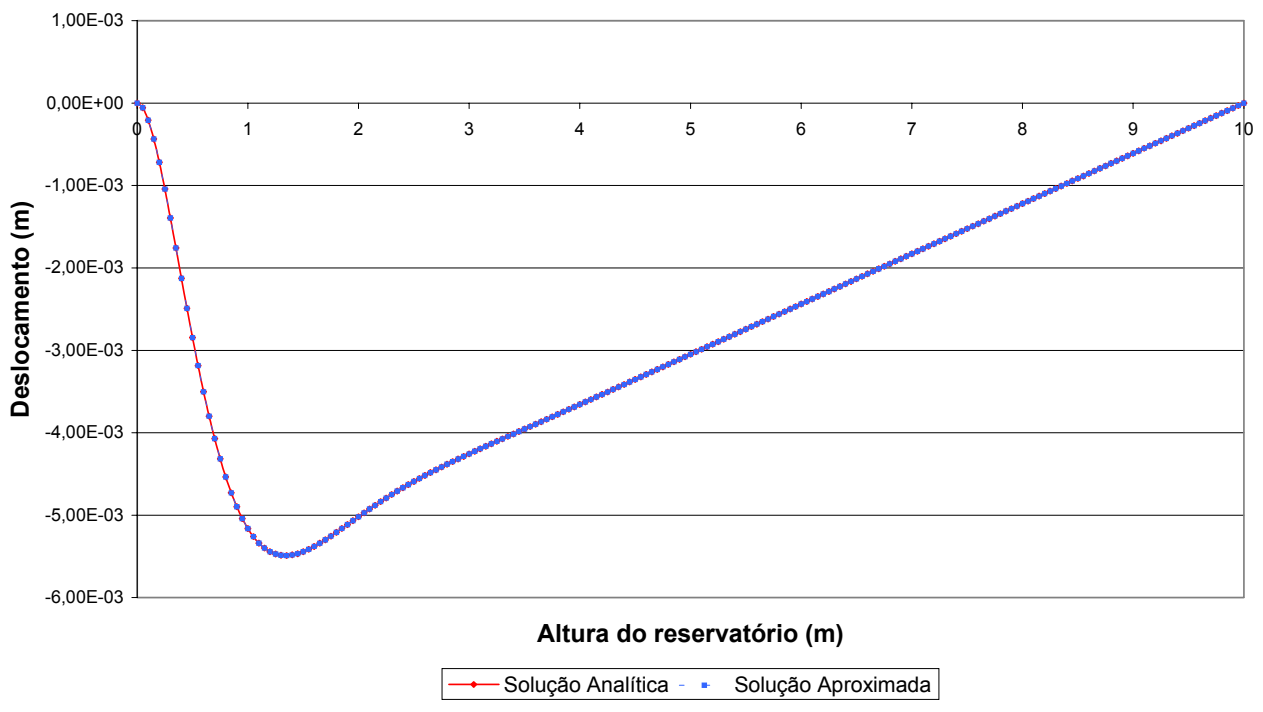

Gráfico 20 - Deslocamento obtido pelo enriquecimento da aproximação base engastada - Galerkin 
Reservatório com base engastada

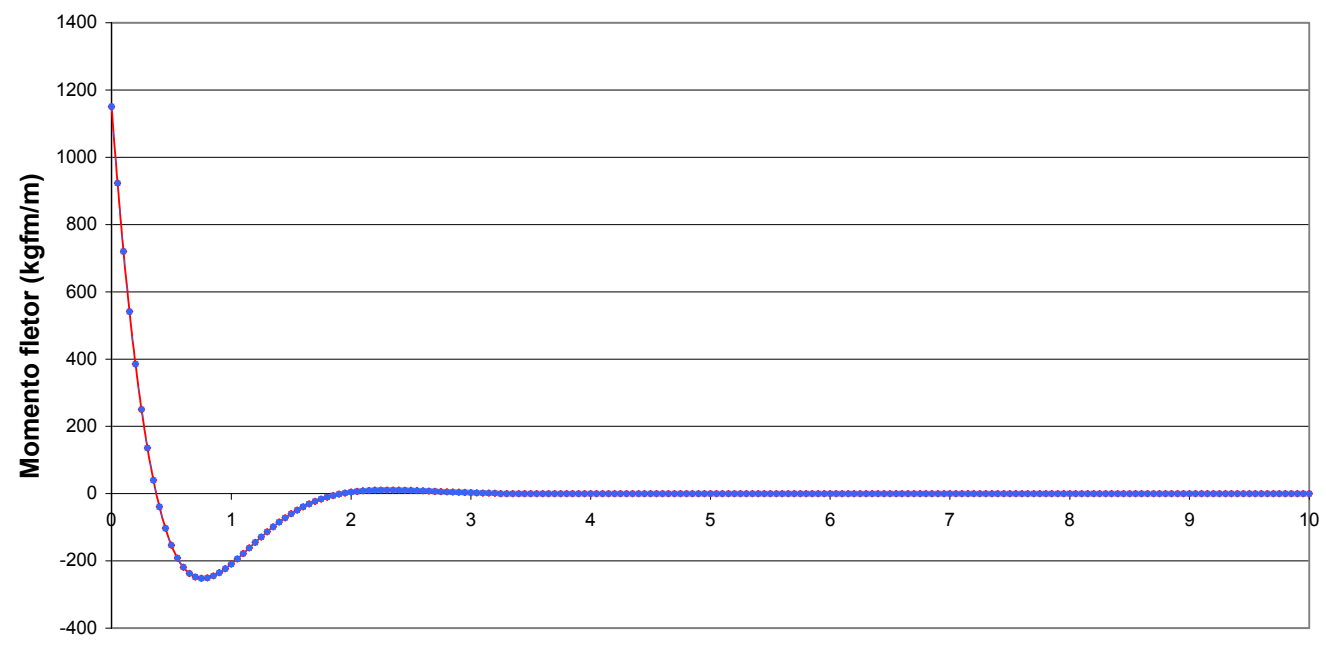

Altura do reservatório (m)

Solução Analítica - " Solução Aproximada

Gráfico 21 - Momento fletor obtido pelo enriquecimento da aproximação base engastada - Galerkin

Reservatório com base engastada

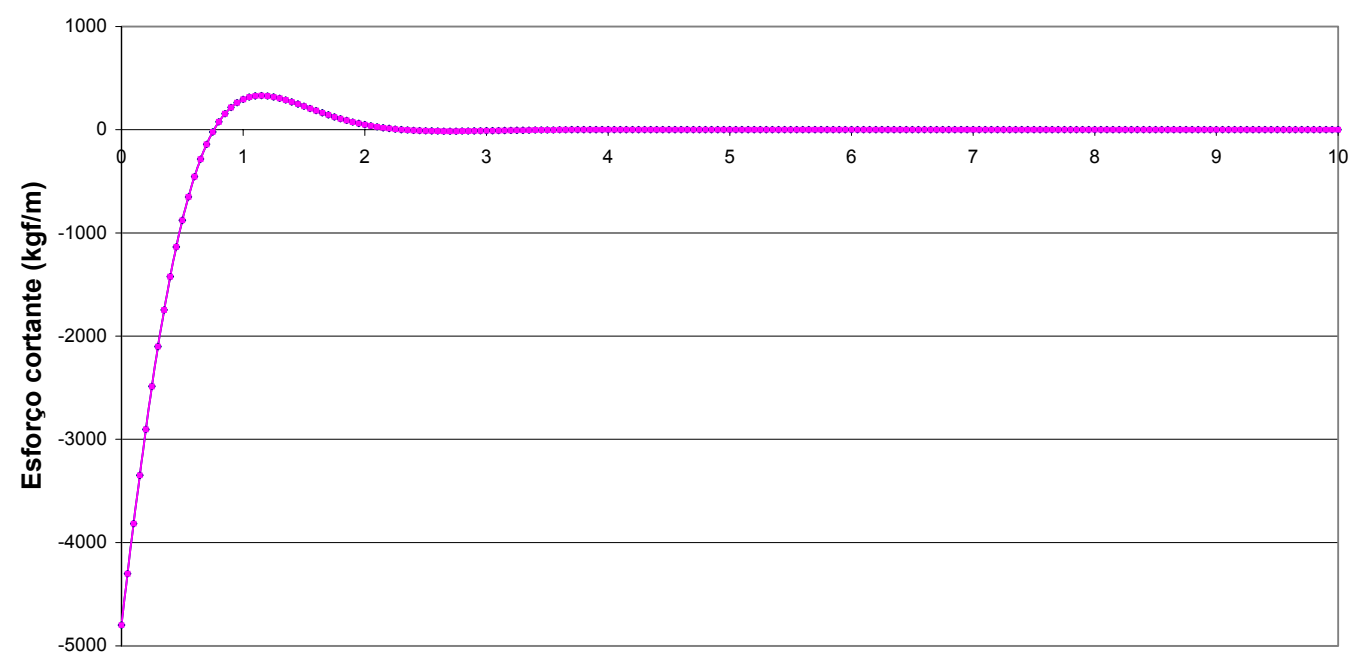

Altura do reservatório $(\mathrm{m})$

$\rightarrow$ Solução Analítica $\rightarrow-$ Solução Aproximada

Gráfico 22 - Esforço cortante obtido pelo enriquecimento da aproximação base engastada - Galerkin 


\subsection{Método dos Mínimos Quadrados}

Os mesmos exemplos anteriores são agora analisados com o Método dos Mínimos Quadrados. Conforme mostram os gráficos de deslocamento, momento fletor e esforço cortante, este método também pode capturar soluções bem precisas ao se adotar uma base para a função aproximativa que contenha as mesmas características da solução exata.

Os resultados referentes aos exemplos de reservatório articulado e engastado são mostrados nas figuras que seguem.

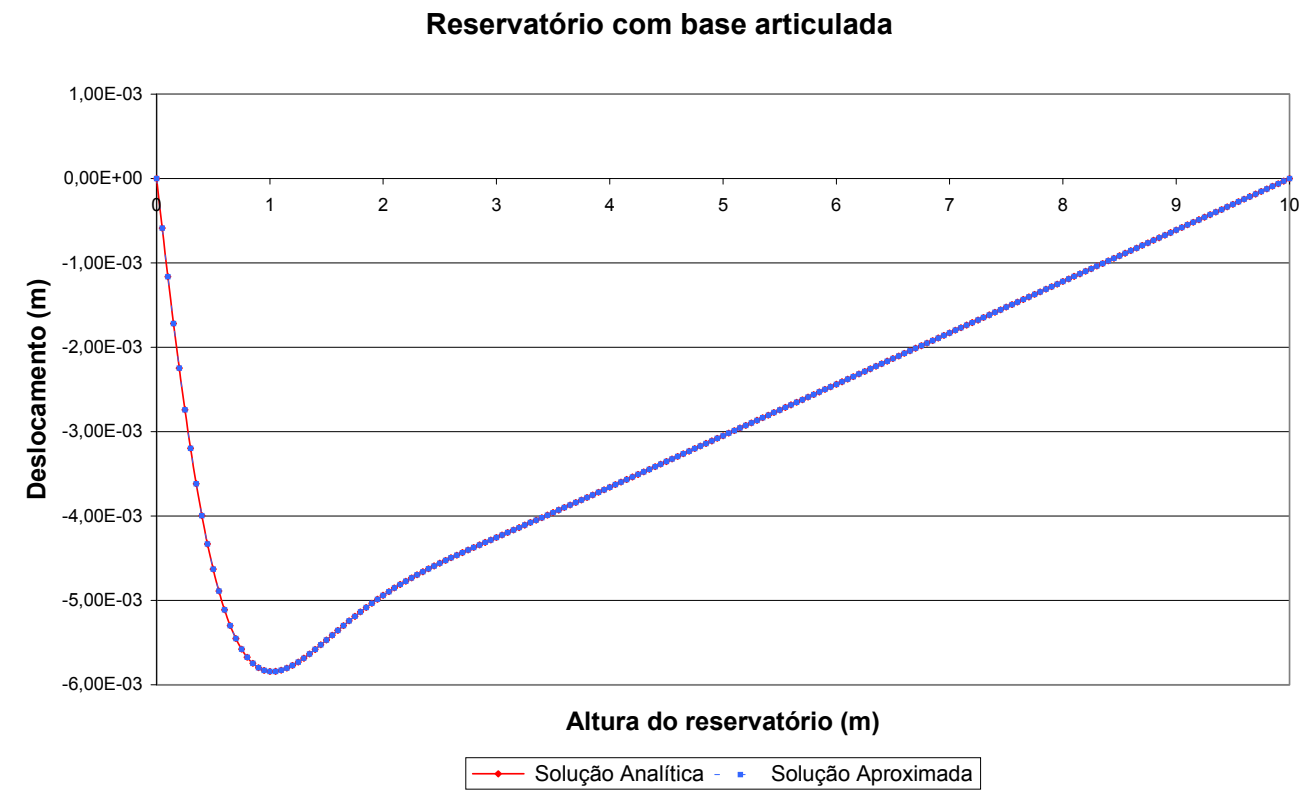

Gráfico 23 - Deslocamento obtido por aproximação exponencial-trigonométrica base articulada - MMQ 
Reservatório com base articulada

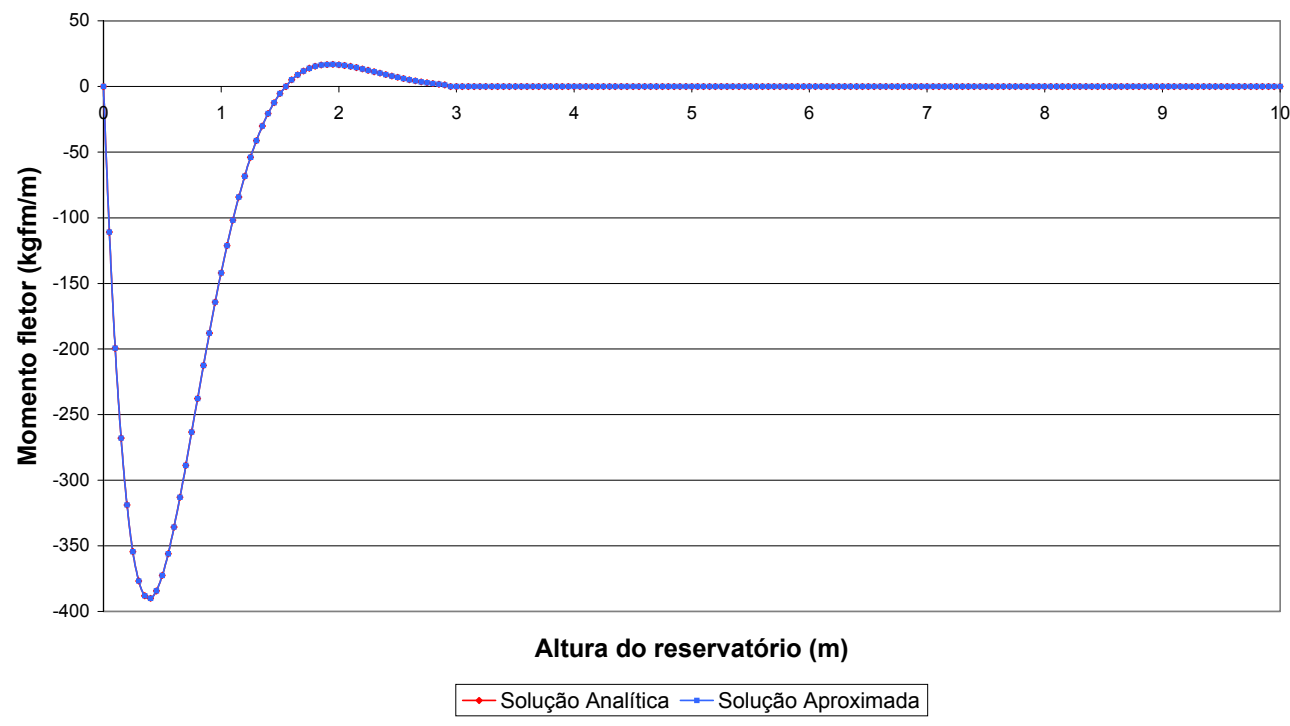

Gráfico 24 - Momento fletor obtido por aproximação exponencial-trigonométrica base articulada - MMQ

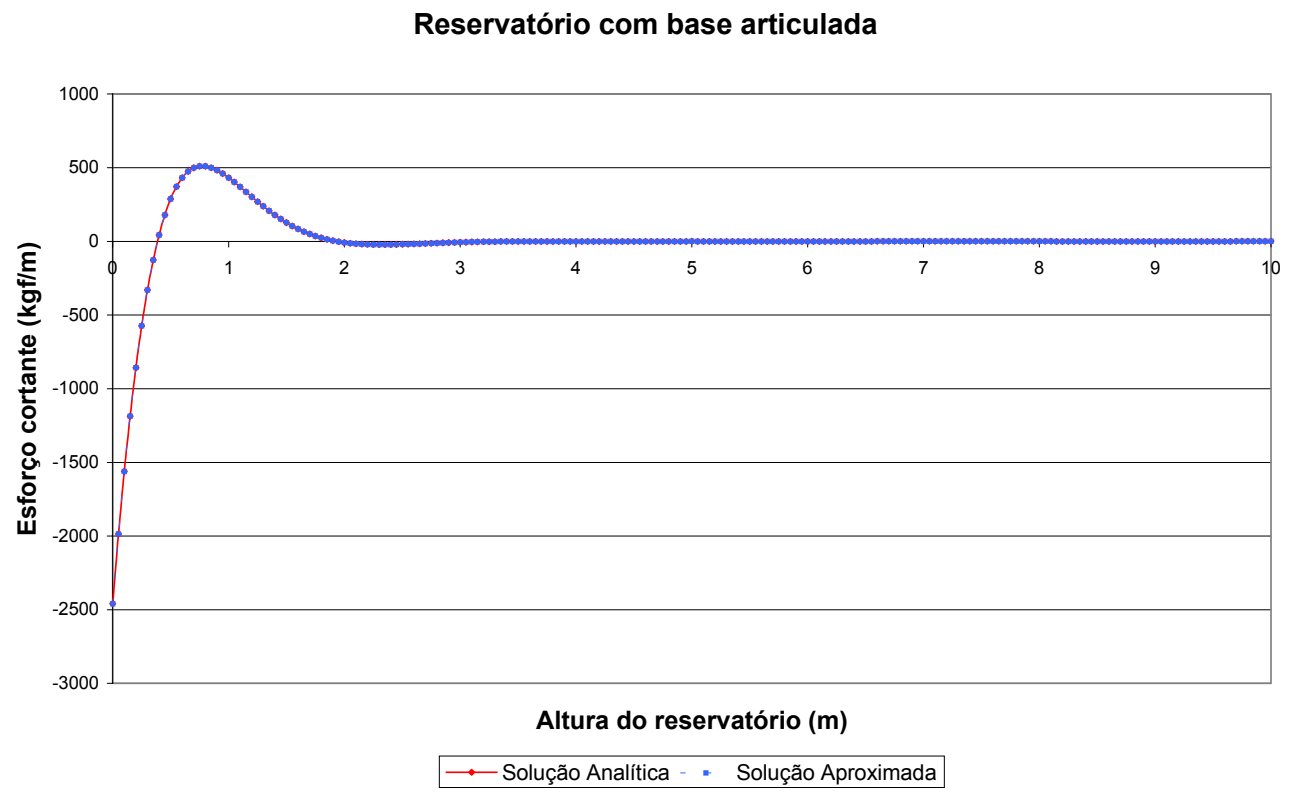

Gráfico 25 - Esforço cortante obtido por aproximação exponencial-trigonométrica base articulada - MMQ 
Reservatório com base engastada

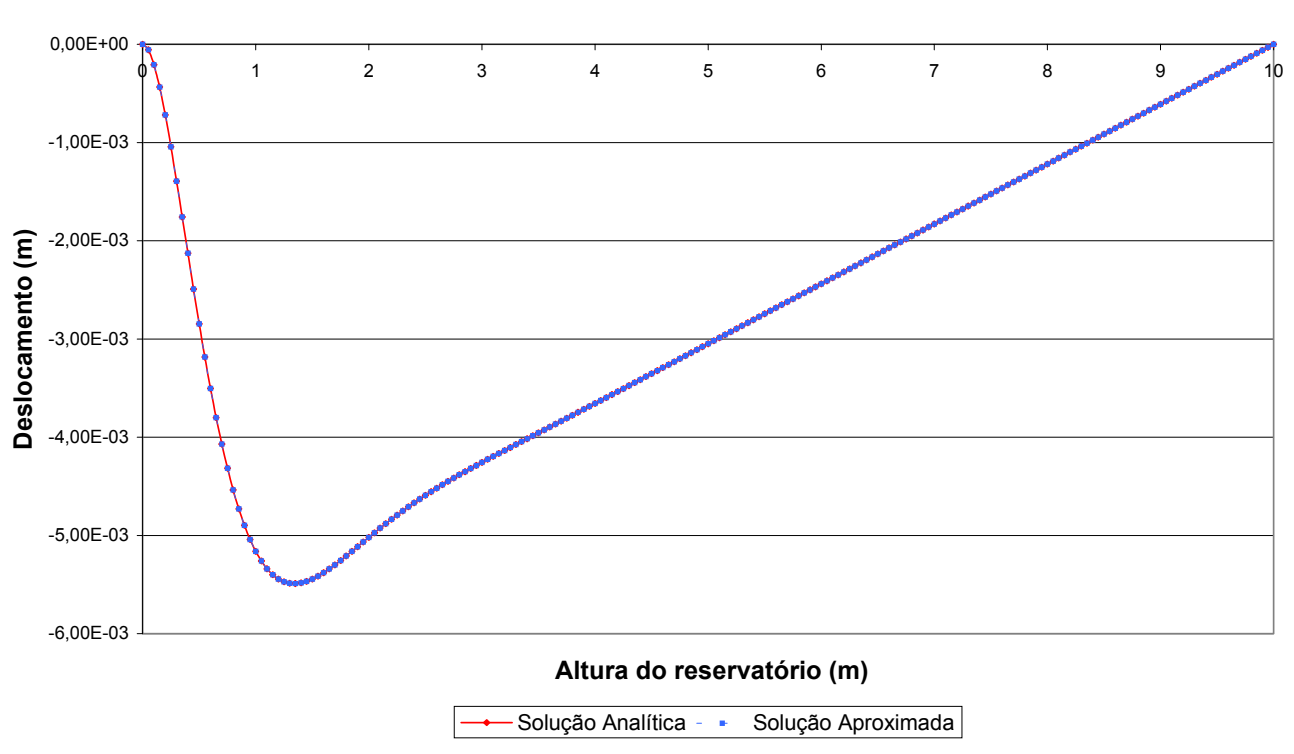

Gráfico 26 - Deslocamento obtido por aproximação exponencial-trigonométrica base engastada - MMQ

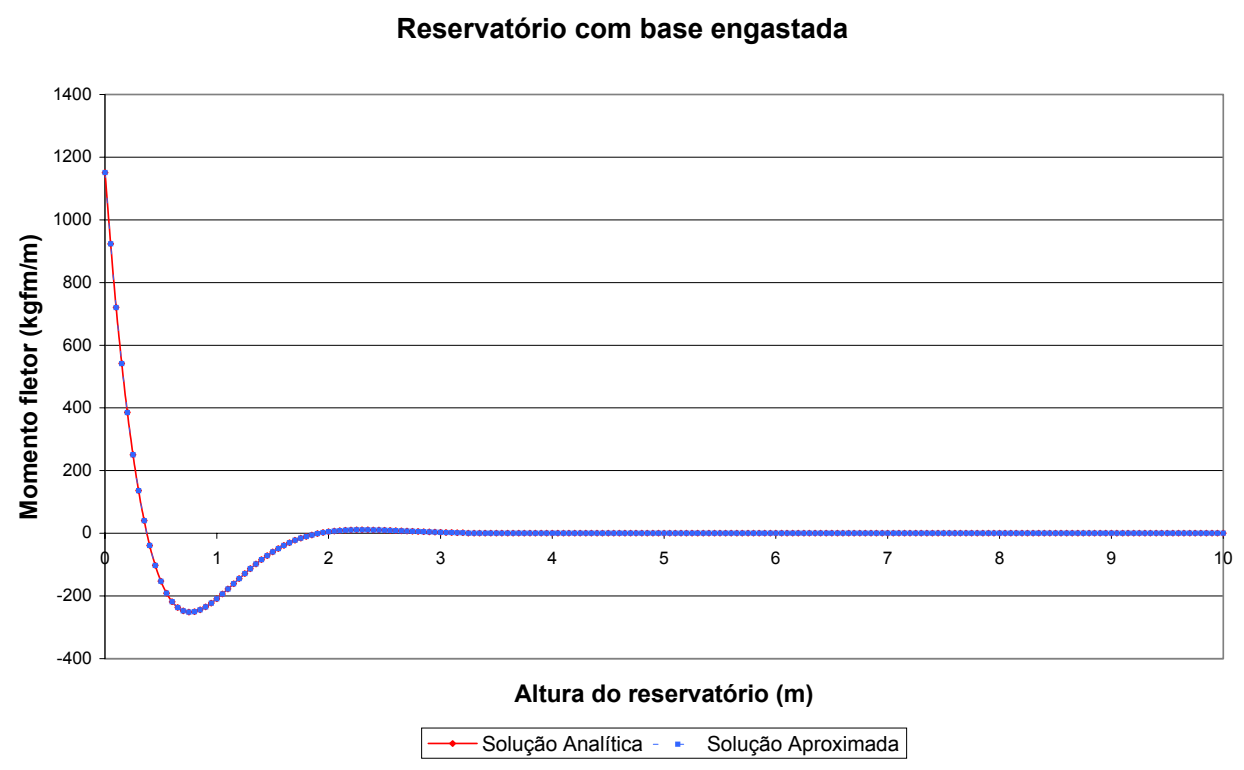

Gráfico 27 - Momento fletor obtido por aproximação exponencial-trigonométrica base engastada - MMQ 
Reservatório com base engastada

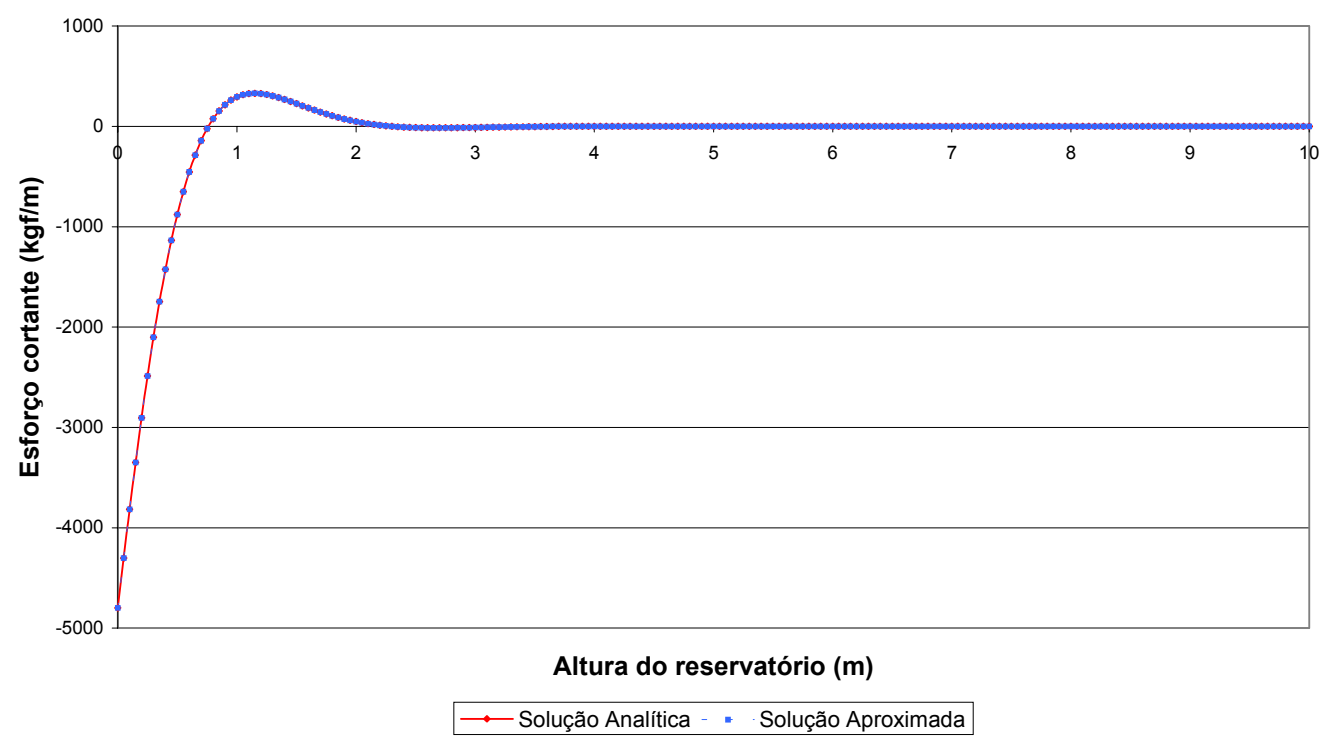

Gráfico 28 - Esforço cortante obtido por aproximação exponencial-trigonométrica base engastada - MMQ 


\section{Método dos Mínimos Quadrados com divisão do domínio de integração}

\subsection{Método dos Elementos Finitos}

O método dos elementos finitos propõe a discretização do domínio de integração mediante a introdução de pontos nodais e a construção de aproximações para a função incógnita do problema por interpolação dos seus valores nodais. No domínio de integração discretizado caracteriza-se ainda um número finito de pequenas regiões entre nós chamadas de elementos finitos.

Em campo unidimensional, a aproximação para o campo de deslocamentos pode ser escrita da seguinte maneira:

$$
\tilde{u}(x)=\alpha_{i} \cdot \phi_{i}(x) \quad c / i=1, \ldots n
$$

sendo $\boldsymbol{n}$ o número de nós e $\phi_{i}(x)$ as funções de forma, as quais devem possuir continuidade suficiente para que existam as integrais que aparecem na forma variacional a ser integrada.

Dentre as características fundamentais do método, destaca-se a de que as constantes $\boldsymbol{\alpha}_{\boldsymbol{i}}$, que aparecem na eq.(5.1), coincidem com valores discretos da função $\tilde{\boldsymbol{u}}(\boldsymbol{x})$ nos pontos nodais. Outra característica do método é que as funções $\phi_{i}(\boldsymbol{x})$, atreladas a cada nó, possuem valor unitário no nó $\boldsymbol{i}$ e nulo nos outros nós. No caso linear as funções podem ser construídas mediante técnica de interpolação lagrangiana:

$$
\phi_{i}(x)=\left\{\begin{array}{lll}
\frac{\left(x-x_{i-1}\right)}{\left(x_{i}-x_{i-1}\right)} & \text { se } & x_{i-1} \leq x \leq x_{i} \\
\frac{\left(x_{i+1}-x\right)}{\left(x_{i+1}-x_{i 1}\right)} & \text { se } & x_{i} \leq x \leq x_{i+1}
\end{array}\right.
$$


As figuras 5.1 e 5.2 ilustram a aproximação dada pela eq.(5.1) e a interpolação descrita pela eq.(5.2) respectivamente.

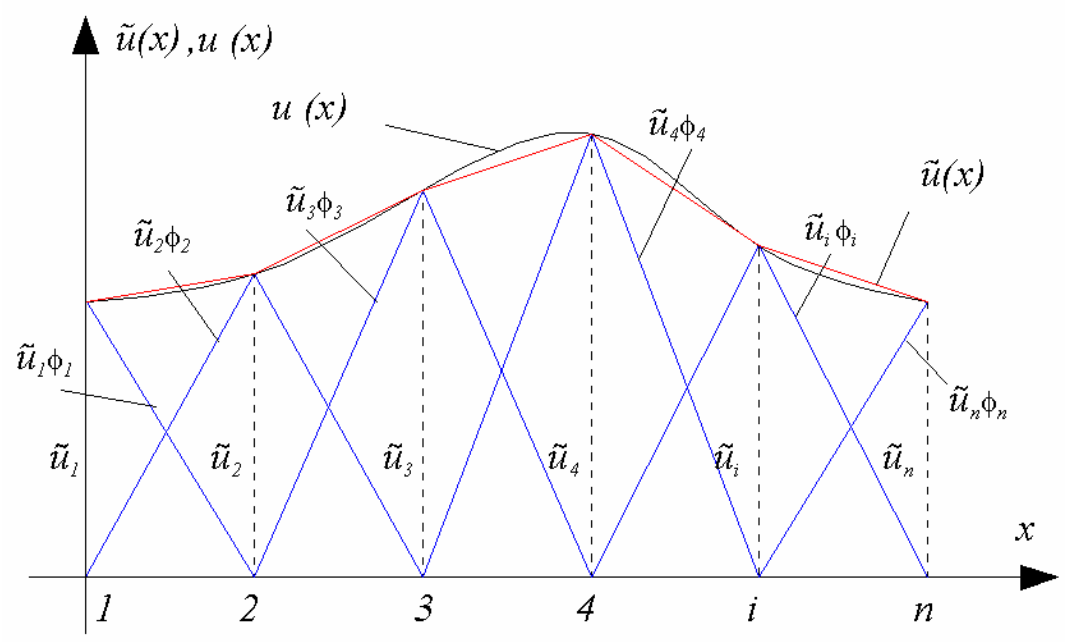

Figura 5.1 - Aproximação para o campo de deslocamentos

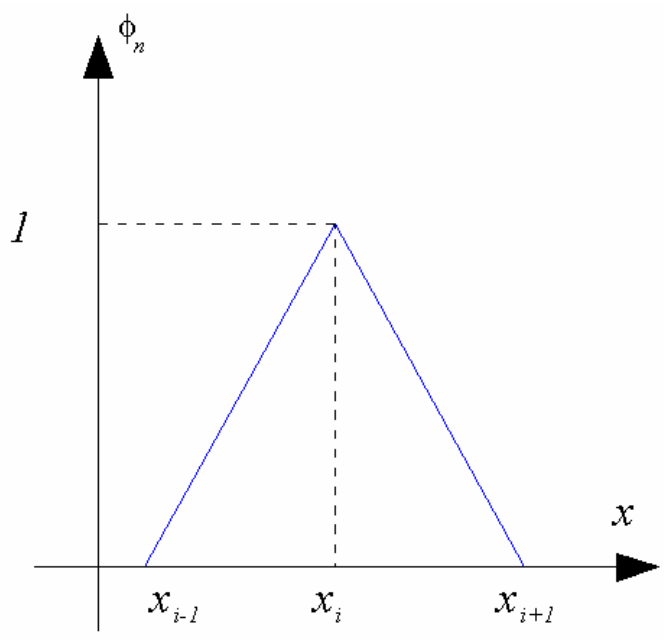

Figura 5.2 - Interpolação dada pelo MEF

O Método do Elementos Finitos pode ser aplicado na geração de soluções aproximadas de problemas de valor de contorno formulados pelo Método de Resíduos 
Ponderados. Tendo-se em vista, em primeiro lugar, a divisão do domínio em elementos, a integral ponderada pode ser dividida numa soma de integrais sobre cada elemento. Deste modo, no domínio $\boldsymbol{\Omega}^{e}=\left(\boldsymbol{y}_{A}, \boldsymbol{y}_{\boldsymbol{B}}\right)$ de um elemento, a forma integral ponderada da eq. (2.12) pode ser escrita da seguinte maneira:

$$
\int_{y_{A}}^{y_{B}}\left(\frac{d^{4} w}{d y^{4}} \cdot v+4 \cdot \beta^{4} \cdot w \cdot v\right) d y=\int_{y_{A}}^{y_{B}}\left(\frac{P_{z}}{D}\right) \cdot v d y
$$

O método dos elementos finitos aplica-se então na geração das aproximações para as funções $\boldsymbol{w}$ e $\boldsymbol{v}$.

\subsection{Método dos Elementos Finitos sobre uma formulação em Mínimos Quadrados}

A função ponderadora, ou função peso, pode ser expressa na forma de uma combinação linear de funções base.

$$
v(y)=\beta_{i} \cdot \Psi_{i}(\mathbf{x}) \quad c / i=1, \ldots n
$$

Substituindo-se a eq.(5.4) na eq.(5.3) resulta em uma somatória de $\boldsymbol{n}$ parcelas que deve ser verificada com coeficientes $\boldsymbol{\beta}_{\boldsymbol{i}}$ quaisquer. Sendo as funções $\boldsymbol{\Psi}_{\mathbf{i}}$ uma base linearmente independente, resulta o seguinte conjunto de equações:

$$
\int_{y_{A}}^{y_{B}}\left(\frac{d^{4} w}{d y^{4}} \cdot \Psi_{i}+4 \cdot \beta^{4} \cdot w \cdot \Psi_{i}\right) d y=\int_{y_{A}}^{y_{B}}\left(\frac{P_{z}}{D}\right) \cdot \Psi_{i} d y c / i=1, \ldots n
$$


A função aproximativa, por sua vez, pode ser descrita da seguinte forma:

$$
\widetilde{w}=\alpha_{j} \cdot \phi_{j} \quad c / j=1, \ldots n
$$

Conforme descrito anteriormente, o Método dos Mínimos Quadrados baseia-se na adoção da função ponderadora como sendo aquela resultante da aplicação do operador diferencial sobre a função aproximativa, de modo que:

$$
\Psi_{i}=A\left(\phi_{i}\right)=\frac{d^{4} \phi_{i}}{d y^{4}}+4 \cdot \beta^{4} \cdot \phi_{i}
$$

Desenvolvendo as duas integrais da eq.(5.5) resultam a eq(5.8) e a eq.(5.9) respectivamente:

$$
\begin{aligned}
& \int_{y_{A}}^{y_{B}}\left(\frac{d^{4}\left(\alpha_{j} \cdot \phi_{j}\right)}{d y^{4}} \cdot \Psi_{i}+4 \cdot \beta^{4} \cdot\left(\alpha_{i} \cdot \phi_{i}\right) \cdot \Psi_{i}\right) d y \Rightarrow \\
& =\alpha_{j} \cdot \quad \int_{y_{A}}^{y_{B}}\left(\frac{d^{4} \phi_{j}}{d y^{4}}+4 \cdot \beta^{4} \cdot \phi_{j}\right) \cdot \Psi_{i} d y \Rightarrow \\
& =\alpha_{j} \cdot \quad \int_{y_{A}}^{y_{B}}\left(\frac{d^{4} \phi_{j}}{d y^{4}}+4 \cdot \beta^{4} \cdot \phi_{j}\right) \cdot\left(\frac{d^{4} \phi_{i}}{d y^{4}}+4 \cdot \beta^{4} \cdot \phi_{i}\right) d y \Rightarrow \\
& =\alpha_{j} \cdot \quad \int_{y_{A}}^{y_{B}}\left[\frac{d^{4} \phi_{i}}{d y^{4}} \cdot \frac{d^{4} \phi_{j}}{d y^{4}}+16 \cdot \beta^{8} \cdot \phi_{i} \cdot \phi_{j}+4 \cdot \beta^{4} \cdot\left(\frac{d^{4} \phi_{i}}{d y^{4}} \cdot \phi_{j}+\phi_{i} \cdot \frac{d^{4} \phi_{j}}{d y^{4}}\right)\right] d y \\
& \int_{y_{A}}^{y_{B}}\left(\frac{P_{z}}{D}\right) \cdot \Psi_{i} d y \Rightarrow \int_{y_{A}}^{y_{B}}\left(\frac{P_{z}}{D}\right) \cdot\left(\frac{d^{4} \phi_{i}}{d y^{4}}+4 \cdot \beta^{4} \cdot \phi_{i}\right) d y
\end{aligned}
$$


A eq.(5.5) pode, então, ser reescrita da seguinte maneira:

$$
\begin{aligned}
\alpha_{j} \cdot & \int_{y_{A}}^{y_{B}}\left[\frac{d^{4} \phi_{i}}{d y^{4}} \cdot \frac{d^{4} \phi_{j}}{d y^{4}}+16 \cdot \beta^{8} \cdot \phi_{i} \cdot \phi_{j}+4 \cdot \beta^{4} \cdot\left(\frac{d^{4} \phi_{i}}{d y^{4}} \cdot \phi_{j}+\phi_{i} \cdot \frac{d^{4} \phi_{j}}{d y^{4}}\right)\right] d y= \\
& \int_{y_{A}}^{y_{B}}\left(\frac{P_{z}}{D}\right) \cdot\left(\frac{d^{4} \phi_{i}}{d y^{4}}+4 \cdot \beta^{4} \cdot \phi_{i}\right) d y
\end{aligned}
$$

Denominando-se a primeira integral da eq.(5.10) de $\boldsymbol{K}_{i j}$ e a segunda integral de $f_{i}$ obtém-se:

$$
K_{i j} \cdot \alpha_{j}=f_{i} \quad c / i, j=1, \ldots n
$$

Deste modo:

$$
\begin{array}{cc}
K_{1 j}= & \int_{y_{A}}^{y_{B}}\left[\frac{d^{4} \phi_{1}}{d y^{4}} \cdot \frac{d^{4} \phi_{j}}{d y^{4}}+16 \cdot \beta^{8} \cdot \phi_{1} \cdot \phi_{j}+4 \cdot \beta^{4} \cdot\left(\frac{d^{4} \phi_{1}}{d y^{4}} \cdot \phi_{j}+\phi_{1} \cdot \frac{d^{4} \phi_{j}}{d y^{4}}\right)\right] d y \\
K_{2 j}= & \int_{y_{A}}^{y_{B}}\left[\frac{d^{4} \phi_{2}}{d y^{4}} \cdot \frac{d^{4} \phi_{j}}{d y^{4}}+16 \cdot \beta^{8} \cdot \phi_{2} \cdot \phi_{j}+4 \cdot \beta^{4} \cdot\left(\frac{d^{4} \phi_{2}}{d y^{4}} \cdot \phi_{j}+\phi_{2} \cdot \frac{d^{4} \phi_{j}}{d y^{4}}\right)\right] d y \\
\vdots & \vdots \\
K_{n j}= & \int_{y_{A}}^{y_{B}}\left[\frac{d^{4} \phi_{n}}{d y^{4}} \cdot \frac{d^{4} \phi_{j}}{d y^{4}}+16 \cdot \beta^{8} \cdot \phi_{n} \cdot \phi_{j}+4 \cdot \beta^{4} \cdot\left(\frac{d^{4} \phi_{n}}{d y^{4}} \cdot \phi_{j}+\phi_{n} \cdot \frac{d^{4} \phi_{j}}{d y^{4}}\right)\right] d y
\end{array}
$$


Assim como:

$$
\begin{array}{ccc}
f_{1}= & \int_{y_{A}}^{y_{B}}\left(\frac{P_{z}}{D}\right) \cdot\left(\frac{d^{4} \phi_{1}}{d y^{4}}+4 \cdot \beta^{4} \cdot \phi_{1}\right) d y \\
f_{2}= & \int_{y_{A}}^{y_{B}}\left(\frac{P_{z}}{D}\right) \cdot\left(\frac{d^{4} \phi_{2}}{d y^{4}}+4 \cdot \beta^{4} \cdot \phi_{2}\right) d y \\
\vdots & \vdots \\
f_{n}= & \int_{y_{A}}^{y_{B}}\left(\frac{P_{z}}{D}\right) \cdot\left(\frac{d^{4} \phi_{n}}{d y^{4}}+4 \cdot \beta^{4} \cdot \phi_{n}\right) d y
\end{array}
$$

Como as integrais da eq.(5.10) pertencem ao domínio $\boldsymbol{\Omega}^{e}=\left(\boldsymbol{y}_{A}, \boldsymbol{y}_{\boldsymbol{B}}\right)$ de um elemento finito $\boldsymbol{e}$, passa-se a representar a eq.(5.11) da seguinte forma:

$K_{i j}^{e} \cdot \alpha_{j}^{e}=f_{i}^{e}$

Considerando-se todo o conjunto de elementos, obtém-se um sistema global de equações cujas incógnitas são os valores nodais da aproximação global. Para exemplificação da obtenção do sistema global, toma-se um caso onde a função aproximativa é constituída de uma base linear (que possui dois parâmetros). Desenvolvendo-se a eq.(5.14), pode-se chegar ao seguinte conjunto de equações:

$$
\begin{aligned}
& K_{11}^{e} \cdot \alpha_{1}^{e}+K_{12}^{e} \cdot \alpha_{2}^{e}=f_{1}^{e} \\
& K_{21}^{e} \cdot \alpha_{1}^{e}+K_{22}^{e} \cdot \alpha_{2}^{e}=f_{2}^{e}
\end{aligned}
$$

Reescrevendo-se esse conjunto em forma matricial tem-se:

$$
\left[\begin{array}{ll}
K_{11}^{e} & K_{12}^{e} \\
K_{21}^{e} & K_{22}^{e}
\end{array}\right] \cdot\left\{\begin{array}{l}
\alpha_{1}^{e} \\
\alpha_{2}^{e}
\end{array}\right\}=\left\{\begin{array}{c}
f_{1}^{e} \\
f_{2}^{e}
\end{array}\right\}
$$


ou seja:

$$
\left[K^{e}\right] \cdot\left\{\alpha^{e}\right\}=\left\{f^{e}\right\}
$$

Tendo-se em vista a conectividade entre os elementos do domínio global, é importante destacar a necessidade de se adotar a continuidade (igualdade) entre os parâmetros pertencentes ao nó comum. Desta forma, considerando-se dois elementos $\boldsymbol{e}$ e $\boldsymbol{e}+\boldsymbol{1}$ onde:

$$
\begin{aligned}
& K_{i j}^{e} \cdot \alpha_{j}^{e}=f_{j i}^{e} \\
& K_{i j}^{e+1} \cdot \alpha_{j}^{e+1}=f_{i}^{e+1}
\end{aligned}
$$

Tomando-se da eq.(5.14) a segunda equação do elemento $\boldsymbol{e}$ e tomando-a com a primeira equação do elemento $\boldsymbol{e}+\boldsymbol{1}$, obtida da eq.(5.18), obtém-se uma relação que permite garantir a continuidade da aproximação no nó entre os elementos $\boldsymbol{e}$ e $\boldsymbol{e}+\boldsymbol{1}$.

$K_{2 j}^{e} \cdot \alpha_{j}^{e}+K_{1 j}^{e+1} \cdot \alpha_{j}^{e+1}=f_{2}^{e}+f_{1}^{e+1}$

Para um caso onde o domínio global contenha $\boldsymbol{E}$ elementos, o sistema global de equações fica formulado pelas equações referentes ao primeiro e último nó, inalteradas, e as equações que se referem aos nós em comum somadas entre si. Considerando-se $\boldsymbol{U}_{\boldsymbol{i}}$ como sendo o parâmetro global associado ao nó $\boldsymbol{i}$, segue o seguinte conjunto de condições: 


$$
\begin{gathered}
\alpha_{1}^{1}=U_{1} \\
\alpha_{2}^{1}+\cdot \alpha_{1}^{2}=U_{2} \\
\alpha_{2}^{2}+\cdot \alpha_{1}^{3}=U_{3} \\
\vdots \\
\alpha_{2}^{E-1}+\cdot \alpha_{1}^{E}=U_{E} \\
\alpha_{2}^{E}=U_{E+1}
\end{gathered}
$$

De modo que podemos reescrever o sistema linear expresso pela eq.(5.14) e eq.(5.18) da seguinte forma:

$$
\left[\begin{array}{ccc}
K_{11}^{e} & K_{12}^{e} & 0 \\
K_{21}^{e} & K_{22}^{e}+K_{11}^{e+1} & K_{12}^{e+1} \\
0 & K_{21}^{e+1} & K_{22}^{e+1}
\end{array}\right] \cdot\left\{\begin{array}{c}
U_{1} \\
U_{2} \\
U_{3}
\end{array}\right\}=\left\{\begin{array}{c}
f_{1}^{e} \\
f_{2}^{e}+f_{1}^{e+1} \\
f_{2}^{e+1}
\end{array}\right\}
$$

Generalizando-se o sistema de equações para $\boldsymbol{E}$ elementos, sendo cada elemento composto de dois parâmetros incógnitos (um parâmetro por nó) e tomado-se por base a eq.(5.19) e a eq.(5.20) tem-se o seguinte sistema linear:

$$
\begin{gathered}
K_{11}^{1} \cdot U_{1}+K_{12}^{1} \cdot U_{2}=f_{1}^{1} \\
K_{21}^{1} \cdot U_{1}+\left(K_{22}^{1}+K_{11}^{2}\right) \cdot U_{2}+K_{12}^{2} \cdot U_{3}=f_{2}^{1}+f_{1}^{2} \\
K_{21}^{2} \cdot \alpha_{2}+\left(K_{22}^{2}+K_{11}^{3}\right) \cdot U_{3}+K_{12}^{3} \cdot U_{4}=f_{2}^{2}+f_{1}^{3} \\
\vdots \\
K_{21}^{E-1} \cdot \alpha_{E-1}+\left(K_{22}^{E-1}+K_{11}^{E}\right) \cdot U_{E}+K_{12}^{E} \cdot U_{E+1}=f_{2}^{E-1}+f_{1}^{E} \\
K_{21}^{E} \cdot U_{E}+K_{22}^{E} \cdot U_{E+1}=f_{2}^{E}
\end{gathered}
$$


Reescrevendo a eq.(5.22) na forma matricial temos:

$$
\left[\begin{array}{cccccc}
K_{11}^{1} & K_{12}^{1} & 0 & 0 & 0 & 0 \\
K_{21}^{1} & \left(K_{22}^{1}+K_{11}^{2}\right) & K_{12}^{2} & 0 & 0 & 0 \\
0 & K_{21}^{2} & \left(K_{22}^{2}+K_{11}^{3}\right) & K_{11}^{3} & 0 & 0 \\
0 & 0 & K_{11}^{3} & \ddots & K_{12}^{E-1} & 0 \\
0 & 0 & 0 & K_{21}^{E-1} & \left(K_{22}^{E-1}+K_{11}^{E}\right) & K_{12}^{E} \\
0 & 0 & 0 & 0 & K_{21}^{E} & K_{22}^{E}
\end{array}\right] \cdot\left\{\begin{array}{c}
U_{1} \\
U_{2} \\
U_{3} \\
\vdots \\
U_{E} \\
U_{E+1}
\end{array}\right\}=\left\{\begin{array}{c}
f_{1}^{1} \\
f_{2}^{1}+f_{1}^{2} \\
f_{2}^{2}+f_{1}^{3} \\
\vdots \\
f_{2}^{E-1}+f_{1}^{E} \\
f_{2}^{E}
\end{array}\right\}
$$

\subsection{Elemento Finito com seis parâmetros}

Com base no desenvolvimento anterior, nota-se que a metodologia garante continuidade sobre os valores dos parâmetros nodais. Admitindo-se então, que os parâmetros tenham relação com os valores da função incógnita e de suas derivadas, a continuidade pode ser estabelecida também sobre as ordens de derivadas. A continuidade sobre as ordens de derivadas pode garantir continuidade dos esforços, uma vez que estes podem ser escritos em função de derivadas da função deslocamento.

Considerando-se a função aproximativa com sendo um polinômio do $5^{\circ}$ grau, que contem seis parâmetros, pode-se considerar um elemento finito contendo seis parâmetros, ou seja, três parâmetros por nó. Pode ainda associar os parâmetros nodais aos valores da função e de suas derivadas.

Sendo a função aproximativa definida como:

$$
P(y)=\alpha_{1} \cdot y^{5}+\alpha_{2} \cdot y^{4}+\alpha_{3} \cdot y^{3}+\alpha_{4} \cdot y^{2}+\alpha_{5} \cdot y+\alpha_{6}
$$

As seis funções de forma do elemento finito resultam das seguintes condições:

Condições impostas a $\phi_{1}(y)$ :

$\phi_{1}(0)=1, \frac{d \phi_{1}(0)}{d y}=0, \frac{d^{2} \phi_{1}(0)}{d y^{2}}=0, \phi_{1}\left(l_{e}\right)=0, \frac{d \phi_{1}\left(l_{e}\right)}{d y}=0, \frac{d^{2} \phi_{1}\left(l_{e}\right)}{d y^{2}}=0$ 
Condições impostas a $\phi_{2}(\boldsymbol{y})$ :

$$
\phi_{2}(0)=0, \frac{d \phi_{2}(0)}{d y}=1, \frac{d^{2} \phi_{2}(0)}{d y^{2}}=0, \phi_{2}\left(l_{e}\right)=0, \frac{d \phi_{2}\left(l_{e}\right)}{d y}=0, \frac{d^{2} \phi_{2}\left(l_{e}\right)}{d y^{2}}=0
$$

Condições impostas a $\phi_{3}(\boldsymbol{y})$ :

$$
\phi_{3}(0)=0, \frac{d \phi_{3}(0)}{d y}=0, \frac{d^{2} \phi_{3}(0)}{d y^{2}}=1, \phi_{3}\left(l_{e}\right)=0, \frac{d \phi_{3}\left(l_{e}\right)}{d y}=0, \frac{d^{2} \phi_{3}\left(l_{e}\right)}{d y^{2}}=0
$$

Condições impostas a $\phi_{4}(\boldsymbol{y})$ :

$$
\phi_{4}(0)=0, \frac{d \phi_{4}(0)}{d y}=0, \frac{d^{2} \phi_{4}(0)}{d y^{2}}=0, \phi_{4}\left(l_{e}\right)=1, \frac{d \phi_{4}\left(l_{e}\right)}{d y}=0, \frac{d^{2} \phi_{4}\left(l_{e}\right)}{d y^{2}}=0
$$

Condições impostas a $\phi_{5}(\boldsymbol{y})$ :

$$
\phi_{5}(0)=0, \frac{d \phi_{5}(0)}{d y}=0, \frac{d^{2} \phi_{5}(0)}{d y^{2}}=0, \phi_{5}\left(l_{e}\right)=0, \frac{d \phi_{5}\left(l_{e}\right)}{d y}=1, \frac{d^{2} \phi_{5}\left(l_{e}\right)}{d y^{2}}=0
$$

Condições impostas a $\boldsymbol{\phi}_{\mathbf{6}}(\boldsymbol{y})$ :

$$
\phi_{6}(0)=0, \frac{d \phi_{6}(0)}{d y}=0, \frac{d^{2} \phi_{6}(0)}{d y^{2}}=0, \phi_{6}\left(l_{e}\right)=0, \frac{d \phi_{6}\left(l_{e}\right)}{d y}=0, \frac{d^{2} \phi_{6}\left(l_{e}\right)}{d y^{2}}=1
$$


Resultam as funções de forma:

$$
\begin{aligned}
& \phi_{1}(y)=\frac{-6 \cdot y^{5}}{l_{e}^{5}}+\frac{15 \cdot y^{4}}{l_{e}^{4}}-\frac{10 \cdot y^{3}}{l_{e}^{3}}+1 \\
& \phi_{2}(y)=\frac{-3 \cdot y^{5}}{l_{e}^{4}}+\frac{8 \cdot y^{4}}{l_{e}^{3}}-\frac{6 \cdot y^{3}}{l_{e}^{2}}+y \\
& \phi_{3}(y)=\frac{-y^{5}}{2 \cdot l_{e}^{3}}+\frac{3 \cdot y^{4}}{2 \cdot l_{e}{ }^{2}}-\frac{3 \cdot y^{3}}{2 \cdot l_{e}}+\frac{y^{2}}{2} \\
& \phi_{4}(y)=\frac{6 \cdot y^{5}}{l_{e}^{5}}-\frac{15 \cdot y^{4}}{l_{e}^{4}}+\frac{10 \cdot y^{3}}{l_{e}^{3}} \\
& \phi_{5}(y)=\frac{3 \cdot y^{5}}{l_{e}^{4}}+\frac{7 \cdot y^{4}}{l_{e}^{3}}-\frac{4 \cdot y^{3}}{l_{e}^{2}} \\
& \phi_{6}(y)=\frac{y^{5}}{2 \cdot l_{e}^{3}}-\frac{y^{4}}{l_{e}^{2}}+\frac{y^{3}}{2 \cdot l_{e}}
\end{aligned}
$$

Segue que a função aproximativa pode ser expressa em função dos parâmetros nodais da seguinte maneira:

$$
P(y)=u_{1} \cdot \phi_{1}+\frac{d u_{1}}{d y} \cdot \phi_{2}+\frac{d^{2} u_{1}}{d y^{2}} \cdot \phi_{3}+u_{2} \cdot \phi_{4}+\frac{d u_{2}}{d y} \cdot \phi_{5}+\frac{d^{2} u_{2}}{d y^{2}} \cdot \phi_{6}
$$


Os gráficos referentes às funções de forma obtidas anteriormente são dados a seguir:

Funções de Forma referentes ao deslocamento

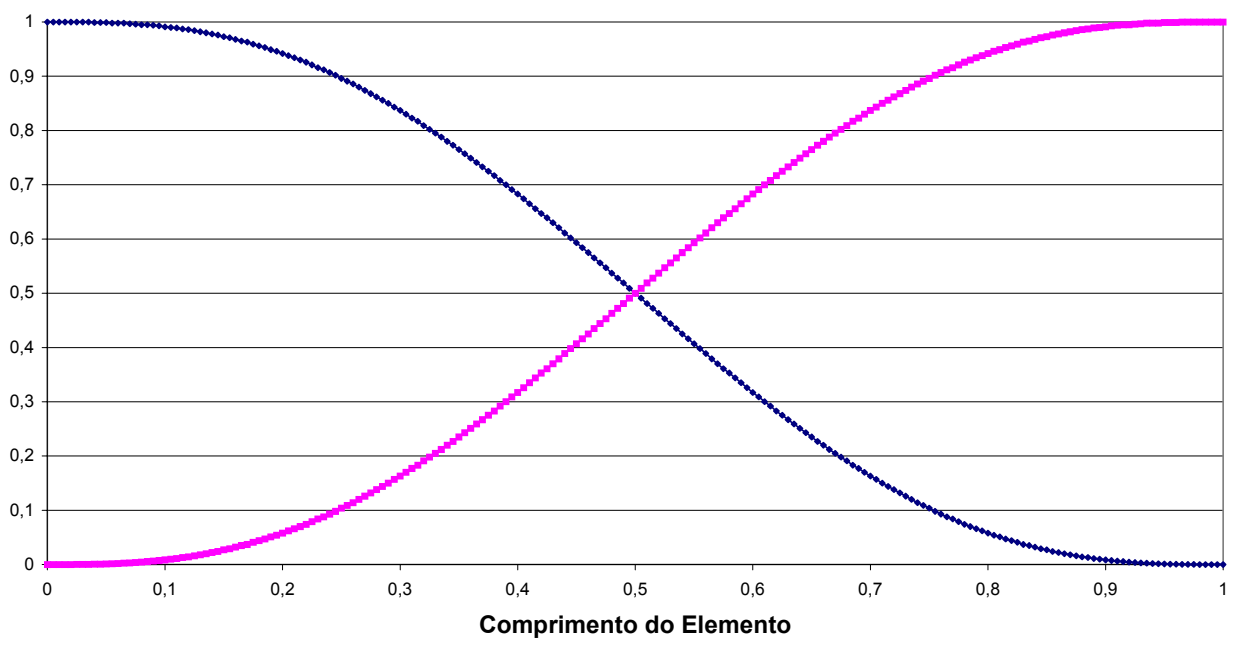

$\multimap \phi 1 \rightarrow \phi 4$

Gráfico 29 - Funções de forma referentes ao deslocamento

Elementos finito com seis parâmetros

Funções de Forma referentes a rotação

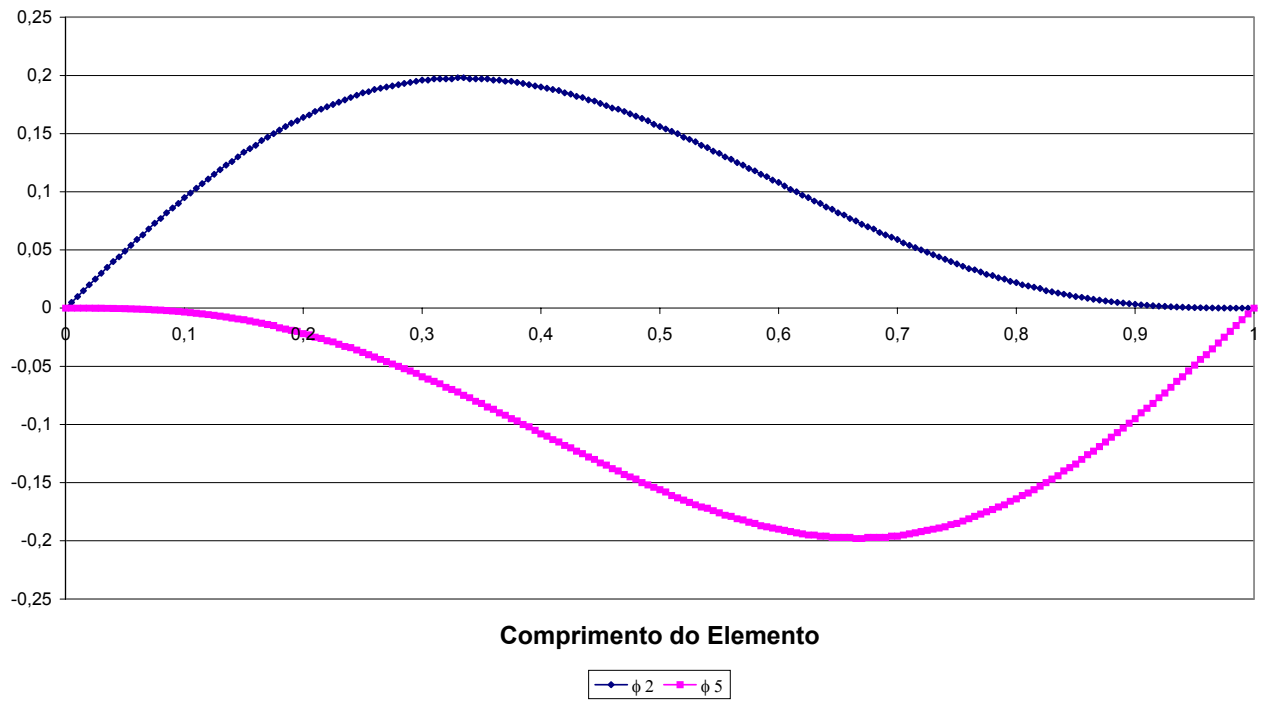

Gráfico 30 - Funções de forma referentes a rotação

Elementos finito com seis parâmetros 
Funções de Forma referentes a curvatura

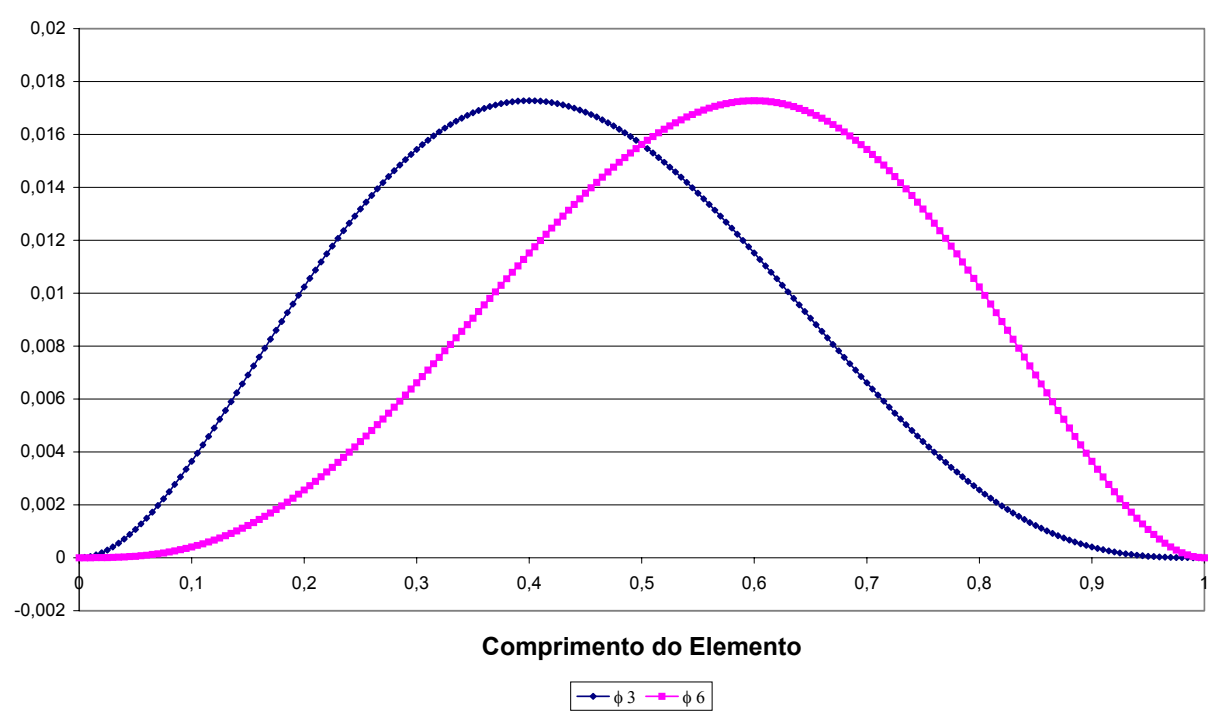

Gráfico 31 - Funções de forma referentes a curvatura

Elementos finito com seis parâmetros

\subsubsection{Método dos Mínimos Quadrados com divisão do domínio de integração: aplicação do elemento de seis parâmetros ao problema de viga}

O problema de uma viga submetida a um carregamento uniformemente

distribuído $\boldsymbol{q}$, pode ser recuperado da eq.(5.10), impondo-se $\quad \beta=\boldsymbol{0}$. Desse modo, a matriz de rigidez e o vetor de forças nodais equivalente, representativos do elemento de viga, são dados por:

$$
\begin{aligned}
K_{i j} & =\int_{x_{A}}^{x_{B}} \frac{d^{4} \phi_{i}}{d x^{4}} \cdot \frac{d^{4} \phi_{j}}{d x^{4}} d x \\
f_{i} & =\int_{x_{A}}^{x_{B}}\left(\frac{q}{D}\right) \cdot\left(\frac{d^{4} \phi_{i}}{d x^{4}}\right) d x
\end{aligned}
$$


onde $\boldsymbol{\Omega}^{e}=\left(\boldsymbol{x}_{A}, \boldsymbol{x}_{\boldsymbol{B}}\right)$.é o domínio do elemento finito.

Nos testes que seguem adotam-se para os mesmos dados apresentados no item 3.4.1.1, exceto o carregamento, sendo $\boldsymbol{q}=1$

\section{a) Viga em balanço}

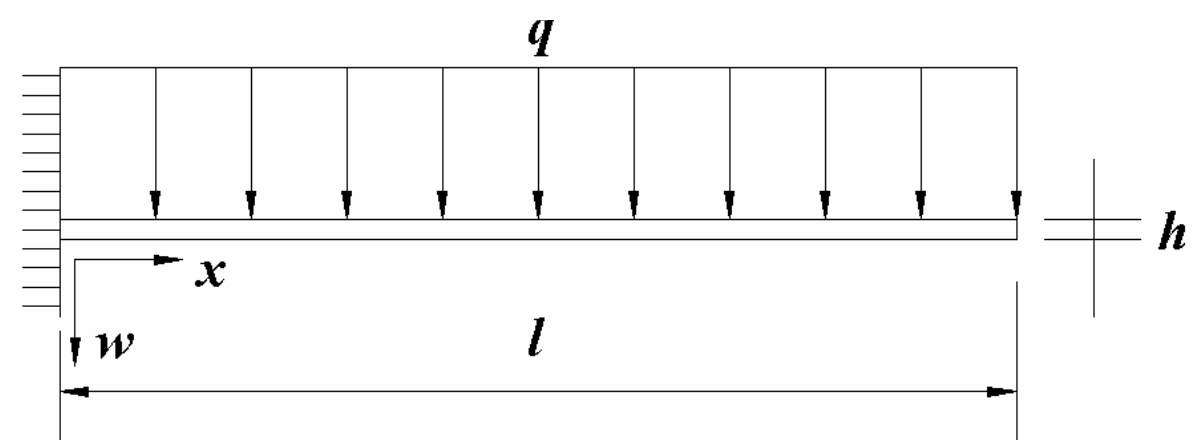

Figura 5.3 - Viga em balanço

Neste caso, a solução analítica requer um polinômio de grau 4 para que a solução aproximativa consiga capturar a solução exata. Como a função aproximativa refere-se a um polinômio de grau 5, é de se esperar que com apenas um elemento a solução exata possa ser recuperada. De fato, as figuras seguintes ilustram a precisão de resultados, tanto no que se refere ao deslocamento $\boldsymbol{w}$, quanto dos esforços solicitantes $\boldsymbol{M}$ e $\boldsymbol{Q}$. 
Viga Engastada-Livre - Elemento finito com seis parâmetros - MMQ

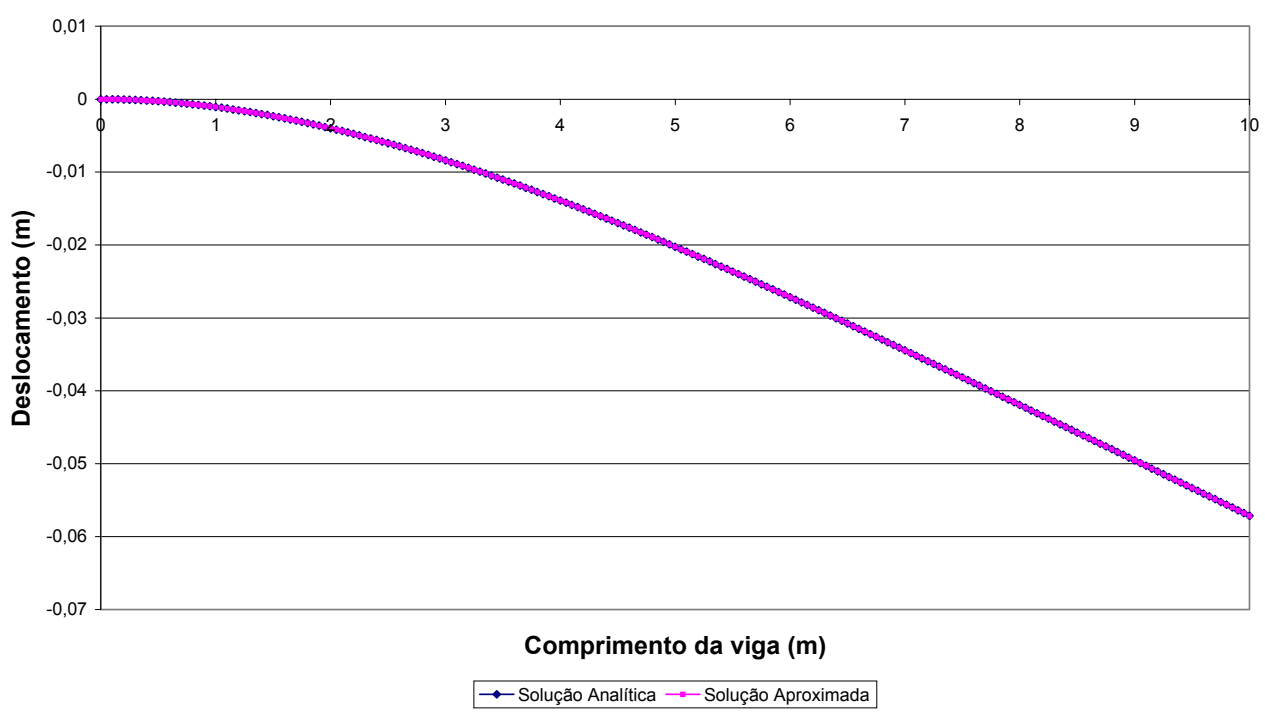

Gráfico 32- Aproximação obtida utilizando 1 elemento finito

Viga Engastada-Livre - Elemento finito com seis parâmetros - MMQ

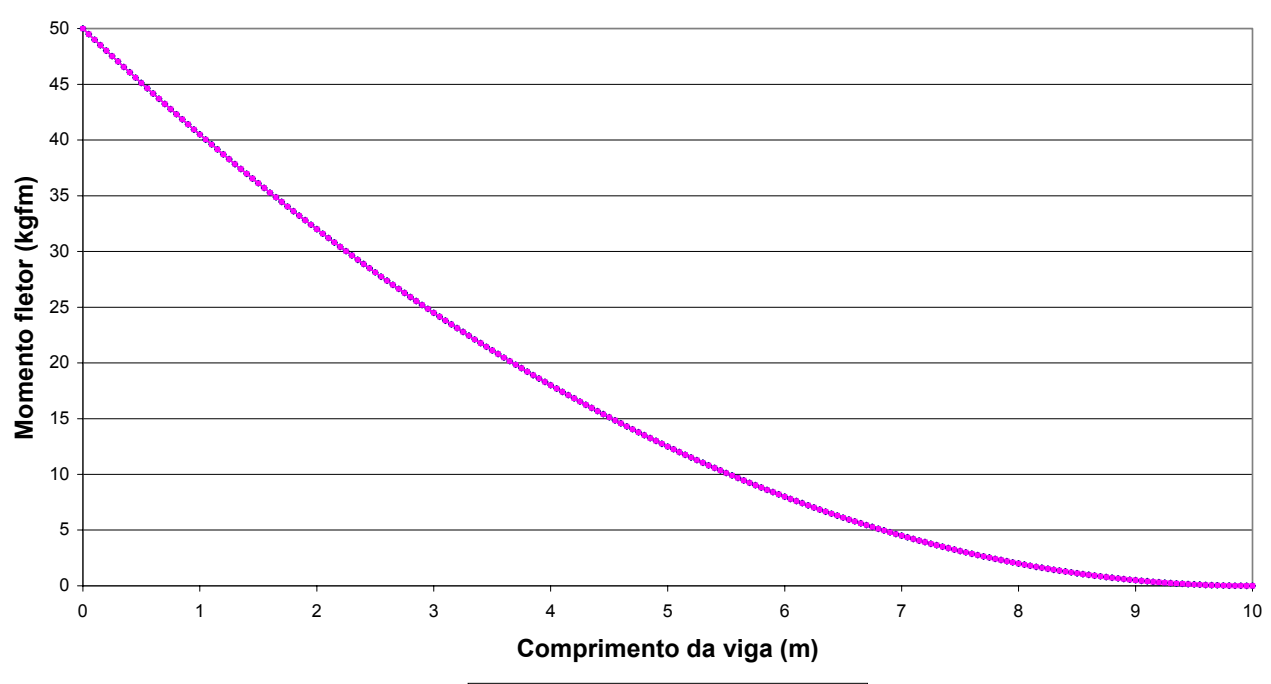

$\rightarrow$-Solução Analítica $\rightarrow$ Solução Aproximada

Gráfico 33- Aproximação obtida utilizando 1 elemento finito 


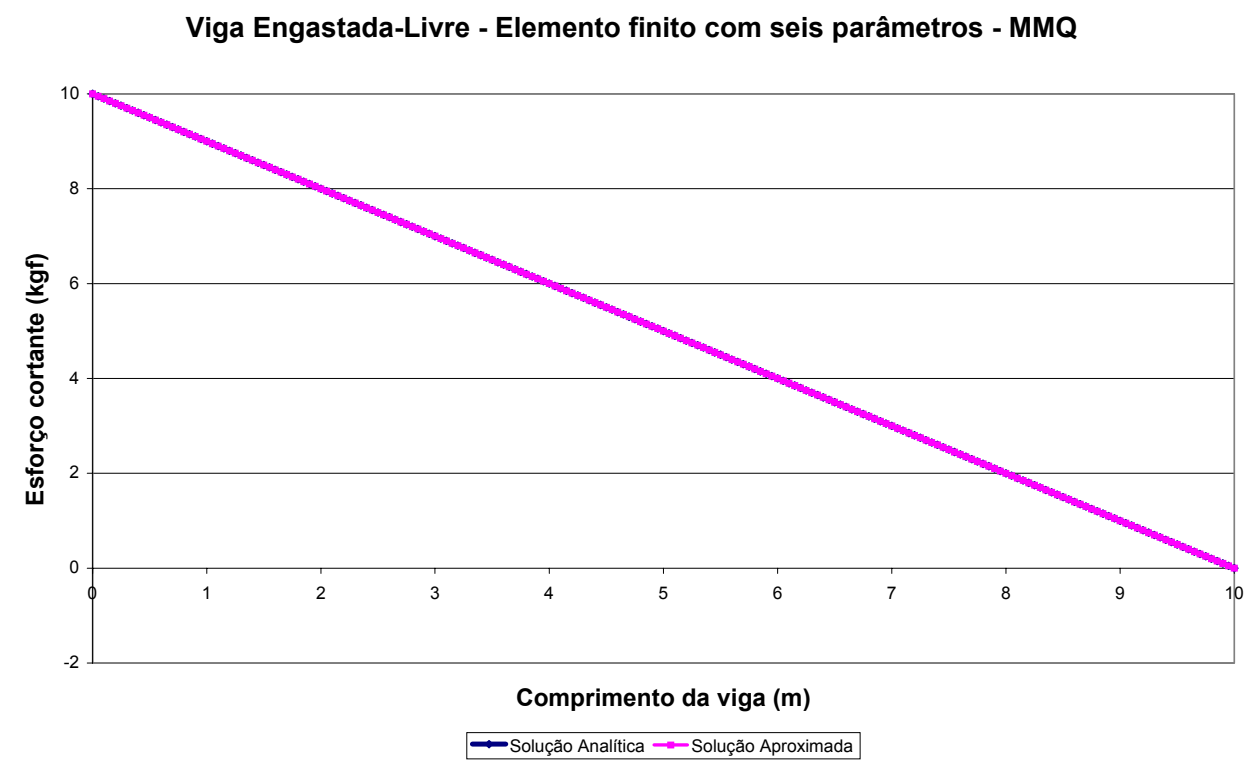

Gráfico 34- Aproximação obtida utilizando 1 elemento finito

Um aspecto importante a se comentar refere-se às condições de contorno impostas ao problema. No caso de viga em balanço existem duas condições de contorno essenciais que referem-se ao deslocamento e rotação nulos no engaste, e duas condições de contorno naturais referentes ao momento fletor e esforço cortante nulos na extremidade livre da viga. Com os graus de liberdade nodais se referem ao valor da função e de suas primeira e segunda derivada, a condição de giro nulo e momento nulo podem então ser impostas diretamente, porém a condição referente ao esforço cortante não.

\subsubsection{Método dos Mínimos Quadrados com divisão do domínio de integração aplicado ao problema dos tubos}

Tendo como base a eq.(5.10), aplica-se no que segue o elemento finito de seis parâmetros na análise de um reservatório cilíndrico engastado, primeiramente, com apenas um elemento. Os dados referentes ao problema constam no item 3.4.1.1., e as figuras seguintes ilustram os resultados obtidos. 
Tubo com base engastada - Elemento finito com seis parâmetros - MMQ

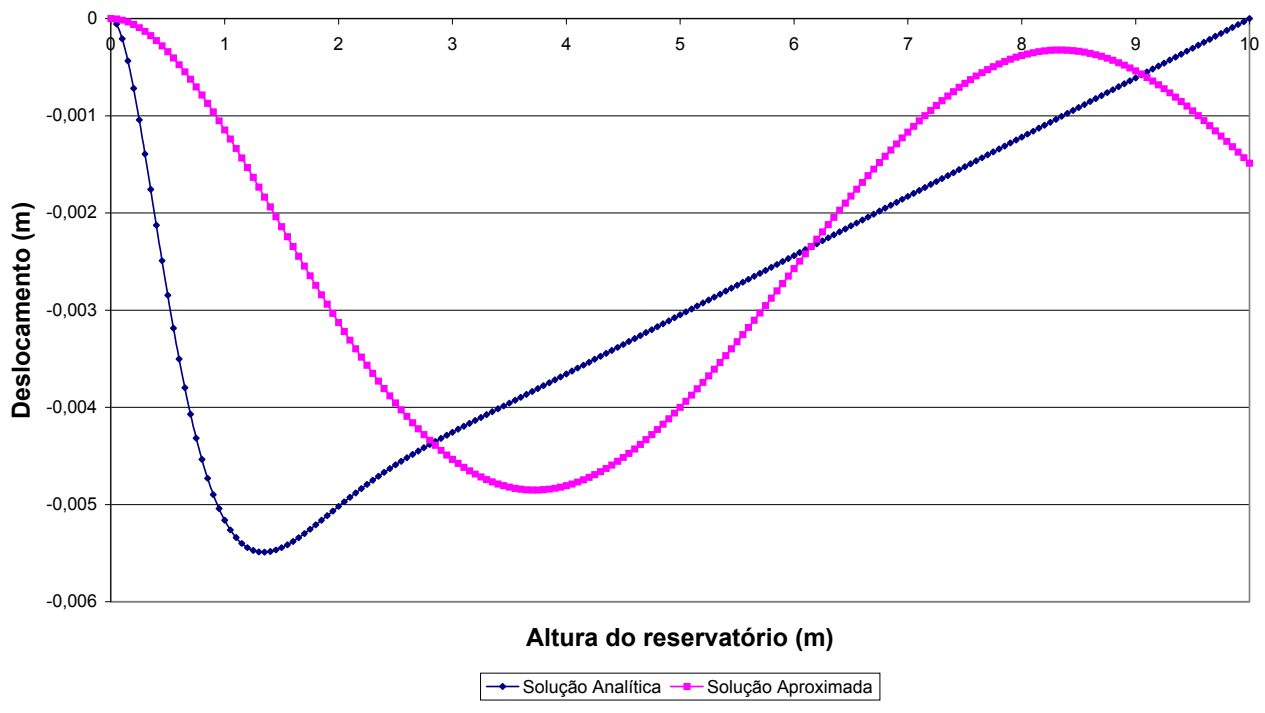

Gráfico 35- Aproximação obtida utilizando 1 elemento finito

Tubo com base engastada - Elemento finito com seis parâmetros - MMQ

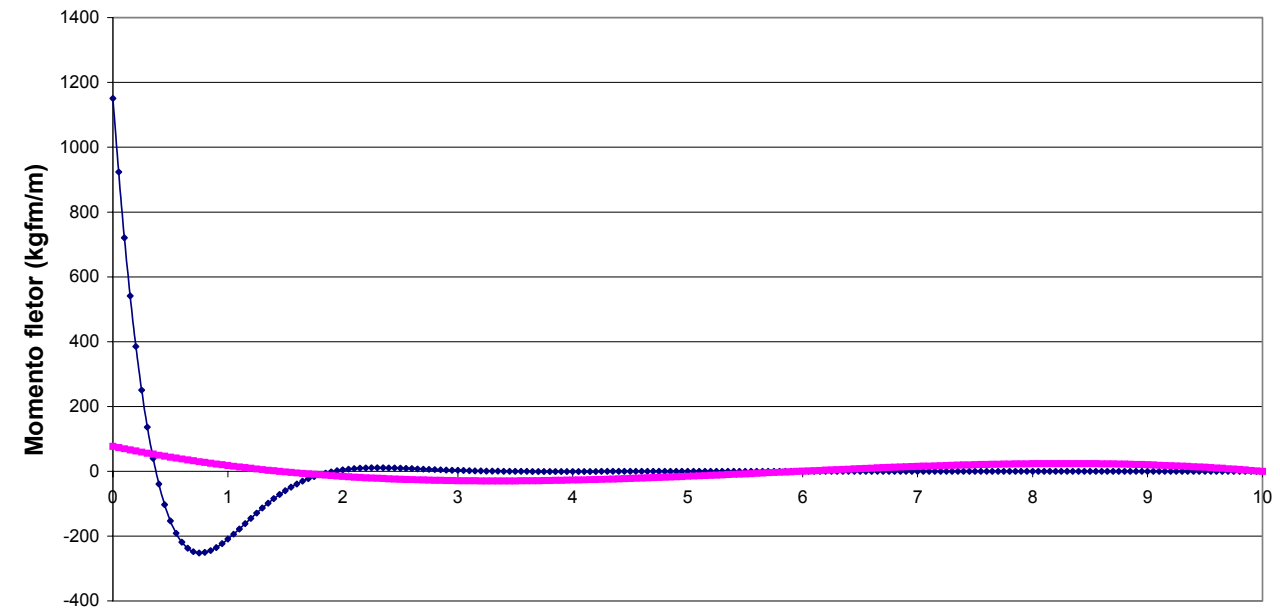

Altura do reservatório $(\mathrm{m})$

$\rightarrow$ Solução Analitica $\rightarrow$-Solução Aproximada

Gráfico 36- Aproximação obtida utilizando 1 elemento finito 
Tubo com base engastada - Elemento finito com seis parâmetros - MMQ

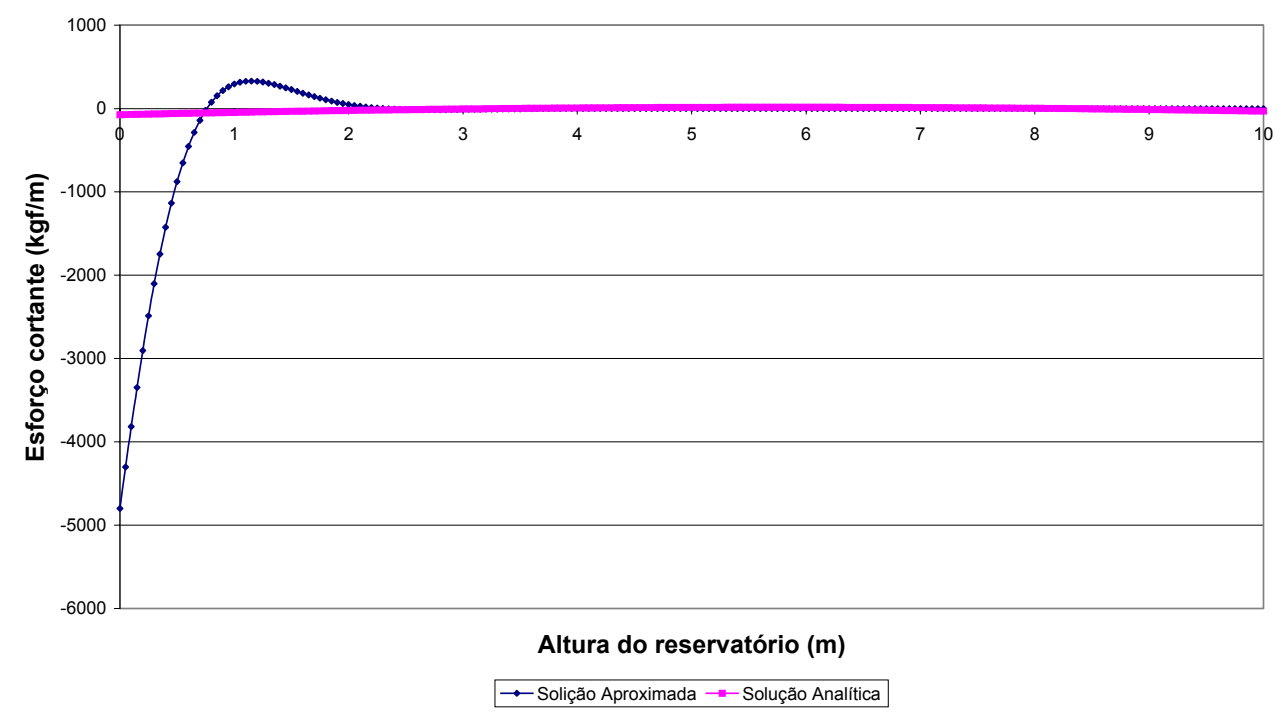

Gráfico 37- Aproximação obtida utilizando 1 elemento finito

Como era de se esperar, a solução aproximada contendo apenas um elemento não foi capaz de capturar a solução analítica, pois, como se sabe, a mesma possui termos exponencial-trigonométricos. Neste caso seria necessário adicionar-se mais elementos, afim de reduzir o erro de aproximação. O exemplo a seguir mostra um reservatório engastado nas mesmas condições, porém, discretizado adotando-se três elementos, conforme mostra a tabela abaixo:

Tabela 5.1 - Comprimento dos elementos finitos

\begin{tabular}{|c|c|c|}
\hline \multicolumn{3}{|c|}{ Reservatório cilíndrico } \\
\hline Elemento Finito & Comprimento $(\mathbf{m})$ & Coordenada global do nó inicial do elemento(m) \\
\hline 1 & 1 & 0 \\
\hline 2 & 1 & 1 \\
\hline 3 & 8 & 2 \\
\hline
\end{tabular}


Tubo com base engastada - Elemento finito com seis parâmetros - MMQ

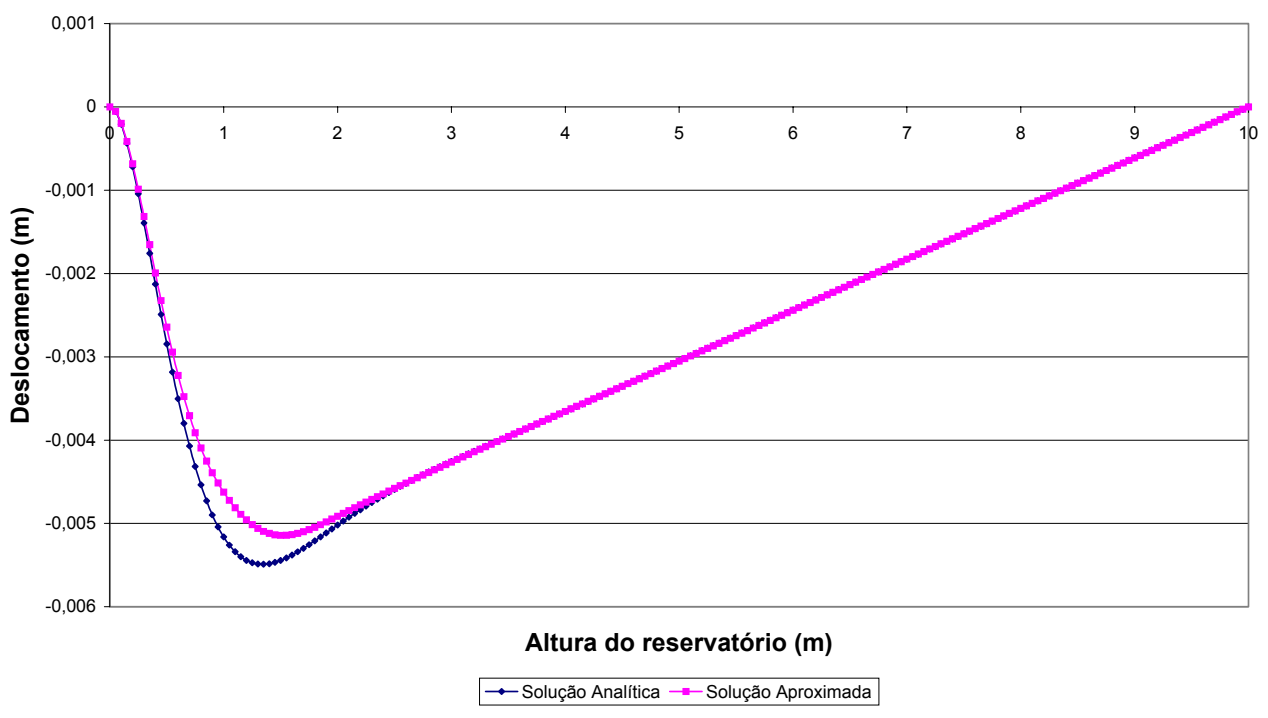

Gráfico 38- Aproximação obtida utilizando 3 elementos finitos

Tubo com base engastada - Elemento finito com seis parâmetros - MMQ

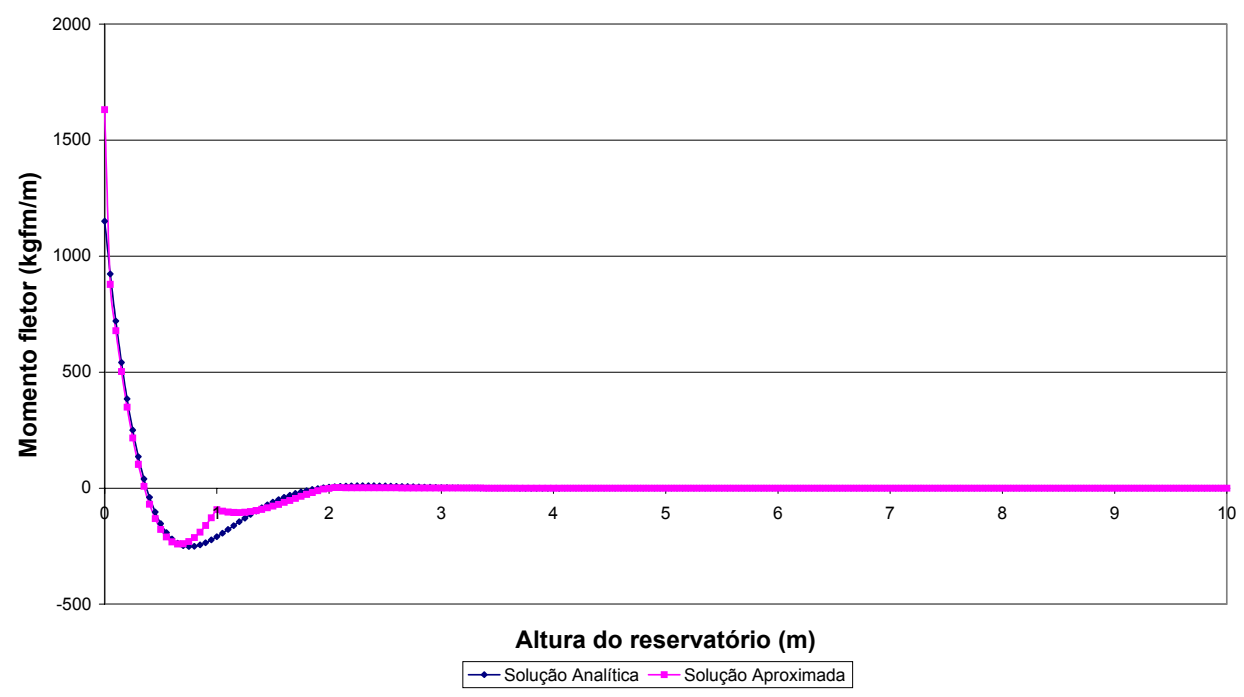

Gráfico 39 - Aproximação obtida utilizando 3 elementos finitos 
Tubo com base engastada - Elemento finito com seis parâmetros - MMQ

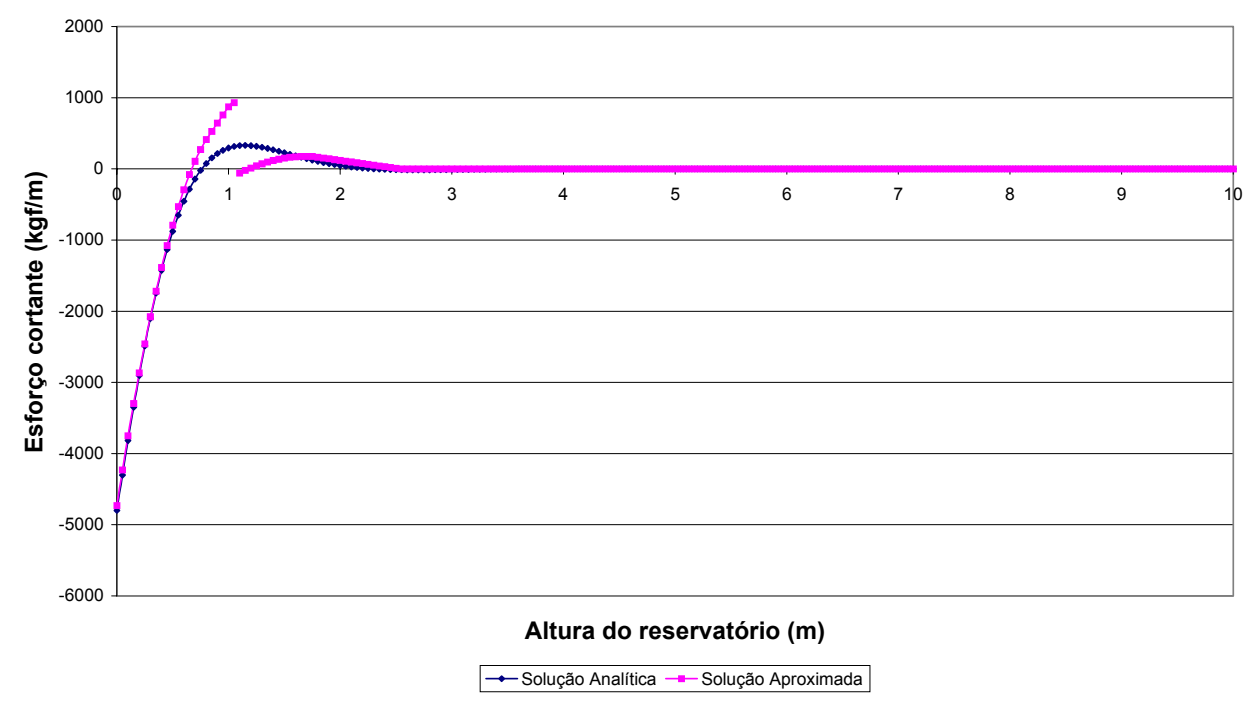

Gráfico 40 - Aproximação obtida utilizando 3 elementos finitos

Comparando-se as aproximações obtidas com três elementos com as obtidas com um único elemento, nota-se a melhor qualidade da aproximação proporcionada pela divisão do domínio, porém um aspecto importante a se comentar é o fato de não haver continuidade de derivadas nos nós referentes ao gráfico de momento fletor. Conseqüentemente o gráfico de esforço cortante aparece com descontinuidade nos valores nodais. E quanto maior for a divisão do domínio, maior será o número de descontinuidades existentes na função aproximativa, em virtude do número de nós aumentarem. Um fato interessante de se notar é que se obtivermos a média dos valores dados no ponto onde há a descontinuidade, esse valor é bem próximo da solução do problema, mostrando desta maneira que se o problema relativo à descontinuidade das derivadas for solucionado, conseqüentemente o método aproximativo conseguirá capturar a solução do problema.

Com base nestes resultados, nota-se que a aproximação é insuficiente para garantir continuidade do esforço cortante. Uma alternativa que pode ser utilizada para resolver este problema consiste na adoção de um polinômio de grau mais elevado que o anterior, o que é mostrado no item seguinte.

A necessidade de maior precisão em relação aos esforços solicitantes depende, naturalmente, do tipo de problema. Nos tubos, em geral, os esforços de flexão são localizados, com a característica de trocarem de sinal em razão do efeito de seu amortecimento. Nesse tipo de estrutura o correto dimensionamento à flexão pode exigir maior precisão da definição dos esforços solicitantes. 


\subsection{Elemento Finito com oito parâmetros}

Considerando-se a função aproximativa como sendo um polinômio do $7^{\circ}$ grau, que contém oito parâmetros, pode-se formular um elemento finito contendo oito parâmetros, ou seja, quatro parâmetros por nó.:

Sendo a função aproximativa definida como:

$P(y)=\alpha_{1} \cdot y^{7}+\alpha_{2} \cdot y^{6}+\alpha_{3} \cdot y^{5}+\alpha_{4} \cdot y^{4}+\alpha_{5} \cdot y^{3}+\alpha_{6} \cdot y^{2}+\alpha_{7} \cdot y+\alpha_{8}$

e impondo-se que os parâmetros coincidam com os valores nodais da função deslocamento e de suas derivadas, obtém-se as oito funções de forma escritas a seguir.

Condições impostas a $\phi_{1}(y)$ :

$$
\begin{aligned}
& \phi_{1}(0)=1, \frac{d \phi_{1}(0)}{d y}=0, \frac{d^{2} \phi_{1}(0)}{d y^{2}}=0, \frac{d^{3} \phi_{1}(0)}{d y^{3}}=0, \\
& \phi_{1}\left(l_{e}\right)=0, \frac{d \phi_{1}\left(l_{e}\right)}{d y}=0, \frac{d^{2} \phi_{1}\left(l_{e}\right)}{d y^{2}}=0, \frac{d^{3} \phi_{1}\left(l_{e}\right)}{d y^{3}}=0
\end{aligned}
$$

Condições impostas a $\phi_{2}(y)$ :

$$
\begin{aligned}
& \phi_{2}(0)=0, \frac{d \phi_{2}(0)}{d y}=1, \frac{d^{2} \phi_{2}(0)}{d y^{2}}=0, \frac{d^{3} \phi_{2}(0)}{d y^{3}}=0, \\
& \phi_{2}\left(l_{e}\right)=0, \frac{d \phi_{2}\left(l_{e}\right)}{d y}=0, \frac{d^{2} \phi_{2}\left(l_{e}\right)}{d y^{2}}=0, \frac{d^{3} \phi_{2}\left(l_{e}\right)}{d y^{3}}=0
\end{aligned}
$$

Condições impostas a $\phi_{3}(\boldsymbol{y})$ :

$$
\begin{aligned}
& \phi_{3}(0)=0, \frac{d \phi_{3}(0)}{d y}=0, \frac{d^{2} \phi_{3}(0)}{d y^{2}}=1, \frac{d^{3} \phi_{3}(0)}{d y^{3}}=0, \\
& \phi_{3}\left(l_{e}\right)=0, \frac{d \phi_{3}\left(l_{e}\right)}{d y}=0, \frac{d^{2} \phi_{3}\left(l_{e}\right)}{d y^{2}}=0, \frac{d^{3} \phi_{3}\left(l_{e}\right)}{d y^{3}}=0
\end{aligned}
$$


Condições impostas a $\phi_{4}(y)$ :

$$
\begin{aligned}
& \phi_{4}(0)=0, \frac{d \phi_{4}(0)}{d y}=0, \frac{d^{2} \phi_{4}(0)}{d y^{2}}=0, \frac{d^{3} \phi_{4}(0)}{d y^{3}}=1, \\
& \phi_{4}\left(l_{e}\right)=0, \frac{d \phi_{4}\left(l_{e}\right)}{d y}=0, \frac{d^{2} \phi_{4}\left(l_{e}\right)}{d y^{2}}=0, \frac{d^{3} \phi_{4}\left(l_{e}\right)}{d y^{3}}=0
\end{aligned}
$$

Condições impostas a $\phi_{5}(\boldsymbol{y})$ :

$$
\begin{aligned}
& \phi_{5}(0)=0, \frac{d \phi_{5}(0)}{d y}=0, \frac{d^{2} \phi_{5}(0)}{d y^{2}}=0, \frac{d^{3} \phi_{5}(0)}{d y^{3}}=0, \\
& \phi_{5}\left(l_{e}\right)=1, \frac{d \phi_{5}\left(l_{e}\right)}{d y}=0, \frac{d^{2} \phi_{5}\left(l_{e}\right)}{d y^{2}}=0, \frac{d^{3} \phi_{5}\left(l_{e}\right)}{d y^{3}}=0
\end{aligned}
$$

Condições impostas a $\boldsymbol{\phi}_{\mathbf{6}}(\boldsymbol{y})$ :

$$
\begin{aligned}
& \phi_{6}(0)=0, \frac{d \phi_{6}(0)}{d y}=0, \frac{d^{2} \phi_{6}(0)}{d y^{2}}=0, \frac{d^{3} \phi_{6}(0)}{d y^{3}}=0, \\
& \phi_{6}\left(l_{e}\right)=0, \frac{d \phi_{6}\left(l_{e}\right)}{d y}=1, \frac{d^{2} \phi_{6}\left(l_{e}\right)}{d y^{2}}=0, \frac{d^{3} \phi_{6}\left(l_{e}\right)}{d y^{3}}=0
\end{aligned}
$$

Condições impostas a $\phi_{7}(\boldsymbol{y})$ :

$$
\begin{aligned}
& \phi_{7}(0)=0, \frac{d \phi_{7}(0)}{d y}=0, \frac{d^{2} \phi_{7}(0)}{d y^{2}}=0, \frac{d^{3} \phi_{7}(0)}{d y^{3}}=0, \\
& \phi_{7}\left(l_{e}\right)=0, \frac{d \phi_{7}\left(l_{e}\right)}{d y}=0, \frac{d^{2} \phi_{7}\left(l_{e}\right)}{d y^{2}}=1, \frac{d^{3} \phi_{7}\left(l_{e}\right)}{d y^{3}}=0
\end{aligned}
$$

Condições impostas a $\phi_{\boldsymbol{\delta}}(\boldsymbol{y})$ :

$$
\begin{aligned}
& \phi_{8}(0)=0, \frac{d \phi_{8}(0)}{d y}=0, \frac{d^{2} \phi_{8}(0)}{d y^{2}}=0, \frac{d^{3} \phi_{8}(0)}{d y^{3}}=0, \\
& \phi_{8}\left(l_{e}\right)=0, \frac{d \phi_{8}\left(l_{e}\right)}{d y}=0, \frac{d^{2} \phi_{8}\left(l_{e}\right)}{d y^{2}}=0, \frac{d^{3} \phi_{8}\left(l_{e}\right)}{d y^{3}}=1
\end{aligned}
$$


Resultam as funções de forma:

$$
\begin{aligned}
& \phi_{1}(y)=\frac{20 \cdot y^{7}}{l_{e}^{7}}-\frac{70 \cdot y^{6}}{l_{e}^{6}}+\frac{84 \cdot y^{5}}{l_{e}^{5}}-\frac{35 \cdot y^{4}}{l_{e}^{4}}+1 \\
& \phi_{2}(y)=\frac{10 \cdot y^{7}}{l_{e}{ }^{6}}-\frac{36 \cdot y^{6}}{l_{e}{ }^{5}}+\frac{45 \cdot y^{5}}{l_{e}{ }^{4}}-\frac{20 \cdot y^{4}}{l_{e}{ }^{3}}+y \\
& \phi_{3}(y)=\frac{2 \cdot y^{7}}{l_{e}^{5}}-\frac{15 \cdot y^{6}}{2 \cdot l_{e}{ }^{4}}+\frac{10 \cdot y^{5}}{l_{e}^{3}}-\frac{5 \cdot y^{4}}{l_{e}{ }^{2}}+\frac{y^{2}}{2} \\
& \phi_{4}(y)=\frac{y^{7}}{6 \cdot l_{e}^{4}}-\frac{2 \cdot y^{6}}{3 \cdot l_{e}{ }^{3}}+\frac{y^{5}}{l_{e}^{2}}-\frac{2 \cdot y^{4}}{3 \cdot l_{e}}+\frac{y^{3}}{6} \\
& \phi_{5}(y)=\frac{-20 \cdot y^{7}}{l_{e}^{7}}+\frac{70 \cdot y^{6}}{l_{e}^{6}}-\frac{84 \cdot y^{5}}{l_{e}^{5}}+\frac{35 \cdot y^{4}}{l_{e}^{4}} \\
& \phi_{6}(y)=\frac{10 \cdot y^{7}}{l_{e}^{6}}-\frac{34 \cdot y^{6}}{l_{e}^{5}}+\frac{39 \cdot y^{5}}{l_{e}^{4}}-\frac{15 \cdot y^{4}}{l_{e}^{3}} \\
& \phi_{7}(y)=\frac{-2 \cdot y^{7}}{l_{e}^{5}}-\frac{13 \cdot y^{6}}{2 \cdot l_{e}{ }^{2}}-\frac{7 \cdot y^{5}}{l_{e}^{3}}+\frac{5 \cdot y^{4}}{2 \cdot l_{e}^{2}} \\
& \phi_{8}(y)=\frac{y^{7}}{6 \cdot l_{e}{ }^{4}}-\frac{y^{6}}{2 \cdot l_{e}{ }^{3}}+\frac{y^{5}}{2 \cdot l_{e}{ }^{2}}-\frac{y^{4}}{6 \cdot l_{e}}
\end{aligned}
$$

Desta maneira, o polinômio aproximativo assume, então, a seguinte relação:

$$
P(y)=u_{1} \cdot \phi_{1}+\frac{d u_{1}}{d y} \cdot \phi_{2}+\frac{d^{2} u_{1}}{d y^{2}} \cdot \phi_{3}+\frac{d^{3} u_{1}}{d y^{3}} \cdot \phi_{4}+u_{2} \cdot \phi_{5}+\frac{d u_{2}}{d y} \cdot \phi_{6}+\frac{d^{2} u_{1}}{d y^{2}} \cdot \phi_{7}+\frac{d^{3} u_{2}}{d y^{3}} \cdot \phi_{8}
$$


Os gráficos referentes às funções de forma obtidas anteriormente são dados a seguir:

Funções de Forma referentes ao deslocamento

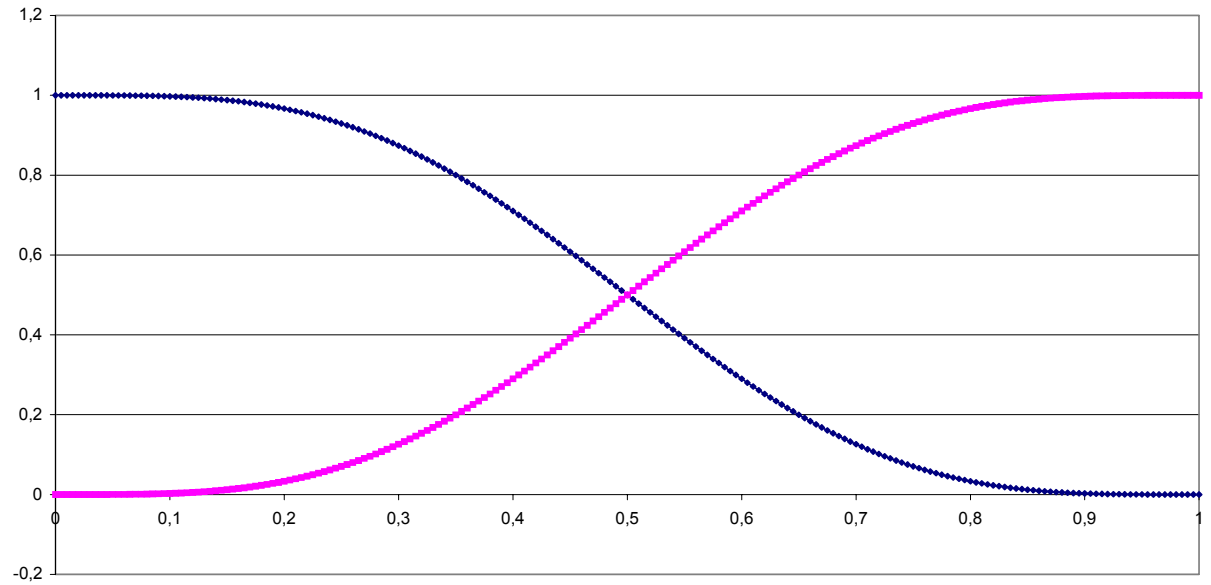

Comprimento do Elemento

$\rightarrow \phi 1-\phi 5$

Gráfico 41 - Funções de forma referentes ao deslocamento Elemento finito com oito parâmetros

Funções de Forma referentes ao deslocamento

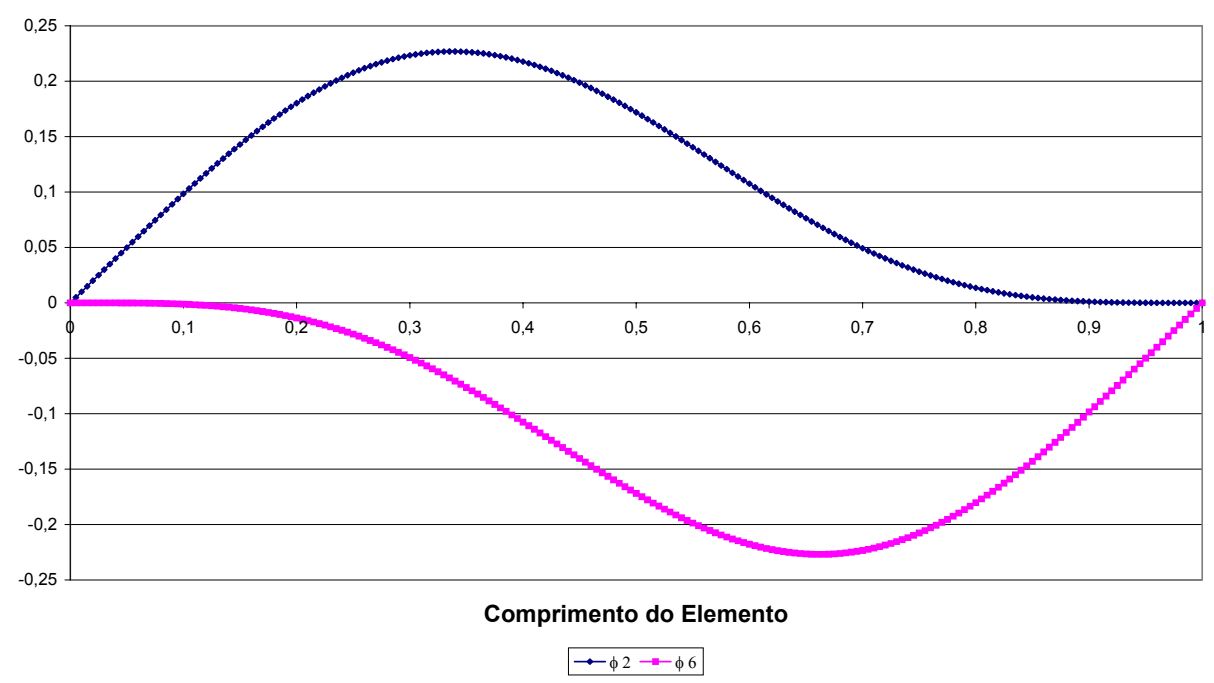

Gráfico 42 - Funções de forma referentes a rotação

Elemento finito com oito parâmetros 
Funções de Forma referentes a curvatura

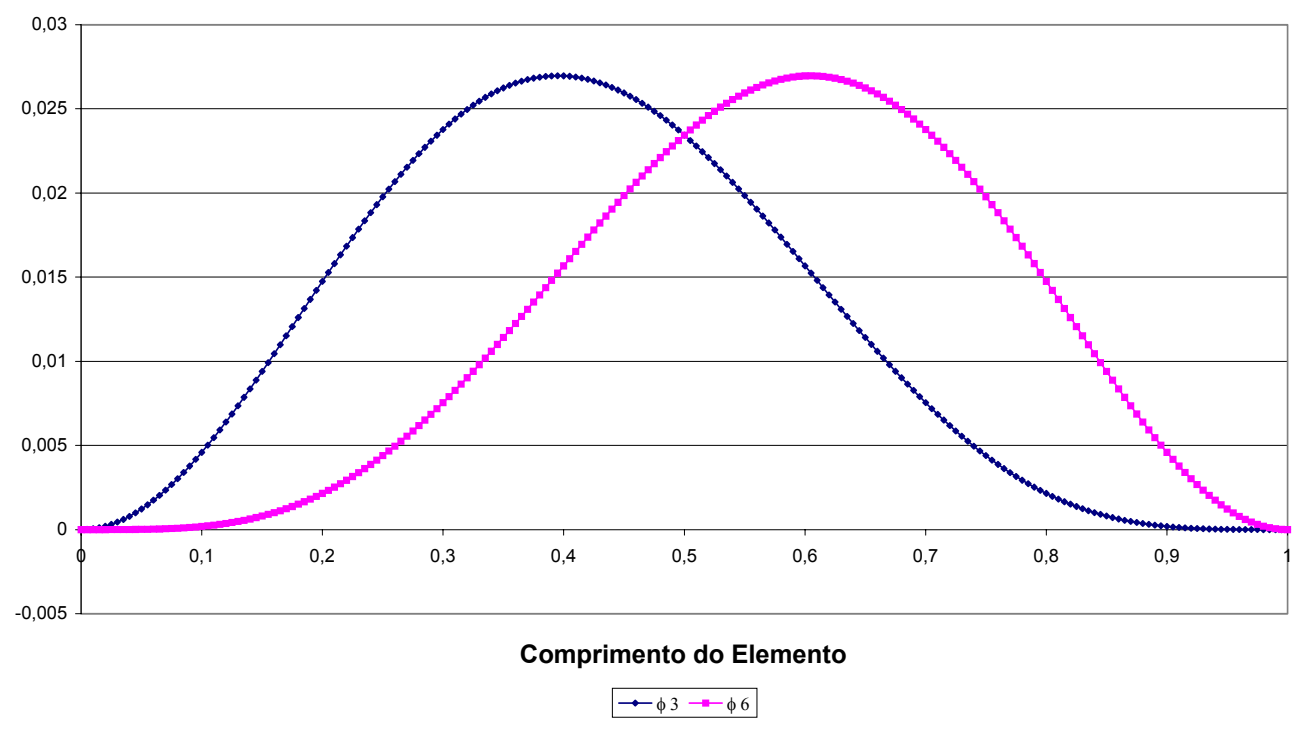

Gráfico 43 - Funções de forma referentes a curvatura Elementos finito com oito parâmetros

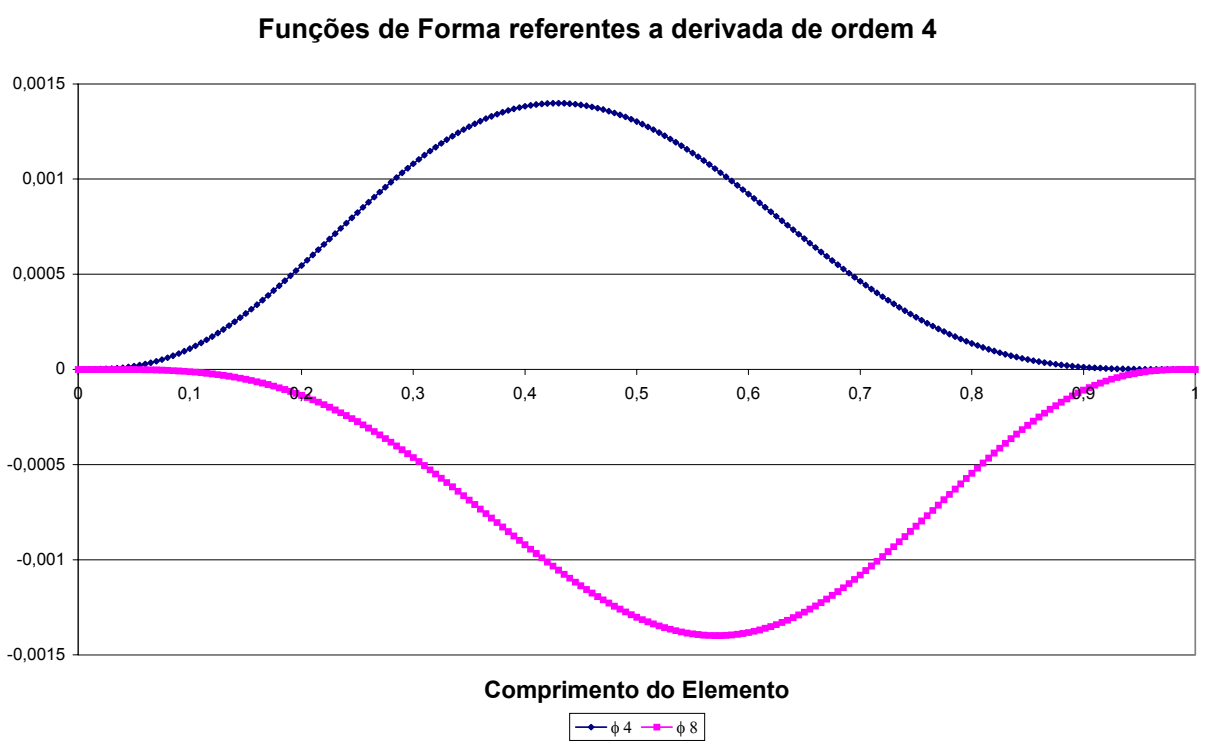

Gráfico 44 - Funções de forma referentes a derivada de ordem 4 Elementos finito com oito parâmetros 


\subsubsection{Método dos Mínimos Quadrados com divisão do domínio de integração: aplicação do elemento finito de oito parâmetros ao problema de viga}

a) Viga em balanço

Trata-se da mesma viga apresentada no item 5.3.1. Neste caso é possível impor a condição de nulidade do esforço cortante na extremidade livre da viga, o que não era possível a aplicação no caso anterior em virtude do elemento finito de seis parâmetros não possuir um parâmetro diretamente associado ao esforço cortante, ou à terceira derivada da função aproximativa. Com o elemento finito de oito parâmetros aplicam-se diretamente as quatro condições de contorno que a equação diferencial representativa do problema necessita: a nulidade do deslocamento e rotação na extremidade engastada da viga, e a nulidade do momento fletor e esforço cortante na extremidade livre. Segue-se o gráficos do exemplo resolvido considerando-se um único elemento finito.

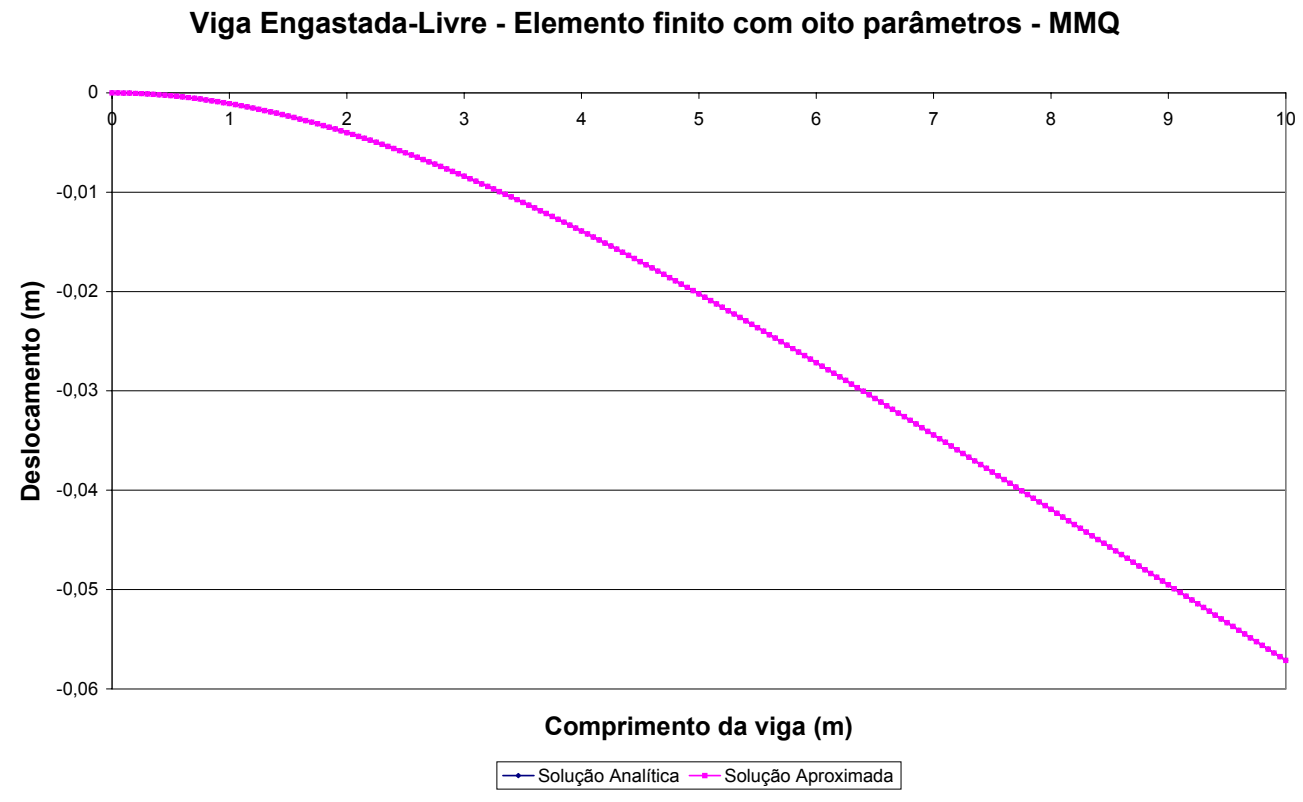

Gráfico 45 - Aproximação obtida utilizando 1 elemento finito 
Viga Engastada-Livre - Elemento finito com oito parâmetros - Galerkin

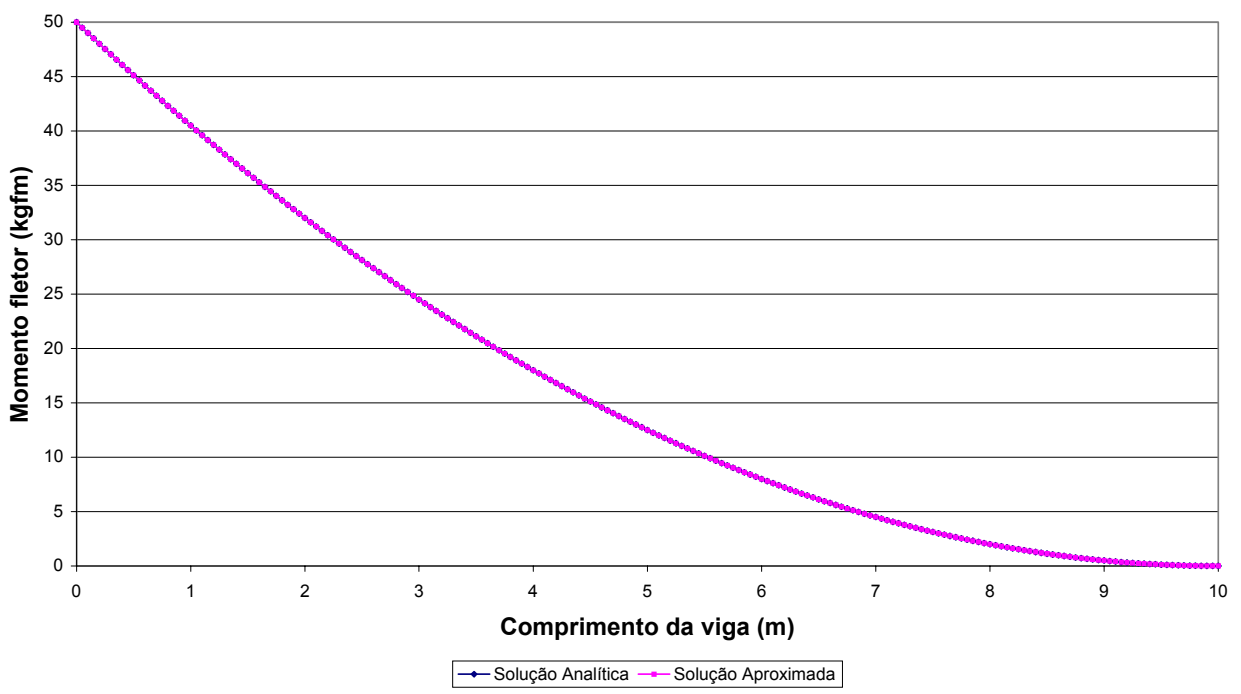

Gráfico 46 - Aproximação obtida utilizando 1 elemento finito

Viga Engastada-Livre - Elemento finito com oito parâmetros - Galerkin

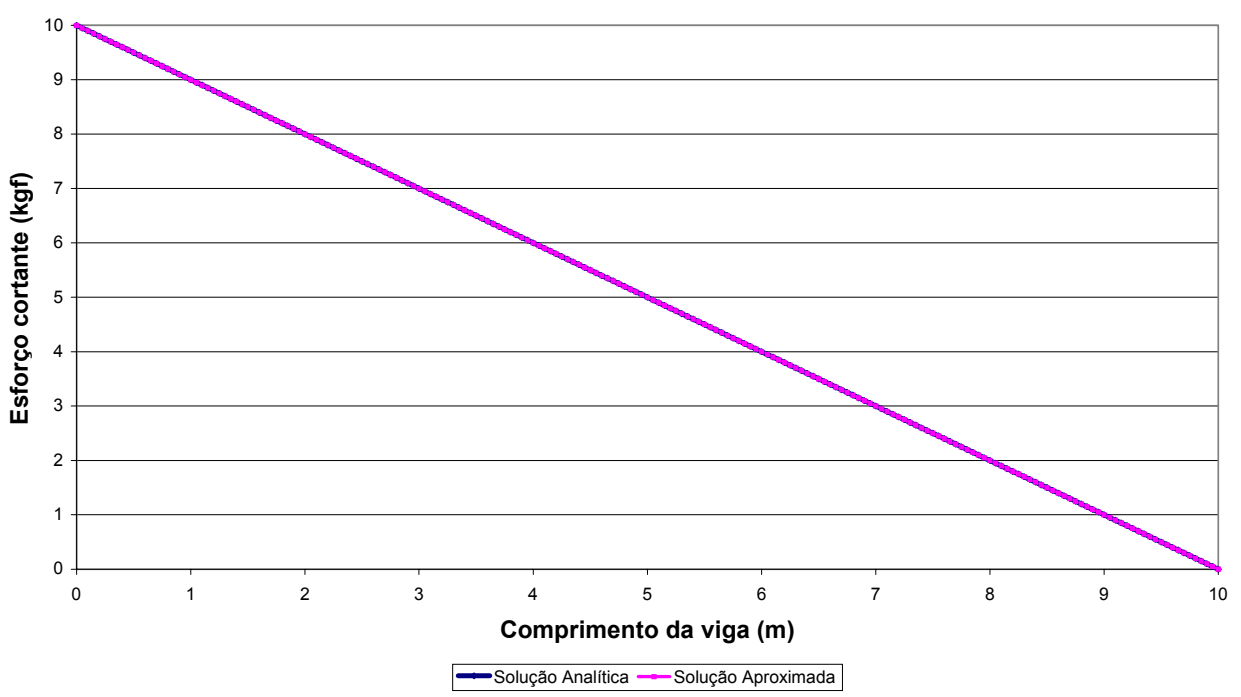

Gráfico 47 - Aproximação obtida utilizando 1 elemento finito 


\subsubsection{Método dos Mínimos Quadrados com divisão do domínio de integração: aplicação do elemento de oito parâmetros ao problema dos tubos}

O mesmo problema que consta no item 5.3.2 é agora resolvido com o elemento finito de oito parâmetros nodais. Primeiramente apresenta-se a resolução de um reservatório engastado na base, mediante adoção de um único elemento finito, aplicando-se a eq.(5.10). É esperado que a solução apresentada por esse elemento seja pouco mais significativa que a resposta aproximada obtida pela adoção do elemento finito com seis parâmetros. As figuras seguintes ilustram as respostas obtidas.

Tubo com base engastada - Elemento finito com oito parâmetros - MMQ

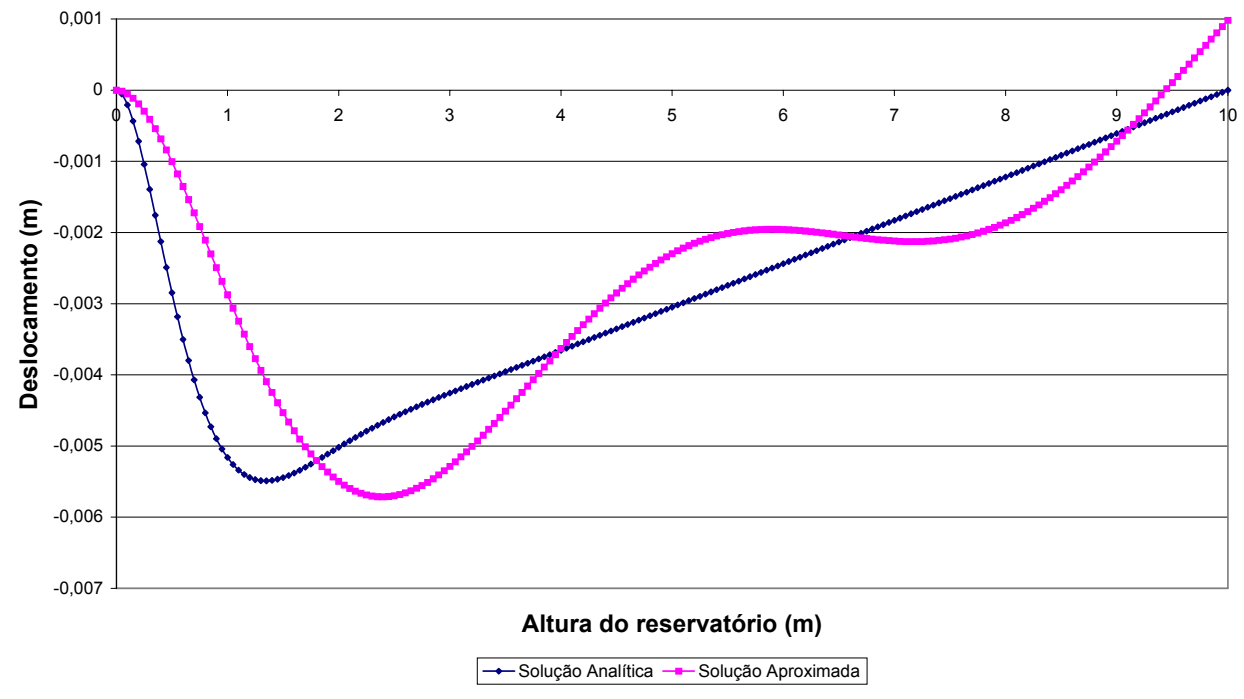

Gráfico 48 - Aproximação obtida utilizando 1 elemento finito 
Tubo com base engastada - Elemento finito com oito parâmetros - MMQ

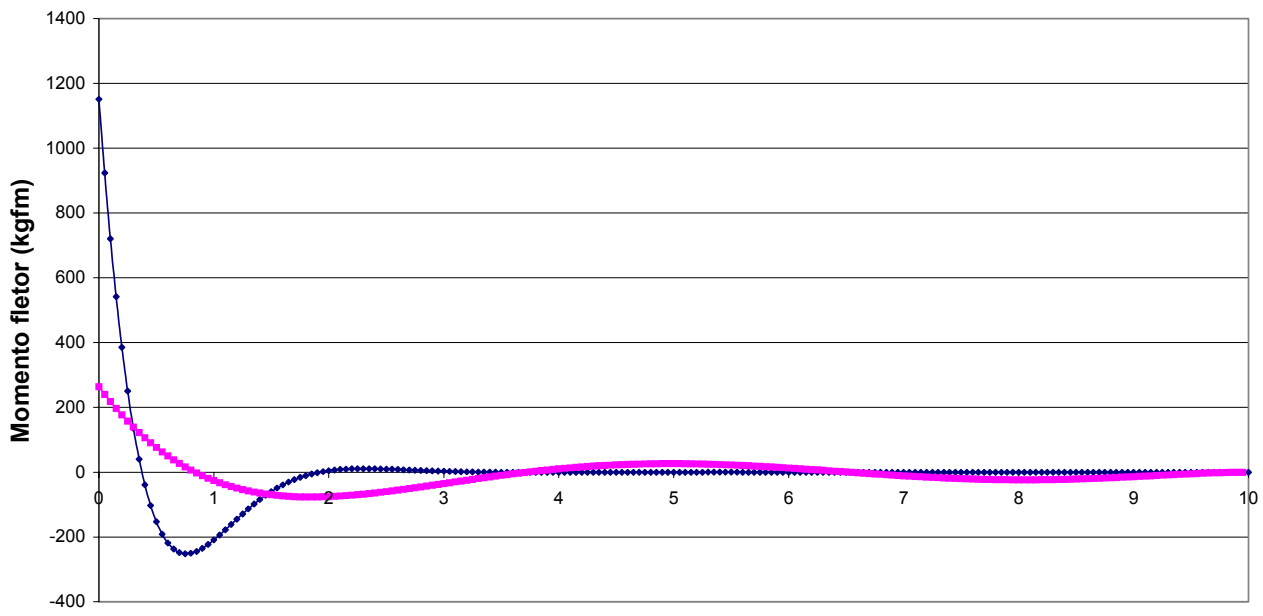

Altura do reservatório $(\mathrm{m})$

$\rightarrow$ Solução Analítica - -Solução Aproximada

\section{Gráfico 49 - Aproximação obtida utilizando 1 elemento finito}

Tubo com base engastada - Elemento finito com oito parâmetros - MMQ

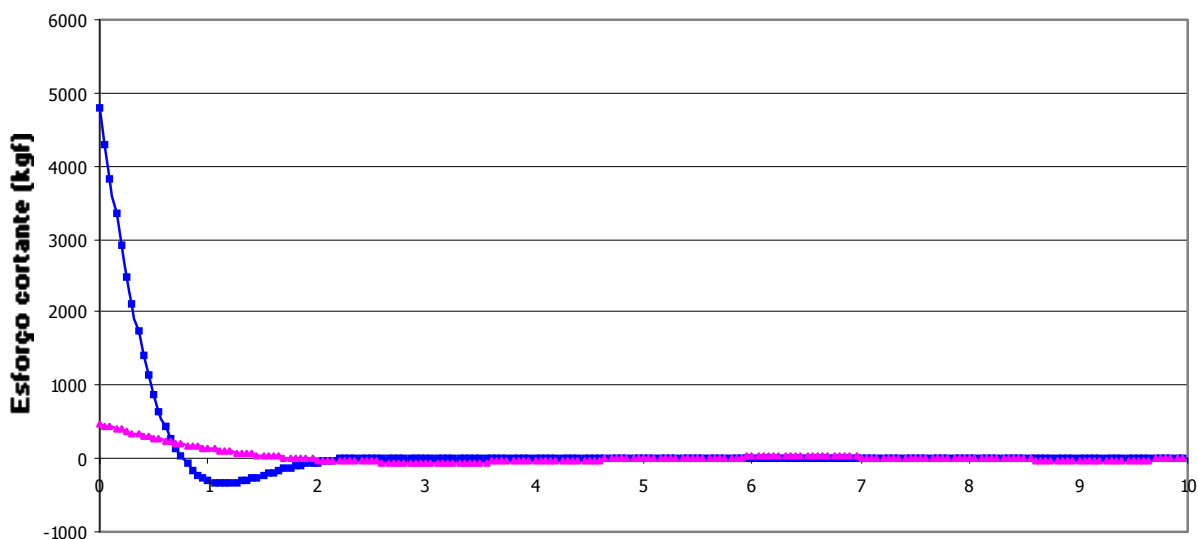

Altura do reservatório $(\mathbf{m})$

SoluçãoAnalítica $\longrightarrow$ Solução Aproximada

\section{Gráfico 50 - Aproximação obtida utilizando 1 elemento finito}

A solução obtida é de fato melhor que aquela fornecida pelo elemento finito de seis parâmetros, porém, ainda não suficiente para capturar a solução exata do problema. Em virtude disso, adota-se a divisão do domínio em três elementos conforme a tabela 5.1, com o objetivo de diminuir o erro de aproximação. As figuras seguintes resumem as respostas obtidas. 
Tubo com base engastada - Elemento finito com seis parâmetros - MMQ

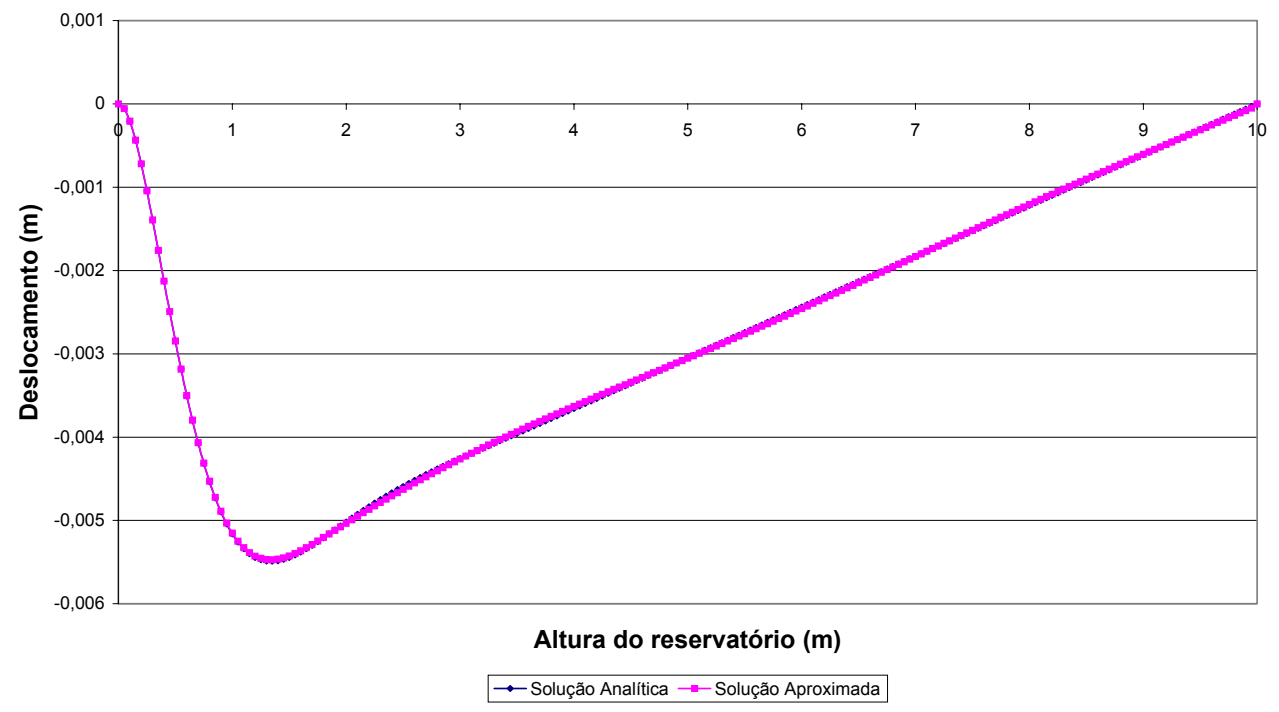

Gráfico 51 - Aproximação obtida utilizando 3 elementos finitos

Tubo com base engastada - Elemento finito com seis parâmetros - MMQ

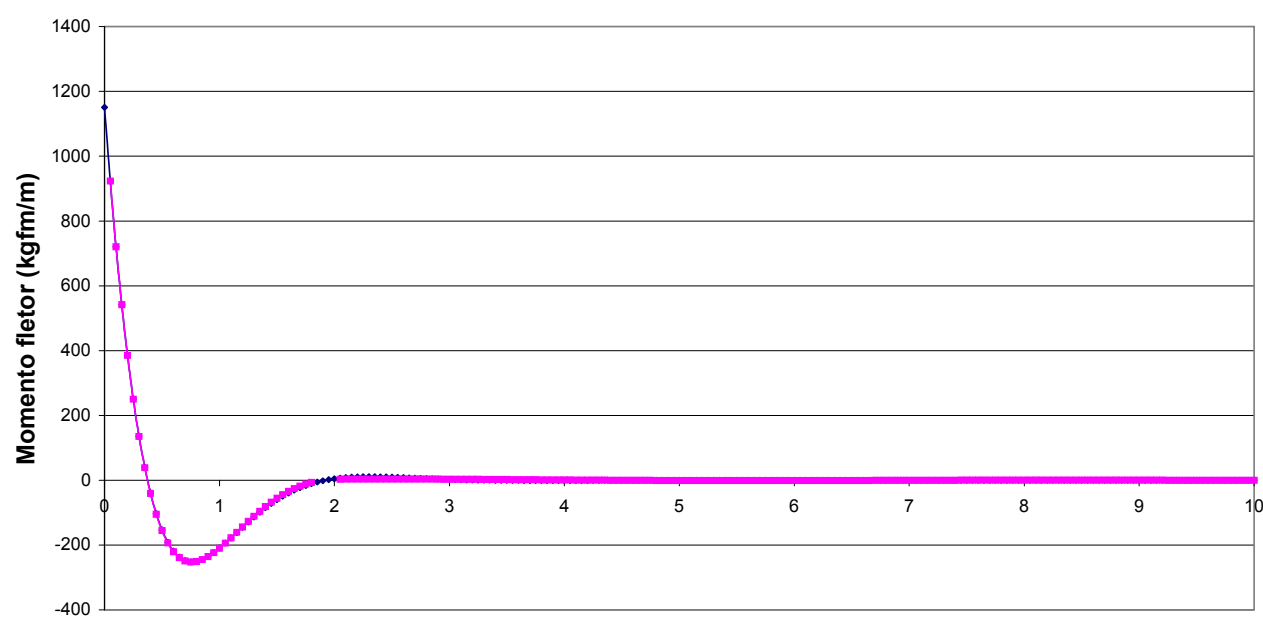

Altura do reservatório $(\mathrm{m})$

$\rightarrow$ Solução Analitica $\rightarrow$-Solução Aproximada

Gráfico 52 - Aproximação obtida utilizando 3 elementos finitos 
Tubo com base engastada - Elemento finito com seis parâmetros - MMQ

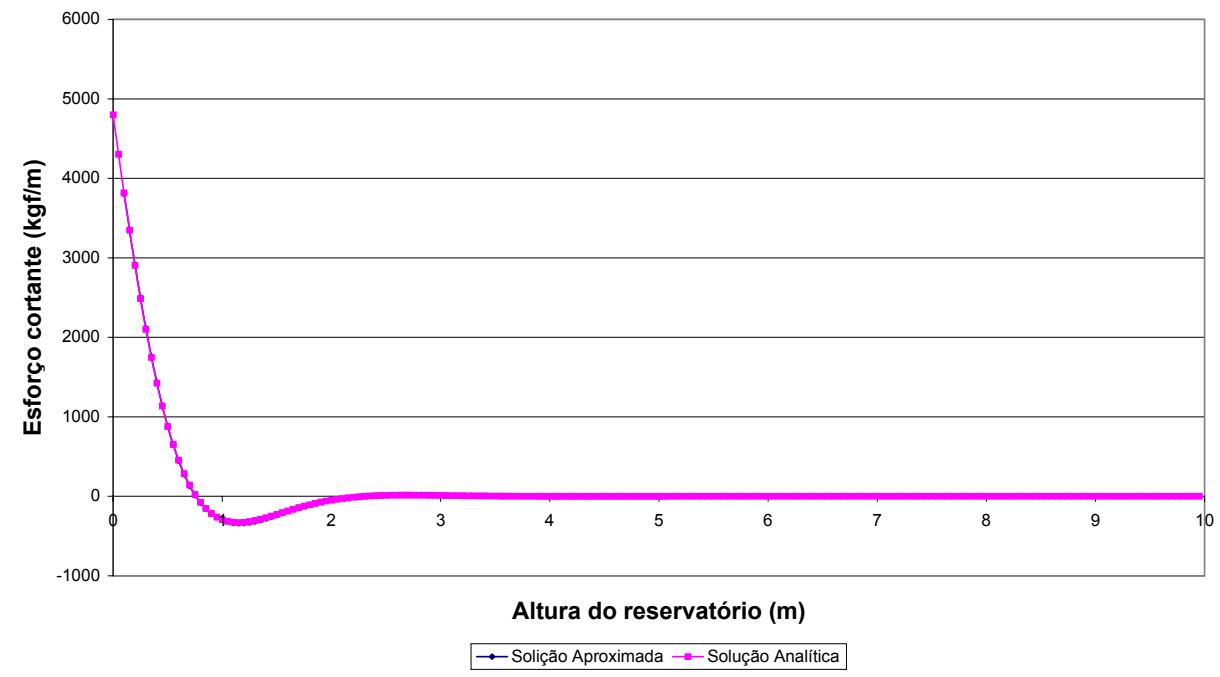

Gráfico 53 - Aproximação obtida utilizando 3 elementos finitos

Como nota pelos gráficos anteriores, a adoção de três elementos finitos é suficiente para que a solução aproximada seja muito próxima da solução exata. Um aspecto importante é que a solução aproximada não apresenta descontinuidades nos esforços solicitantes. À seguir apresentam-se os resultados do exemplo de um reservatório articulado na base, com a mesma disposição de elementos apresentada no exemplo anterior, conforme indicado na tabela 5.1.

Tubo com base articulada - Elemento finito com oito parâmetros - MMQ

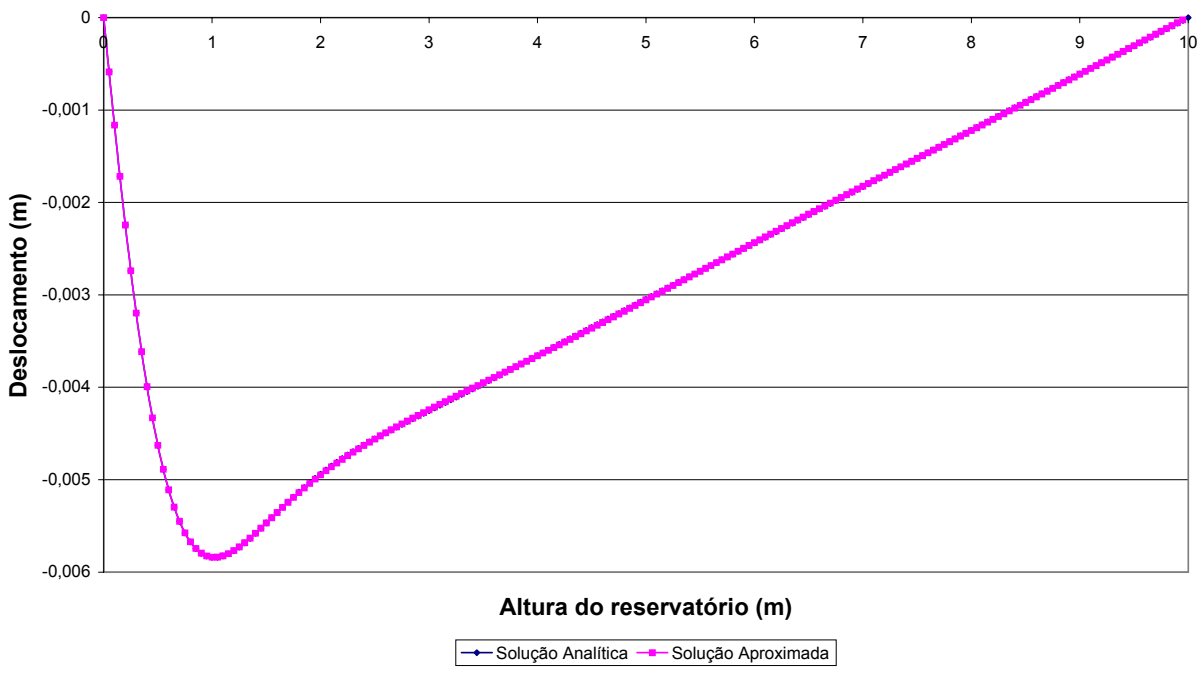

Gráfico 54 - Aproximação obtida utilizando 3 elementos finitos 
Tubo com base articulada - Elemento finito com oito parâmetros - MMQ

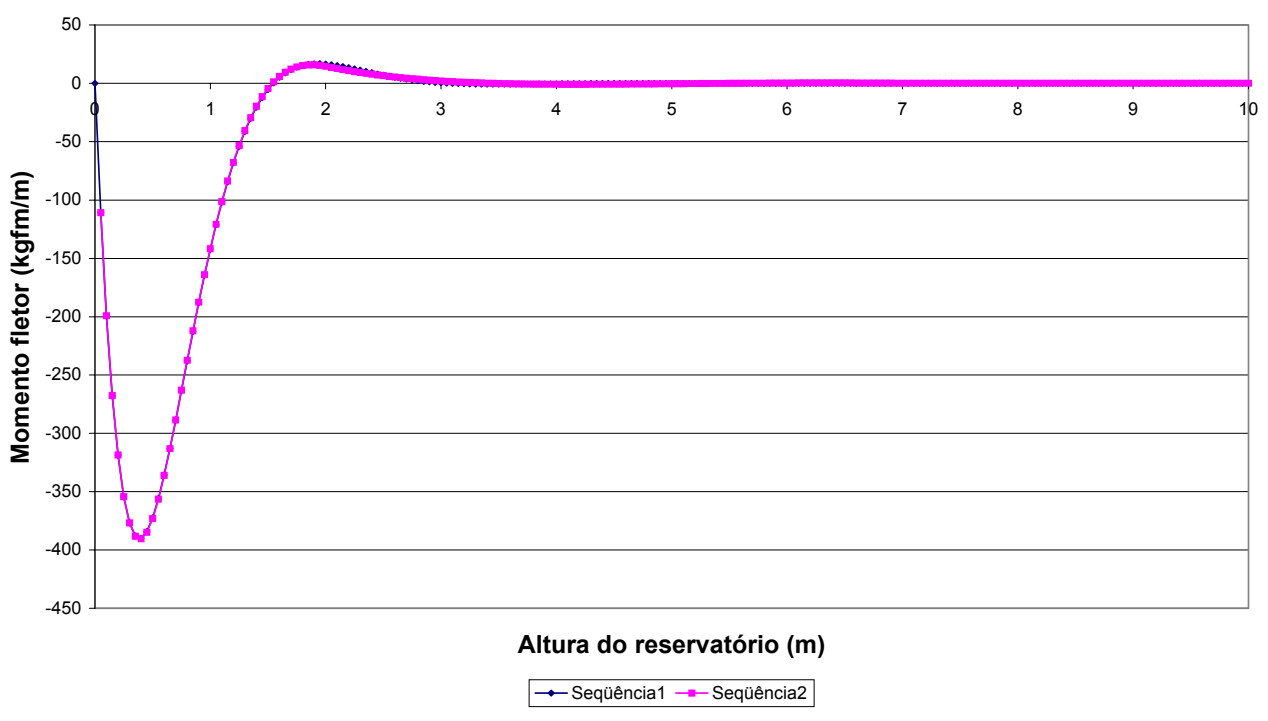

Gráfico 55 - Aproximação obtida utilizando 3 elementos finitos

Tubo com base articulada - Elemento finito com oito parâmetros - MMQ

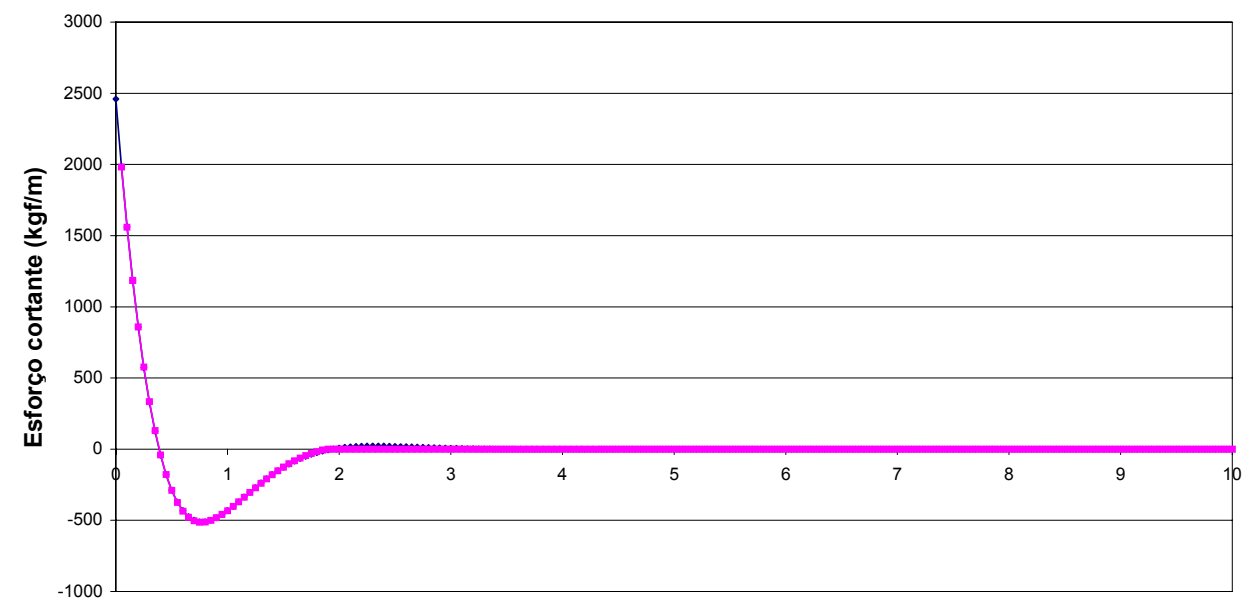

Altura do reservatório $(\mathrm{m})$

$\rightarrow$ Solução Analitica $\rightarrow-$ Solução Aproximada

Gráfico 56 - Aproximação obtida utilizando 3 elementos finitos 
Neste exemplo nota-se também a capacidade do método em reproduzir uma solução de ótima qualidade com apenas três elementos. É preciso observar que o elemento finito com oito parâmetros pode onerar os cálculos do sistema linear representativo do problema, porém com a vantagem de garantir continuidade nos esforços, por possuir parâmetros diretamente relacionados a eles.

No caso dos reservatórios cilíndricos, adotou-se ainda o recurso de colocar elementos menores na região onde há maior concentração de esforços de flexão, deixando um único elemento de comprimento maior na região onde predomina o comportamento de membrana. Certamente a solução aproximada obtida com base nessa estratégia apresenta melhores resultados do que uma disposição contendo o mesmo número de elementos finitos de tamanhos iguais. 


\section{Considerações Finais e conclusões}

Nesta pesquisa, aplicam-se formulações derivadas dos Métodos de Resíduos Ponderados na resolução de reservatórios submetidos a carregamento hidrostático. Foram analisadas as respostas proporcionadas pelos Métodos de Galerkin e Mínimos Quadrados, considerando-se diretamente a integral ponderada da equação diferencial do problema.

Em ambos os métodos foram adotadas diferentes funções aproximativas: bases polinomiais, bases mistas compostas por termos polinomiais lineares e termos exponencial-trigonométricos. Em relação às aproximações geradas com base polinomial de grau superior, verificou-se que na medida em que se aumenta o grau do polinômio a resposta aproximada tende para a resposta exata, porém é necessário adotar termos polinomiais de grau muito elevado para se conseguir maior aderência à solução exata. Comparando-se os métodos para esse tipo de aproximação, constatou-se que ambos apresentaram precisão e esforço computacional bastante similares.

Quanto ao emprego de bases mistas com funções que apresentam as mesmas características da solução exata, em primeiro lugar, não foi necessário aplicar as condições de contorno naturais referentes ao topo livre do reservatório, pois os termos exponenciais geram amortecimento suficiente para zerar os esforços de flexão ao longo da altura dos reservatórios longos. Além disso, em ambos os métodos a solução aproximada coincidiu com a solução exata, evidenciando-se a potencialidade dos métodos em capturar soluções exatas ao se adotar uma base aproximativa que contenha as mesmas características da solução exata.

Um dado a acrescentar é que as alternativas de aproximação testadas não implicaram em custo computacional adicional significativo.

Na seqüência do trabalho introduziu-se a divisão do domínio de integração da formulação obtida pelo Método dos Mínimos Quadrados. O intuito foi o de combinar Elementos Finitos com formulações em Mínimos Quadrados, num recurso ainda não explorado no problema das cascas.

Nas cascas cilíndricas os esforços de flexão se localizam mais intensamente na região adjacente à zona de vinculação. Nesse sentido, procurou-se concentrar a divisão do domínio naquela região, mantendo-se o restante do domínio discretizado com 
elementos maiores. Outro aspecto que se procurou preservar foi o da continuidade dos esforços solicitantes entre elementos. Nesse particular, optou-se por formular um elemento com oito parâmetros nodais. Nos exemplos analisados foram obtidos ótimos resultados com uma discretização composta por dois elementos mais concentrados próximo à base do reservatório e um elemento de comprimento maior na região onde não há a predominância do efeito de flexão (regime de membrana).

Finalmente, entre as alternativas numéricas testadas, aquelas relacionadas ao emprego de bases mistas e que empregaram divisão de domínio se mostraram muito eficientes e de simples implementação computacional. 


\section{Bibliografia Básica}

ASSAN, A. E. (2003). Método dos elementos finitos : Primeiros passos. 2.ed. Campinas: Editora da Unicamp.

BARROS, F. B. (2002). Métodos sem malha e método dos elementos finitos generalizados em análise não-linear de estruturas. Tese (Doutorado). Escola de Engenharia de São Carlos, Universidade de São Paulo.

BATHE, K. J. (1996). Finite element procedures. 2.ed. Prentice-Hall.

BELLUZZI, O., Ciencia de la construcción, Vol. III, Aguilar, Madrid - 1970.

BELYTSCHKO, T.; LU, Y.; GU, L. Element-free Galerkin methods. International Journal for Numerical Methods in Engineering, v. 37, p. 229-256, 1994.

BILlingtON, D. P., Thin Shell Concrete Structures, McGraw-Hill Book Company, Inc. -1982.

DUARTE, C. A.; ODEN, J. T. An h-p adaptive method using cloud. ComputerMethods in Applied Mechanics and Engineering, v. 139, p. 237-262, 1996.

DUARTE, C. A.; ODEN, J. T. Hp Clouds - A Meshless Method to Solve BoundaryValue Problem. [S.1.], Maio 1995. Technical Report.

DUARTE, C. A. The hp-cloud method. Tese (Doutorado)-The University of Texas at Austin, Dezembro 1996.

DUARTE, BABUŜKA,ODEN,(2000). Generalized finite element methods for threedimensional structural mechanics problems. Computers \& Structures, v.77, n.2, p.215232 .

GRAVINA, P. B. J., Teoria e Cálculo das Cascas - Cascas de Revolução, São Paulo 1957.

PROENÇA, S. P. B.; PARAGUAI, L. (1987). Análise de cascas cilíndricas circulares via computador. São Carlos.

PROENÇA, S. P. B. (2003). Formulação Variacional da Mecânica dos Sólidos e Introdução aos Métodos Numéricos - Notas de Aula. São Carlos.

REDDY, J. N. (1993). An introduction to the Finite Element Method. New York. McGraw-Hill.

TIMOSHENKO, S. P.; GOODIER, J. N. (1980). Teoria da Elasticidade. Guanabara Dois S. A.

TIMOSHENKO, S., WOINOWSKY-KRIEGER, S., Theory of Plates and Shells, McGraw-Hill Book Company, Inc. - 1959. 
TORRES, I. F. R. (2003). Desenvolvimento e aplicação do método dos elementos finitos generalizados em análise tridimensional não-linear de sólidos. Tese (Doutorado). Escola de Engenharia de São Carlos, Universidade de São Paulo.

ZIENKIEWICZ, O. C.; TAYLOR, R. L. (2000). The finite element method-Volume 1 : The Basis. 5.ed. Butterworth Heinemann. 